\title{
1 Polymorphism and thermophysical properties of L-
}

3 Vojtěch Štejfa ${ }^{a,{ }^{*}}$, Ala Bazyleva ${ }^{b}$, Michal Fulem ${ }^{a}$, Jan Rohlíček $^{c}$, Eliška Skořepová ${ }^{d}$, Květoslav

$5{ }^{a}$ Department of Physical Chemistry, University of Chemistry and Technology, Prague,

6 Technická 5, CZ-166 28 Prague 6, Czech Republic

$7{ }^{\mathrm{b}}$ Applied Chemicals and Materials Division, National Institute of Standards and Technology,

$8 \quad$ Boulder, CO 80305-3337, USA

$9{ }^{\mathrm{c}}$ Institute of Physics of the Czech Academy of Sciences, Na Slovance 2, 18221 Praha 8, Czech

10 Republic

$11{ }^{\mathrm{d}}$ Department of Chemical Engineering, University of Chemistry and Technology Prague,

12 Technická 3, 16628, Prague 6, Czech Republic.

$13{ }^{\mathrm{e}}$ Chemistry Faculty, Belarusian State University, Leningradskaya 14, 220030 Minsk, Belarus

$15 *$ Corresponding author: stejfav@vscht.cz

16 This article is dedicated to the celebration of the contributions to Chemical Thermodynamics of

17 Professor Gennady J. Kabo on the occasion of his 80th birthday. 


\section{Abstract}

20 The thermodynamic properties, phase behaviour, and kinetics of polymorphic transformations of

21 racemic (DL-) and enantiopure (L-) menthol were studied using a combination of advanced

22 experimental techniques, including static vapour pressure measurements, adiabatic calorimetry,

23 Tian-Calvet calorimetry, differential scanning calorimetry (DSC), and variable-temperature X-

24 ray powder diffraction. Several concomitant polymorphs ( $\alpha, \beta, \gamma$, and $\delta$ forms) were observed

25 and studied. A continuous transformation to the stable $\alpha$ form was detected by DSC and

26 monitored in detail using X-ray powder diffraction. A long-term coexistence of the stable

27 crystalline form with the liquid phase was observed. The vapour pressure measurements of both

28 compounds were performed using two static apparatus over a temperature range from $274 \mathrm{~K}$ to

29363 K. Condensed-phase heat capacities were measured by adiabatic and Tian-Calvet calorimetry

30 in the wide temperature interval from $5 \mathrm{~K}$ to $368 \mathrm{~K}$. Experimental data of L- and DL-menthol are

31 compared mutually as well as with available literature results. The thermodynamic functions of

32 crystalline and liquid L-menthol between $0 \mathrm{~K}$ and $370 \mathrm{~K}$ were calculated from the calorimetric

33 results. The thermodynamic properties in the ideal-gas state were obtained by combining

34 statistical thermodynamics and quantum chemical calculations based on a thorough

35 conformational analysis. Calculated ideal-gas heat capacities and experimental data on vapour

36 pressure and condensed-phase heat capacity were treated simultaneously to obtain a consistent

37 thermodynamic description. Based on the obtained results, the phase diagrams of L-menthol and

38 DL-menthol were suggested.

40 Keywords: monoterpenoids; menthol; vapour pressure; heat capacity; variable-temperature

41 XRPD; thermodynamic properties; ideal gas; statistical thermodynamics. 


\section{$43 \quad 1$ Introduction}

44 Menthol is a widely used chemical compound used in perfumes and cosmetics and serving as 45 pharmaceutical excipient, food additive, and tobacco flavouring, due to its pleasant smell and

46 cooling effect [1]. The compound is isolated as enantiopure L-menthol from natural peppermint

47 oil or produced using either asymmetric synthesis or the Haarmann-Reimer process. In any of the

48 production methods, isolation from multi-component systems via distillation, extraction, or

49 crystallization is a necessary step. The recent increase of interest in the description of solid-liquid

50 equilibria (SLE) [2-6] and liquid-liquid equilibria (LLE) [7] of menthol-based mixtures is likely

51 related to an attempt to improve the process efficiency.

52 The four concomitant polymorphs of L-menthol and their transformations were described as early

53 as 1917 [8], although the term "concomitant" for this uncommon behaviour itself was introduced

54 much later [9]. Nowadays, both L- and DL-menthol are known to have several monotropically

55 related polymorphs $[2,10,11]$. The crystal structures were solved for the $\alpha$ phase of both L-

56 menthol [12] and DL-menthol [2], whereas only the cell parameters are known for the $\beta$

57 polymorphs of L- and DL-menthol [2]. Neither crystallographic nor thermodynamic studies on

58 the remaining known polymorphs $(\gamma$ and $\delta$ phases of L-menthol and $\gamma$ phase of DL-menthol,

59 which were identified by visual observations, hot plate microscopy, and Flash DSC) have been

60 conducted yet, except for enthalpy of fusion [10], because of their short lifetimes. Studies [11]

61 and [2] traced interesting connections between polymorphism of enantiopure and racemic

62 menthols and SLE behaviour of their mixture, and, although the conclusions are not in obvious

63 agreement, some facts seem to be certain. Specifically, the $\alpha$ form of DL-menthol is a racemate

64 (racemic compound) with low symmetry (space group $P \overline{1}$ ), whereas the $\beta$ phase of DL-menthol

65 is a pseudoracemate (solid solution), as evidenced by both X-ray and calorimetric studies. The $\beta$ 
66 polymorphs of L- and DL-menthol have very similar cell parameters and lack all but the periodic

67 translational symmetry in the crystalline structure (space group $P 1$ ). It should be noted that, 68 inconsistently with the rest of the literature, Lipkind and Chickos [13] claimed that L-menthol 69 exists in the form of a plastic crystal at room temperature. They supported the statement by a 70 comment that it does not exhibit an X-ray diffraction pattern, which is contradicted by the pattern 71 presented in [2].

72 Well defined thermodynamic properties and phase behaviour of a pure compound form a 73 necessary basis for studies of related mixtures, especially in the case of complicated polymorphic 74 behaviour, such as that of L- and DL-menthol. Considering the number of studies on menthol 75 polymorphism and SLE behaviour of their mixtures, it is surprising, how little knowledge and 76 agreement there is regarding thermodynamic properties of pure L- and DL-menthol. 77 Temperatures and enthalpies of fusion of some polymorphs of L- and DL-menthol were reported 78 several times, but a solid review and comparison of the previous values is needed. Heat capacities 79 of the condensed phases for L-menthol were recently determined [6] by differential scanning 80 calorimetry (DSC) which typically provides heat capacity data with much higher uncertainty than 81 adiabatic or Tian-Calvet calorimetry. Vapour pressure measurements of menthols were 82 performed in [14-17]. Only the data by Guetachew et al. [17] were measured by a direct method 83 with a well-documented procedure giving the most reliable dataset for liquid L-menthol up to 84 now.

85 In this work, a thorough study of thermodynamic properties and phase behaviour of L- and DL86 menthol was carried out as a continuation of our effort [18-22] to establish reliable physico87 chemical data for biogenic compounds relevant to environmental modelling as well as to other 88 types of calculations and processes requiring phase equilibrium and thermodynamic data. The 
89 experimental part consists of vapour pressure measurements using two static apparatus, and

90 calorimetric measurements of the solid and liquid-phase heat capacities (adiabatic and Tian-

91 Calvet calorimetry). Special attention was paid to obtaining the properties of all observed

92 polymorphs and to guarantee the nature of the studied phases. To get a better insight into the

93 phase transformations, DSC and variable-temperature X-ray powder diffraction (XRPD) were

94 further used to investigate the phase behaviour and kinetics of the transformation between the

95 polymorphs.

96 Developing a consistent thermodynamic description of L- and DL-menthol simultaneously

97 considering measured vapour pressures and related thermal properties [23] requires

98 thermodynamic properties in the ideal-gas state. These were obtained in this work by combining

99 quantum-chemical and statistical-thermodynamics calculations.

\section{Experimental and theoretical section}

\section{$102 \quad 2.1 \quad$ Materials}

103 The description of the samples used in this work, including their purity, methods of purification,

104 and purity analysis, is given in Table 1. Two samples of L-menthol from different sources were

105 used in this work. All studied samples were of commercial origin. The enantiomeric excess in L-

106 menthol from Fluka is stated by the producer to be 0.994 , giving specific rotation of $[\alpha]_{\mathrm{D}}^{20}=-$

10750.3 degree $\cdot \mathrm{mL} \cdot \mathrm{g}^{-1} \cdot \mathrm{dm}^{-1}$ (according to the supplier certificate). The enantiomeric composition in

108 the natural L-menthol sample from RUE Belpharmatsiya was not separately determined, but it is

109 expected to be comparable, according to the specific rotation of $(-49 \pm 1) \mathrm{degree} \cdot \mathrm{ml} \cdot \mathrm{g}^{-1} \cdot \mathrm{dm}^{-1}$

110 (measured in an ATAGO automatic polarimeter AP-300 at $T=298.3 \mathrm{~K}$ and $\lambda=589 \mathrm{~nm}$; 
111 consistent with [12]). Handling of the samples prior to experiments was carried out under a dry

112 nitrogen atmosphere in a glove box. The water content could not be measured for L-menthol

113 from Fluka due to the small amount of the dry sample, but it is expected to be similar to that of

114 DL-menthol. The water content in the L-menthol sample from RUE Belpharmatsiya was not

115 separately determined, since the fractional-melting analysis applied to that sample is sensitive to

116 all impurities, including water.

117 It should be emphasized that the purity was also checked after the measurements of vapour

118 pressure and heat capacity using the Tian-Calvet calorimeter, and no decomposition was

119 detected. The mole-fraction purity increased after the vapour pressure measurements to $>0.9995$

120 and 0.995 for L-menthol and DL-menthol, respectively, due to distilling off volatile impurities.

121 The atomic masses of elements recommended by IUPAC (conventional weights reported in Table

1223 in [24]) were used to derive the molar mass of menthol: $0.156269 \mathrm{~kg} \cdot \mathrm{mol}^{-1}$, formula $\mathrm{C}_{10} \mathrm{H}_{20} \mathrm{O}$.

\section{Table 1}

125 Sample description

\begin{tabular}{ccccc}
\hline Chemical name & CAS RN & Source & $\begin{array}{c}\text { Mole fraction } \\
\text { purity }\end{array}$ & $\begin{array}{c}\text { Mass-fraction water } \\
\text { content }\end{array}$ \\
\hline Natural L-Menthol $^{\text {a }}$ & $2216-51-5$ & $\begin{array}{c}\text { RUE } \\
\text { Belpharmatsiya }\end{array}$ & $0.9973^{\mathrm{b}}$ & N/A \\
L-Menthol $^{\mathrm{c}}$ & $2216-51-5$ & Fluka & $0.999^{\mathrm{d}} ; 0.999^{\mathrm{e}}$ & N/A \\
DL-Menthol $^{\mathrm{c}}$ & $89-78-1$ & SIAL & $0.988^{\mathrm{d}} ; 0.992^{\mathrm{e}}$ & $9 \cdot 10^{-6 \mathrm{f}}$ \\
\hline
\end{tabular}

${ }^{\mathrm{a}}$ Sample used for the measurements by adiabatic calorimetry. The sample is a pharmaceutical ingredient. The sample was stored in a desiccator over $\mathrm{P}_{2} \mathrm{O}_{5}$ for a month prior to the experiments.

$128{ }^{\mathrm{b}}$ Purity determined by fractional melting in an adiabatic calorimeter (see Table S1 and Figure S3 in the

129 Supplementary Data (SD)). In addition, no impurity peaks were detected by gas chromatography using 130 chromatograph HP 5890 Series II (equipped with a fused-silica capillary column coated with $0.25 \mu \mathrm{m} \mathrm{HP-}$

131 INNOWAX, $50 \mathrm{~m}$ length and $0.32 \mathrm{~mm}$ diameter, column temperature programmed between $323 \mathrm{~K}$ and $498 \mathrm{~K}$ ) and 132 HP 5972 quadrupole mass-selective detector (operated at $553 \mathrm{~K}$ ). 
$133{ }^{\mathrm{c}}$ Samples used for the XRPD, vapour pressure, Tian-Calvet calorimetry, and DSC experiments. The samples were 134 melted and dried over $0.4 \mathrm{~nm}$ molecular sieves (Merck).

$135{ }^{\mathrm{d}}$ Purity provided by the manufacturer in the certificate of analysis determined by gas-liquid chromatography (GLC).

$136{ }^{\mathrm{e}}$ Purity determined by GLC using the chromatograph Hewlett-Packard 6890A equipped with a column HP-1, length

$13725 \mathrm{~m}$, film thickness $0.52 \mu \mathrm{m}$, diameter $0.30 \mathrm{~mm}$, and FID detector in the temperature range from 313 to $523 \mathrm{~K}$ with 138 inlet temperature of $373 \mathrm{~K}$. Average of two determinations.

$139{ }^{\mathrm{f}}$ Mass fraction of water determined by Karl-Fischer analysis by Metrohm 831. Average of three determinations.

\section{$140 \quad 2.2 \quad$ Phase behaviour measurements}

141 All temperatures reported in this paper are based on the international temperature scale ITS-90.

142 The phase behaviour of the studied compounds was investigated from $273 \mathrm{~K}$ with a heat-flux 143 differential scanning calorimeter TA Q1000 (TA Instruments, USA) using the continuous method

144 with a heating rate of $2 \mathrm{~K} \cdot \mathrm{min}^{-1}$. The calorimeter was periodically calibrated with onset 145 temperatures and enthalpies of fusion of five reference materials [25] selected to uniformly cover 146 the desired temperature range: water (distilled and de-mineralized by Millipore RQ), gallium, 147 naphthalene, indium, and tin (from the calibration set provided by GEFTA). The sample load of 5 $148 \mathrm{mg}$ to $10 \mathrm{mg}$ was determined by an analytical balance that had resolution of $0.01 \mathrm{mg}$ and was 149 periodically calibrated.

\section{$150 \quad 2.3 \quad X$-ray powder diffraction experiments}

151 To gain deeper insight into the solid phase transformations and behaviour of DL-menthol,

152 variable temperature X-ray powder diffraction (VT-XRPD) was employed. The isothermal phase

153 stability in the temperature range between $233 \mathrm{~K}$ and $303 \mathrm{~K}$ was studied by the XRPD technique

154 using a powder diffractometer, Empyrean of PANalytical, which was equipped with a sealed $\mathrm{Cu}$

155 X-ray tube, capillary holder, PIXCel ${ }^{3 \mathrm{D}}$ detector, and an Oxford Cryostream cooling head. The

156 sample was placed into several borosilicate capillaries with diameters of $0.5 \mathrm{~mm}$ and $0.7 \mathrm{~mm}$.

157 Two different techniques were used to fill the capillaries: (i) solid powder was ground at room 
158 temperature and placed into a capillary, and (ii) a sample was melted and poured into the 159 capillary.

160 Two polymorphs ( $\alpha$ and $\beta$ ) of DL-menthol were observed by XRPD, while $\gamma$ has a too short

161 lifetime. The crystal structure of the stable $\alpha$ phase is known from single-crystal X-ray diffraction

162 [2]. Since the crystal structure of the metastable $\beta$ phase is unknown, the Rietveld method [26]

163 could not be used to obtain the relative amount of the $\alpha$ and $\beta$ phases in the samples. The

164 composition of the samples was instead determined from the change of the integrated intensities

165 of selected reflections during the measurement. In the case of the $\alpha$ phase, the $(\overline{1} 01)$ reflection

166 was used, and the peak corresponding to $(210)$ and $(2 \overline{1} 0)$ reflections was used in the case of

167 the $\beta$ phase. The approximate amount of the amorphous/liquid phase at $303 \mathrm{~K}$ was obtained

168 according to the principles published by Scarlett and Madsen [27].

$1692.4 \quad$ Heat capacity measurements by adiabatic calorimetry

170 Heat capacities at the saturated vapour pressure $\left(C_{\mathrm{s}, \mathrm{m}}\right)$ for the $\alpha$-crystalline and liquid L-menthol

171 over the temperature range $5 \mathrm{~K}$ to $370 \mathrm{~K}$ and its melting parameters were measured in two

172 adiabatic calorimeters. The $C_{\mathrm{s}, \mathrm{m}}$ measurements between $5 \mathrm{~K}$ and $108 \mathrm{~K}$ (liquid-helium bath) were

173 conducted in a vacuum adiabatic calorimeter TAU-1 (VNIIFTRI, Moscow, Russia) described in

$174[28,29]$. The reliability of the heat-capacity measurements with the TAU-1 calorimeter was

175 verified in experiments with benzoic acid and high-purity copper, and the expanded uncertainty

176 with 0.95 level of confidence was estimated to be $2 \%$ near $5 \mathrm{~K}$ and $0.4 \%$ above $40 \mathrm{~K}$ [30]. A

177 vacuum adiabatic calorimeter TAU-10 (“Termis", Moscow, Russia) was used between $80 \mathrm{~K}$ and

$178370 \mathrm{~K}$ (liquid-nitrogen bath) with the reproducibility and relative expanded uncertainty $(0.95$

179 level of confidence) of the $C_{\mathrm{s}, \mathrm{m}}$ measurements determined to be $0.1 \%$ and $0.4 \%$, respectively.

180 The TAU-10 calorimeter details and verification experiments were described previously in [31]. 
181 During the experiments in both calorimeters, the temperature was measured with Fe-Rh

182 resistance thermometers calibrated on ITS-90 at VNIIFTRI (Mendeleyevo, Moscow Region,

183 Russia) with the standard uncertainty of $0.01 \mathrm{~K}$.

184 Calorimetric cells made of stainless steel $\left(V \approx 1.0 \mathrm{~cm}^{3}\right)$ in TAU-1 and of titanium $\left(V=1.13 \mathrm{~cm}^{3}\right)$

185 in TAU-10 were loaded with solid samples of $0.83748 \mathrm{~g}$ and $0.71244 \mathrm{~g}$, respectively. The masses

186 were determined with an accuracy of $\pm 0.02 \mathrm{mg}$ and corrected for buoyancy. After loading, the

187 containers were degassed under vacuum (residual pressure of $\sim 10 \mathrm{~Pa}$ ) for $0.5 \mathrm{~h}$. Helium gas

$188(p \approx 5 \mathrm{kPa}$ and $T=293 \mathrm{~K})$ was introduced into the cell to facilitate heat transfer during the

189 measurements. The containers were sealed using indium rings. The ratio of the sample heat

190 capacity to the total (sample + cell) heat capacity was not less than 0.5 below $45 \mathrm{~K}$ and above the

191 melting temperature and not less than 0.35 in between. The heat capacity of helium gas sealed in

192 the calorimetric cell was accounted for in the treatment of the experimental data.

193 The temperature steps for the heat-capacity measurements were approximately equal to $T / 20$ at $194 T<40 \mathrm{~K}$ and (1.5 to 2.5$) \mathrm{K}$ above $40 \mathrm{~K}$. Heating periods were (80 to 150$) \mathrm{s}$ below $30 \mathrm{~K}$, 195 (200 to 300$) \mathrm{s}$ for $T=(30$ to 55$) \mathrm{K}, 380 \mathrm{~s}$ for $T=(55$ to 108$) \mathrm{K}$ in TAU-1, and $400 \mathrm{~s}$ in TAU-10.

196 The thermal relaxation time was (80 to 200) s at $T<60 \mathrm{~K}, 230 \mathrm{~s}$ in TAU-1, and $150 \mathrm{~s}$ in TAU-10

197 at higher temperatures. The periods for the temperature-drift measurements were (70 to 200) s for

$198 T<60 \mathrm{~K}$, (200 to 250$) \mathrm{s}$ for $T=(60$ to 108$) \mathrm{K}$ in TAU-1, and (300 to 400) $\mathrm{s}$ in TAU-10. To

199 obtain the sample purity and triple-point temperature, two fractional-melting experiments were

200 conducted. The enthalpy of fusion was obtained from a combination of a series of experiments

201 with continuous energy input (i.e., one-step heating of the sample from a temperature below the

202 beginning of the phase transition region to a temperature above it) and the two fractional-melting 203 experiments. 
204 Based on the vapour pressure of the sample measured in this work, an adjustment of $C_{\mathrm{s}, \mathrm{m}}$ to $C_{p, \mathrm{~m}}^{0}$

205 was much smaller than the experimental uncertainty in the studied temperature range and was

206 neglected (i.e., $C_{\mathrm{s}, \mathrm{m}} \approx C_{p, \mathrm{~m}}^{0}$ ).

$207 \quad 2.5$ Heat capacity measurements by Tian-Calvet calorimetry

208 Crystalline and liquid heat capacities of both L- and DL-menthol were also measured with a

209 Tian-Calvet calorimeter (SETARAM $\mu$ DSC IIIa, France) in the temperature range from $260 \mathrm{~K}$ to

$210359 \mathrm{~K}$ using the continuous method [32], whose performance was tested by Štejfa et al. [20]. A

211 heating rate of $0.3 \mathrm{~K} \cdot \mathrm{min}^{-1}$ was used with isothermal delays of $2600 \mathrm{~s}$ before and after the

212 continuous heating. After applying the standard procedures, including slope correction and signal

213 smoothing, the heat capacity was calculated from the heat-flow record corresponding to an empty

214 sample cell, the sample cell filled with synthetic sapphire (reference compound, NIST SRM 720),

215 and subsequently with the sample. Approximately 10000 experimental heat capacity data points

216 were obtained. For tabulation of the heat capacities obtained using the continuous method, the

217 raw heat capacity data were averaged over $5 \mathrm{~K}$ intervals. The heat capacities are reported at the

218 mean temperature of each $5 \mathrm{~K}$ interval. The combined expanded uncertainty (0.95 level of

219 confidence) of the heat capacity measurements is estimated to be $U_{\mathrm{c}}\left(C_{p, \mathrm{~m}}^{0}\right)=0.01 C_{p, \mathrm{~m}}^{0}$.

\section{$220 \quad 2.6 \quad$ Vapour pressure measurements}

221 Vapour pressure measurements were performed using the static method (with capacitance 222 diaphragm gauges) with the STAT6 and STAT8 apparatus. The STAT6 and STAT8 apparatus 223 were previously described in detail in [33] and [34], respectively, and thus only a concise 224 description is provided here. 
225 The performance of the STAT6 apparatus was checked by measurements of naphthalene, which

226 is recommended for calibrating vapour pressure apparatus [35], and recently by $n$-octane and $n$ -

227 decane. The agreement with the recommended data $[23,35]$ was within the combined expanded

228 uncertainty ( 0.95 level of confidence, $k=2$ ) of the STAT6 apparatus, which is adequately

229 described by $U_{c}(p / \mathrm{Pa})=0.005 p / \mathrm{Pa}+0.05$.

230 The STAT8 apparatus was calibrated by measurements of three reference materials, naphthalene,

$231 n$-decane, and ferrocene, over the whole working range of the apparatus [34]. The combined

232 expanded uncertainty of vapour pressure measurements $U_{\mathrm{c}}(p)(0.95$ level of confidence, $k=2)$

233 using the STAT8 apparatus was estimated based on the deviations of experimental data points

234 from the recommended vapour pressures $[23,35,36]$ to be $U_{\mathrm{c}}(p / \mathrm{Pa})=0.01 p / \mathrm{Pa}+0.05$.

235 Prior to the measurement of the vapour pressure, both apparatus were checked for tightness by an

236 MKS PICO helium leak detector (MKS Instruments, USA). The vapour pressure measurements

237 were performed in the temperature interval from $274 \mathrm{~K}$ to $308 \mathrm{~K}$ and $277 \mathrm{~K}$ to $363 \mathrm{~K}$ with

238 STAT6 and STAT8 apparatus, respectively, with in situ degassing of the sample through

239 performing a large number of measuring cycles consisting of establishing the phase equilibrium

240 followed by pumping of the vapour space formed. The measurements were carried out at selected

241 temperatures repeated in a random order to track a systematic decrease of the measured pressure

242 due to degassing of the sample. When that pressure decrease was negligible (after completing

243 hundreds of measuring cycles enabled by full automation of the apparatus), the sample was

244 considered completely degassed, and the final set of data was recorded. At least three

245 experimental points were obtained for each temperature. 


\subsection{Theoretical calculations}

247 The conformational study, optimization of molecular geometries, energy and harmonic frequency

248 calculations, and scans of potential energy of internal rotations were performed with the Gaussian

24909 software [37] using the density functional theory (DFT) at the B3LYP-D3/6-311+G(d,p) level

250 of theory. The energies of the most stable (triequatorial) conformers were also recalculated using

251 LCCSD(T)/aug-cc-pVQZ with the MRCC software package [38] for structures optimized at the

252 DF-MP2/aug-cc-pVQZ level of theory with Psi4 v. 1.1 [39], where $\operatorname{LCCSD(T)}$ is an efficient

253 local coupled-cluster method proposed recently [40] and DF-MP2 is the Møller-Plesett second-

254 order perturbation theory in density-fitted (also referred to as "resolution-of-identity", RI)

255 approximation. The detailed conformational study was performed, as the number and relative

256 energies of conformers are crucial for calculating ideal-gas properties. After obtaining structures

257 for all stable conformers, the thermodynamic properties of enantiopure menthol in the ideal-gas

258 state were calculated by statistical thermodynamics using the R1SM model. This model combines

259 the RRHO ("rigid rotor-harmonic oscillator") approximation with a correction for methyl

260 rotations using the 1-D HR ("one-dimensional hindered rotor") formalism [41] for each

261 conformer and subsequent application of the mixing model [42]

$$
\begin{gathered}
C_{p, \mathrm{~m}}^{0}=\sum_{i=1}^{N} x_{i} C_{p, \mathrm{~m}, i}^{0}+\frac{1}{R T^{2}} \sum_{i=1}^{N} x_{i} \sum_{j>i}^{N} x_{j}\left(\Delta_{\mathrm{r}} H_{i j}(0 \mathrm{~K})\right)^{2}, \\
S_{\mathrm{m}}^{0}=\sum_{i=1}^{N} x_{i} S_{\mathrm{m}, i}^{0}-R \sum_{i=1}^{N} x_{i} \ln x_{i},
\end{gathered}
$$

264 where $x_{\mathrm{i}}$ are the mole fractions of the corresponding conformers at temperature $T$,

$$
x_{i}=e^{-\frac{\Delta G_{i}(T)}{R T}} / \sum_{j=1}^{N} e^{-\frac{\Delta G_{j}(T)}{R T}},
$$


$266 N$ is the number of conformers (including their optical isomers for achiral molecules),

$267 \Delta_{\mathrm{r}} H_{i j}(0 \mathrm{~K})$ is the enthalpy of transformation of the $i^{\text {th }}$ conformer to the $j^{\text {th }}$ conformer at $0 \mathrm{~K}$,

$268 \Delta G_{i}(T)$ is the relative Gibbs energy of $i$-th conformer (designation "relative" means relative to

269 the most stable conformer for all properties in Eqs. (3) and (4)), and $C_{p, \mathrm{~m}, i}^{0}$ and $S_{\mathrm{m}, i}^{0}$ are the ideal-

270 gas heat capacity and standard ideal-gas entropy of the $i^{\text {th }}$ conformer. $\Delta G_{i}(T)$ is calculated as:

$$
\Delta G_{i}(T)=\Delta E_{i}^{0 \mathrm{~K}}+\Delta E_{i}^{\mathrm{ZPE}}+\Delta H_{i}^{\mathrm{Therm}}(T)-T \Delta S_{i}(T),
$$

272 where $\Delta S_{i}(T)$ is the relative entropy of $i$-th conformer, $\Delta H_{i}^{\text {Therm }}(T)$ is the relative thermal

273 enthalpy of $i$-th conformer, $\Delta E_{i}^{\mathrm{TPE}}$ is the relative zero-point vibrational energy, and $\Delta E_{i}^{0 \mathrm{~K}}$ is the

274 relative electronic energy. $\Delta S_{i}(T), \Delta H_{i}^{\text {Therm }}(T)$, and $\Delta E_{i}^{\mathrm{TPE}}$ are calculated in the RRHO

275 approximation with 1-D HR correction for the methyl tops. Similar approach was used in our

276 previous works [21, 43, 44]. Relative electronic energies and zero-point vibrational energies of

277 the conformers were included from the calculation at the B3LYP-D3/6-311+G(d,p) level of

278 theory, except for the electronic energies of the most stable (triequatorial) conformers, which

279 were calculated at the LCCSD(T)/aug-cc-pVQZ level of theory, as described above.

280 The B3LYP-D3/6-311+G(d,p) calculated fundamental frequencies were scaled by a double-linear 281 scaling factor $\left(0.9980-1.55 \mathrm{E}-05 \mathrm{v} /\left(\mathrm{cm}^{-1}\right)\right) / 0.961$ for frequencies below/above $2000 \mathrm{~cm}^{-1}$

282 developed on experimental vibrational frequencies of $n$-alkanes. The contributions of internal

283 rotations of methyl tops were calculated using the 1-D HR scheme, which required the energy

284 barriers and the reduced moments of inertia $I_{\mathrm{r}}$ for methyl rotations, the internal symmetry number

$285\left(\sigma_{\mathrm{i}}=3\right)$, and the identification and exclusion of these torsional modes from the vibrational 286 contribution to the partition function. The potential energy profiles of methyl rotations were 
calculated at the B3LYP-D3/6-311+G(d,p) level of theory using a relaxed scan with a step of $10^{\circ}$

288 for the most stable conformer. The reduced moments of inertia $I_{\mathrm{r}}$ for methyl rotations were 289 calculated according to Pitzer and Gwinn [45] from the optimized molecular parameters. The 290 energy levels were obtained by solving a one-dimensional Schrödinger equation for hindered 291 internal rotation using the FGH method [46].

\section{$293 \quad 3 \quad$ Results and discussion}

$2943.1 \quad$ Phase behaviour

295 In this work, we focused on the characterization of the polymorphs of L- and DL-menthol by 296 thermodynamic and diffraction techniques. Not all of the described polymorphs of these 297 compounds can be studied by these techniques. The stability and/or preparation conditions of the 298 metastable forms limit their study significantly, since common techniques, such as adiabatic 299 calorimetry, Tian-Calvet calorimetry, or static measurements of the vapour pressure, are too 300 slow. We were able to detect melting of the $\alpha, \beta, \gamma$ and $\delta$ polymorphs of L-menthol and of the $\alpha$ 301 and $\beta$ polymorphs of DL-menthol using DSC, although Corvis et al. [10] suggested that the $\gamma$

302 form of L-menthol can be detected only when using flash DSC. On the other hand, the $\gamma$ phase of 303 DL-menthol observed in [10] was not detected in this work.

304 Several modifications of L-menthol seem to crystalize simultaneously and immediately start to 305 transform to more stable modifications when running DSC experiments. Such behaviour, denoted 306 as concomitant polymorphism, is rare but documented for some other compounds [9]. The first 307 task was an accurate measurement of fusion enthalpy of the $\alpha$ polymorph $\left(\Delta_{\alpha}^{1} H_{\mathrm{m}}^{0}\right.$ ) using DSC,

308 since the results varied even in experiments, where a single peak was detected in the thermogram.

309 Therefore, the $\alpha$ phases of both L- and DL-menthol were prepared in the DSC by two 
310 approaches: (i) heating a crystallized sample slightly above the $\beta$ phase melting temperature

311 ( $\left.T_{\text {fus }, \beta}\right)$ followed by cooling well below it, and (ii) long isothermal conversion from the $\beta$ phase at

312 temperatures around $273 \mathrm{~K}$ or $293 \mathrm{~K}$ for DL- and L-menthol, respectively. It should be noted that

313 the spontaneous phase change from the $\beta$ to $\alpha$ phase is not accompanied by any exothermal effect

314 within the detection limits of the TA Q1000 calorimeter at given conditions. The DSC runs with

315 the $\alpha$ phase prepared by melting of the $\beta$ phase usually yielded a single peak at the melting

316 temperature corresponding to the $\alpha$ phase $\left(T_{\text {fus }, \alpha}\right)$. However, $\Delta_{\alpha}^{1} H_{\mathrm{m}}^{0}$ of both DL- and L-menthol

317 obtained by this process are ( 0.5 to 1$) \mathrm{kJ} \mathrm{mol}^{-1}$ lower than that for the $\alpha$ polymorph prepared by

318 transformation of the $\beta$ phase, although there were no signs of any other peak in the DSC

319 thermogram, except for a few experiments with DL-menthol performed at a high heating rate,

320 where a subtle peak of melting of the $\beta$ phase was observed (in agreement with XPRD

321 observation in Figure S4 in SD). The resulting assumption that the subcooled liquid phase may

322 coexist with the $\alpha$ phase for a long time period was further studied using XRPD and examined

323 during adiabatic measurements. The transformation and crystallization rate of the $\alpha$ phase was

324 also observed to be lower for L-menthol than for DL-menthol.

325 Even though several combinations of heating rates and quenching times were tested, it was not

326 possible to obtain the fusion enthalpy of the metastable forms of L-menthol directly. The melting

327 enthalpy of the $\beta$ polymorph $\left(\Delta_{\beta}^{1} H_{\mathrm{m}}^{0}\right)$ was calculated from the DSC runs where the melting

328 peaks of the $\alpha$ and $\beta$ phases were of comparable size. The ratio of polymorphs was derived from

329 the $\Delta_{\alpha}^{1} H_{\mathrm{m}}^{0}$ of the pure $\alpha$ phase, i.e., as $\Delta_{\beta}^{1} H_{\mathrm{m}}^{0}=A_{\beta} /\left(1-A_{\alpha} / \Delta_{\alpha}^{1} H_{\mathrm{m}}^{0}\right)$, where $A$ is the melting peak

330 area per chemical amount of the whole sample. The melting enthalpies of the $\gamma$ and $\delta$ polymorphs

331 of L-menthol have higher uncertainty as they were calculated from experiments with three or four 
332 partially overlapping melting peaks, as shown in Figure 1. Separation of the peaks using a lower

333 heating rate is not possible due to the short lifetime of the metastable polymorphs since their melt

334 immediately crystallizes to more stable phases. Several different thermograms are displayed in

335 Figure 1 together with a demonstration of the $\Delta_{\beta}^{1} H_{\mathrm{m}}^{0}$ calculation. The measurements for DL-

336 menthol showed certain differences relative to L-menthol. Quenching of the melt to $288 \mathrm{~K}$

337 followed by fast heating, suggested in [2], resulted in a direct measurement of $\Delta_{\beta}^{1} H_{\mathrm{m}}^{0}$ of DL-

338 menthol. The resulting value was in excellent agreement with a value calculated following the

339 methodology for L-menthol. Any other polymorphs of DL-menthol were not detected. The fusion

340 temperatures and enthalpies of all observed polymorphs of L-and DL-menthol are listed in Table

3412.

342 To obtain reliable condensed-phase properties (heat capacity and melting parameters) of the

343 stable $\alpha$ phase of L-menthol, adiabatic calorimetry was used. Since adiabatic calorimetry

344 measurements are very slow by their nature (each heat-capacity point takes $15 \mathrm{~min}$ to $30 \mathrm{~min}$ on

345 average) and rapid cooling is not achievable (typical cooling rate is around $0.03 \mathrm{~K} \cdot \mathrm{s}^{-1}$ around

346 room temperature), all regular procedures by the method gave only the stable $\alpha$ phase of L-

347 menthol without any traces of metastable modifications. In addition, crystals were annealed at

$348 \sim 298 \mathrm{~K}$ for (4-5) hours in the adiabatic calorimeter to make sure that no metastable modification

349 remained. In all adiabatic calorimetry series, reproducible enthalpy of fusion of the $\alpha$ phase was

350 observed (see Table S2 in the SD for details).

351 We were also able to determine heat capacity and vapour pressure of the $\beta$ phase of DL-menthol

352 during experiments using the Tian-Calvet calorimeter and STAT6. The same was not possible 
353 during measurements for L-menthol nor using STAT8 apparatus due to its slower cooling rate 354 compared to STAT6.

355 The literature values for normal $T_{\text {fus }, \alpha}$ of L-menthol range from $315 \mathrm{~K}$ to $316.7 \mathrm{~K}$. Three values 356 obtained in this work by different techniques (DSC, adiabatic calorimetry, and vapour pressure 357 measurements) for two independent samples fit within the range from $315.4 \mathrm{~K}$ to $315.6 \mathrm{~K}$ and lie 358 in the lower part of the interval. On the other hand, $T_{\mathrm{fus}, \beta}=310.0 \mathrm{~K}$ measured in this work for L359 menthol is higher than most of the literature values ranging from $308.5 \mathrm{~K}$ to $310.7 \mathrm{~K}$. The 360 explanation of this slight disagreement in not evident as purity, enantiomeric excess in the 361 sample, or calibration of DSC should not significantly affect the difference between the melting

362 points of polymorphs. Values of $\Delta_{\alpha}^{1} H_{\mathrm{m}}^{0}$ summarized in Table 2 exhibit a scatter larger than 2

$363 \mathrm{~kJ} \cdot \mathrm{mol}^{-1}$, which could be probably assigned to the observed long-term coexistence of the $\alpha$ form

364 and liquid. Most of the values (including the difference in slope of our vapour pressure 365 measurements and excepting for the value reported in [2]) are about $0.5 \mathrm{~kJ} \cdot \mathrm{mol}^{-1}$ lower than our

366 DSC and adiabatic results, corresponding rather to our DSC experiments performed with the 367 samples containing the residual liquid (see the pink thermogram in Figure 1). XRPD results for

368 DL-menthol also support a long-term co-existence of the liquid and $\alpha$ form as discussed in the 369 next section. However, we note that the phase change mechanisms may be different for L- and 370 DL-menthol and affected by different experimental conditions including container materials and

371 sample mass. The data on $\Delta_{\mathrm{cr}}^{1} H_{\mathrm{m}}^{0}$ and $T_{\text {fus }}$ of other L-menthol polymorphs are scarce, however, 372 the values are in reasonable agreement considering the difficulties associated with their 373 determinations. 
374 Only two records on $\Delta_{\mathrm{cr}}^{1} H_{\mathrm{m}}^{0}$ and $T_{\text {fus }}$ for the $\alpha$ and $\beta$ polymorphs of DL-menthol were found in

375 the literature, [2] (both polymorphs) and [47] (one polymorph). From the comparison of the

376 results, it is obvious that $\Delta_{\beta}^{1} H_{\mathrm{m}}^{0}$ and $T_{\mathrm{fus}, \beta}$ are reported in [47] although the polymorphism is not

377 mentioned in the paper and the study itself focused on differences in properties of pure

378 enantiomers and racemic crystals (note that $\beta$-DL-menthol is a pseudoracemate). There is a slight

379 disagreement in the value of $\Delta_{\alpha}^{1} H_{\mathrm{m}}^{0}$ and $T_{\mathrm{fus}, \alpha}$ measured in this work and in [2], similarly to L-

380 menthol. Our result obtained by DSC is in close agreement with that obtained using the vapour

381 pressure measurements and, therefore, seems to be more reliable. On the other hand, $\Delta_{\beta}^{1} H_{\mathrm{m}}^{0}$ and

$382 T_{\mathrm{fus}, \beta}$ of DL-menthol from all sources are in a good agreement.

383 The melting properties of menthols were previously studied mostly by DSC, so all the available

384 data summarized in Table 2 should have comparable uncertainties, while the new data from

385 adiabatic calorimetry for the $\alpha$ polymorph of L-menthol have uncertainties lower by a factor of

386 ten. The reported uncertainties of some literature values in Table 2 can be considered too

387 optimistic, if inherent uncertainties of the DSC method and complicated phase behaviour of

388 menthol are taken into account. We recommend the adiabatic calorimetry results for the $\alpha$ form of

389 L-menthol and mean values of the DSC and vapour pressure results in the other cases (given as

390 bold values in Table 2). The use of the melting parameters for the $\alpha$ form of L-menthol from

391 adiabatic calorimetry is justified, since (i) weighted mean of the available values would yield an

392 almost identical value due to the large difference in realistically estimated uncertainties, (ii) the

393 enthalpies of fusion from the literature can be subject to the presence of residual liquid, as

394 discussed above, and (iii) when deriving the thermodynamic functions from the heat capacity and 
395 melting parameters in Section 3.3, the use of consistent total enthalpies upon integration is

396 required.

397

398 Table 2

399 Temperatures and enthalpies of fusion of L- and DL-menthol at $0.1 \mathrm{MPa}^{\mathrm{a}}$

\begin{tabular}{|c|c|c|c|c|}
\hline \multirow{3}{*}{ polymorph } & \multicolumn{2}{|c|}{ L-menthol } & \multicolumn{2}{|c|}{ DL-menthol } \\
\hline & $T_{\text {fus }} /$ & $\Delta_{\mathrm{cr}}^{1} H_{\mathrm{m}}^{0} /$ & $T_{\text {fus }} /$ & $\Delta_{\mathrm{cr}}^{1} H_{\mathrm{m}}^{0} /$ \\
\hline & $\mathrm{K}$ & $\mathrm{kJ} \mathrm{mol}^{-1}$ & $\mathrm{~K}$ & $\mathrm{~kJ} \mathrm{~mol}^{-1}$ \\
\hline$\alpha$ phase & $\begin{array}{l}\mathbf{3 1 5 . 6 0} \pm \mathbf{0 . 0 2}^{\mathbf{b , c}} \\
315.4 \pm 0.3^{\mathrm{d}} \\
315.4^{\mathrm{e}} \\
316.1 \pm 0.3[2] \\
316^{\mathrm{f}}[47] \\
316.7 \pm 0.1[3] \\
315[48] \\
315.6[8] \\
315.7[11] \\
315.4[49] \\
315.6[50]\end{array}$ & $\begin{array}{l}\mathbf{1 3 . 4 7} \pm \mathbf{0 . 0 6}^{\mathbf{b , c}} \\
13.3 \pm 0.3^{\mathrm{d}} \\
12.5^{\mathrm{e}} \\
14.1 \pm 0.2[2] \\
11.9^{\mathrm{f}}[47] \\
12.83 \pm 0.10[3] \\
12.4[48]\end{array}$ & $\begin{array}{l}305.7 \pm 0.3^{\mathrm{d}} \\
305.9^{\mathrm{e}} \\
307.0 \pm 0.3[2] \\
307.2[11] \\
\mathbf{3 0 6 . 5} \pm \mathbf{0 . 8} \text { (mean) }^{\mathbf{c}}\end{array}$ & $\begin{array}{l}13.7 \pm 0.3^{\mathrm{d}} \\
13.7^{\mathrm{e}} \\
14.2 \pm 0.2[2] \\
\mathbf{1 3 . 9} \pm \mathbf{0 . 3}(\text { mean) }\end{array}$ \\
\hline$\beta$ phase & $\begin{array}{l}310.0 \pm 0.3^{\mathrm{d}} \\
308.5 \pm 0.3[2] \\
308.6[8] \\
310.7[11] \\
309.5[50] \\
\mathbf{3 0 9 . 5} \pm \mathbf{0 . 9} \text { (mean) }^{\mathbf{c}}\end{array}$ & $\begin{array}{l}11.4 \pm 0.5^{\mathrm{d}} \\
11.0 \pm 0.2[2] \\
\mathbf{1 1 . 2} \pm \mathbf{0 . 3}(\text { mean) }\end{array}$ & $\begin{array}{l}300.7 \pm 0.4^{\mathrm{d}} \\
300.5^{\mathrm{e}} \\
300.5 \pm 0.3[2] \\
301^{\mathrm{f}}[47] \\
300.5^{[11]} \\
\mathbf{3 0 0 . 6} \pm \mathbf{0 . 1} \text { (mean) }^{\mathbf{c}}\end{array}$ & $\begin{array}{l}9.9 \pm 0.4^{\mathrm{d}} \\
10.0^{\mathrm{e}} \\
9.3 \pm 0.2[2] \\
10.3^{\mathrm{f}}[47] \\
\mathbf{9 . 7} \pm \mathbf{0 . 4}(\text { mean) }\end{array}$ \\
\hline$\gamma$ phase & $\begin{array}{l}308.7 \pm 0.5^{\mathrm{d}, \mathrm{g}} \\
306.0 \pm 0.6[10] \\
306.6[8] \\
309.7[11] \\
\mathbf{3 0 7 . 8} \pm \mathbf{1 . 7} \text { (mean) }^{\mathbf{c}}\end{array}$ & $\begin{array}{l}6.7 \pm 2.0^{\mathrm{d}, \mathrm{g}} \\
6.2[10] \\
\mathbf{6 . 5} \pm \mathbf{0 . 4}(\text { mean) }\end{array}$ & $\begin{array}{l}295.9 \pm 0.6[10] \\
296.5[2]^{\mathrm{h}}\end{array}$ & $1.9 \pm 0.2[10]$ \\
\hline$\delta$ phase & $\begin{array}{l}304.3 \pm 1.0^{\mathrm{d}, \mathrm{g}} \\
304.6[8] \\
306.2[11] \\
\mathbf{3 0 5 . 0} \pm \mathbf{1 . 0} \text { (mean) }^{\mathbf{c}}\end{array}$ & $7.3 \pm 2.0^{\mathrm{d}, \mathrm{g}}$ & & \\
\hline
\end{tabular}

$400{ }^{a}$ Only literature values obtained during calorimetric studies (DSC, if not specified otherwise) and vapour pressure

401 studies are included. The type of uncertainty for the literature values was not specified in the corresponding sources

402 except for [3], where the uncertainty is described as standard uncertainty.

403 b This work, triple-point temperature from adiabatic calorimetry. Expanded uncertainties with 0.95 level of 404 confidence are provided. 
${ }^{c}$ Recommended value (in bold) calculated either as average of DSC results (specified uncertainty is the expanded uncertainties with 0.95 level of confidence) or as an adiabatic-calorimetry value when available.

${ }^{\mathrm{d}}$ This work, DSC TA Q1000. Expanded uncertainties with 0.95 level of confidence are provided.

408 e This work, calculated from the vapour pressure measurements using static method (STAT6 and STAT8 apparatus).

409 The value of $\Delta_{\mathrm{cr}}^{1} H_{\mathrm{m}}^{0}$ for L-menthol is affected by the coexistence of the $\alpha$ phase and liquid.

$410{ }^{\mathrm{f}}$ Measured by DTA without specification of the corresponding polymorph. We matched the data to specific phases 411 according to the specified $T_{\text {fus }}$.

$412 \mathrm{~g}$ The $\gamma$ - and $\delta$-phase melting peaks are always followed by crystallization or overlap with melting of more stable 413 polymorphs (see Figure 1). The determination of $T_{\mathrm{fus}}$ and $\Delta_{\mathrm{cr}}^{1} H_{\mathrm{m}}^{0}$ for these forms is therefore less accurate.

414 h Indirect determination from Roozeboom's melting loop.

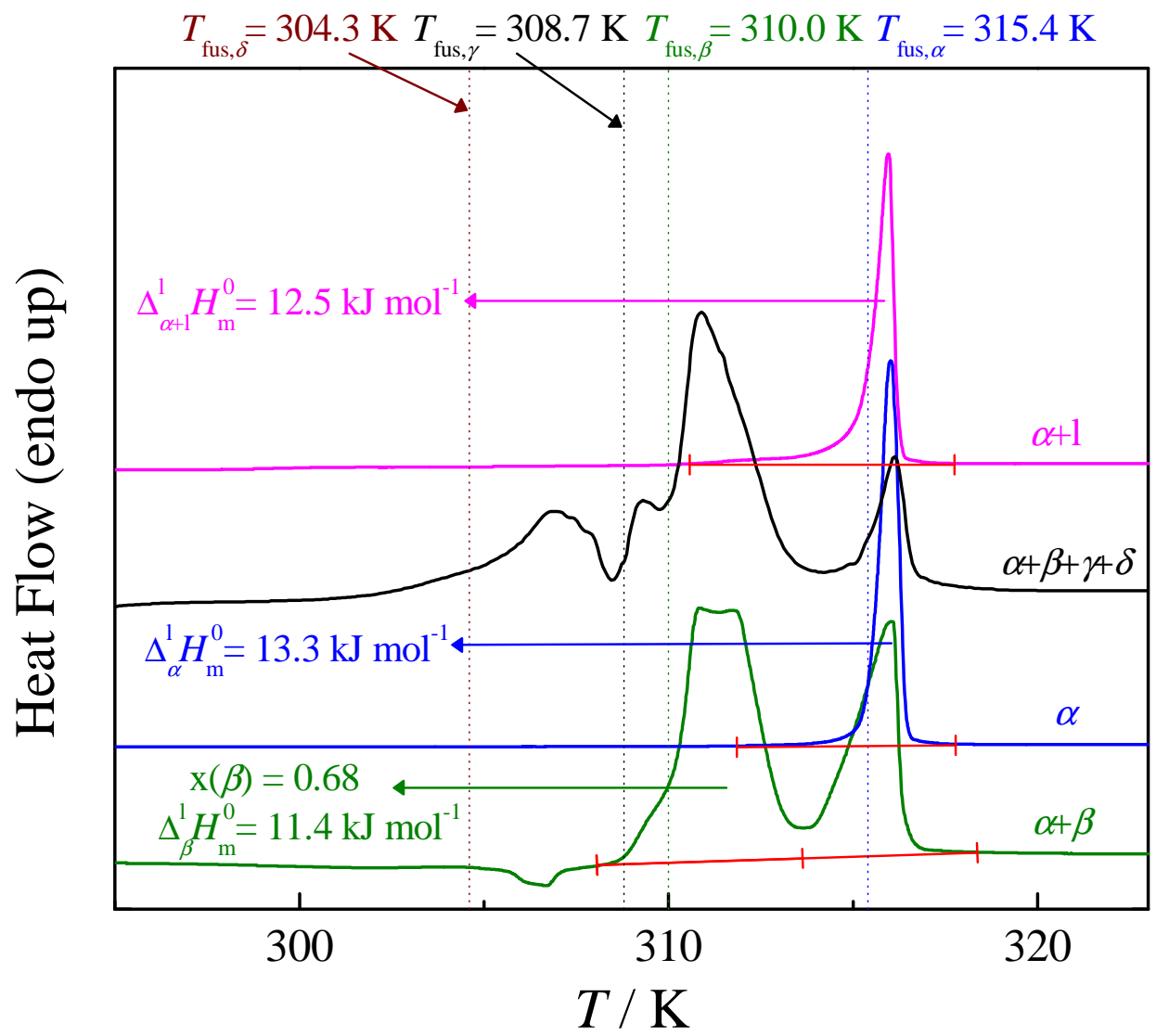

417 Figure 1. Phase behaviour of L-menthol at $0.1 \mathrm{MPa}$. Thermograms were recorded in the heating mode 418 with different heating rates (HR), scaled and shifted for clarity.,$- \mathrm{HR}=2 \mathrm{~K} \cdot \mathrm{min}^{-1}$, freshly crystallized 419 sample, demonstration of calculation of $\Delta_{\beta}^{1} H_{\mathrm{m}}^{0} ;-, \mathrm{HR}=0.5 \mathrm{~K} \cdot \mathrm{min}^{-1}$, the aged $\alpha$ sample obtained by 
420 transformation from the $\beta$-phase; $-\mathrm{HR}=10 \mathrm{~K} \cdot \mathrm{min}^{-1}$, freshly crystallized sample;,$- \mathrm{HR}=2 \mathrm{~K} \cdot \mathrm{min}^{-1}$,

421 the $\alpha$ sample prepared by crystallization followed by heating to $313 \mathrm{~K}$ (above $T_{\text {fus }, \beta}$ ).

$423 \quad 3.2 X$-ray study and kinetics of transformation of DL-menthol from the $\beta$ to $\alpha$ phase

424 The maximum lifetime of $\beta$-DL-menthol was observed to be tens of minutes up to several hours 425 depending on the maintained temperature in both vapour pressure and DSC measurements. The 426 VT-XRPD method was also employed since it enables in-situ monitoring of the polymorphic 427 composition. A series of XRPD measurements was performed to determine isothermal 428 conversion rate of the $\beta$ to $\alpha$ polymorph at various temperatures. DL-menthol was selected for the 429 study, as the occurrence of the other polymorphs of L-menthol would complicate the study. 430 However, the transformation of the $\beta$ to $\alpha$ polymorph in the case of L-menthol is believed to 431 behave in a qualitatively similar way, although it was observed to be slower during the DSC 432 experiments.

433 The phase conversion curves were recorded at several temperatures between $233 \mathrm{~K}$ and $298 \mathrm{~K}$ 434 and fitted by the Johnson-Mehl-Avrami (JMA) equation [51]:

$$
x(\beta)=e^{-k\left(t-t_{0}\right)^{n}}
$$

436 where $x(\beta)$ is the fraction of the $\beta$ polymorph, $t_{0}$ is the initial lag (induction time) before the phase 437 change started, $n$ is a geometric parameter determining the nature of nucleation, and $k$ is the rate 438 constant of the transformation. The induction time of a (re)crystallization process has a stochastic 439 nature. Therefore, as expected, the $t_{0}$ value was found to be highly variable during the 440 experiments at the same temperature and acted primarily for aligning the curves during the 441 treatment. The fitting procedure was found to be only weakly dependent on $n$, which varied 442 between 1.5 and 3 for different curves. Finally, $n=2$ was fixed, which would, from theory, 
443 correspond to the heterogeneous nucleation and crystal growth in one dimension [51], which 444 matches well with the needle shape of menthol crystals.

445 The smoothed conversion curves and the temperature dependence of the parameter $k$ and phase 446 change half-life $\tau_{1 / 2}$ are displayed in Figure 2. The obtained parameters of the conversion curves 447 with respect to temperature are listed in Table S3 in the SD. Our results demonstrate that the $\beta$ - $\alpha$ 448 phase transition proceeds continuously with the highest transformation rate around $268 \mathrm{~K}$ as a 449 result of interplay between thermodynamic and kinetic aspects. These conclusions are in 450 agreement with a previous stability study [2], although we did not detect any decrease of the $\beta$ 451 phase stability above $288 \mathrm{~K}$.

452 Another XRPD experiment was designed to support the assumption of coexistence of the super 453 cooled liquid and the $\alpha$ phase. A liquid DL-menthol sample was quenched to $288 \mathrm{~K}$ and left to 454 crystallize, thereby initiating a continuous transformation from $\beta$ to $\alpha$. When reaching $x(\beta) \approx 0.8$, 455 the sample was heated to $303 \mathrm{~K}$ with the heating rate of about $4 \mathrm{~K} \cdot \mathrm{min}^{-1}$, where the $\beta$ phase 456 melted. The gradual increase in the intensity of the $\alpha$-phase reflections and the decrease in the 457 background halo demonstrated in Figure S5 in the SI proved the coexistence of the liquid and $\alpha$ 458 phase on the order of hours, although the assessment has a large uncertainty. The measurements 459 indicate there is a residual (and not detectably decreasing) ratio of amorphous phase in DL460 menthol even after 24 hours at $303 \mathrm{~K}$. Even after a repeated cooling, the liquid part of the sample 461 coexisting with the $\alpha$ phase was observed to crystallize into the $\beta$ phase by both DSC and XRPD, 462 which, however, transformed to the $\alpha$ phase in a relatively short time (see Figure S4 in the SI). 463 Considering the slow $\alpha$-phase formation from both the liquid and $\beta$ phase, the rate-determining 464 step is probably the organization of the molecules into the $\alpha$-phase lattice. The comparison of the 
465 experiments in Figure 3 also suggests that the rate of formation of the $\alpha$ phase by transformation 466 from the $\beta$ phase is faster than by crystallization from the liquid phase.

467 It should be also noted that we have performed a successful indexation of the $\beta$ phase of DL468 menthol with the resulting unit cell identical to the one reported in [2]. The complicated nature of

469 the crystal structure, however, did not allow for the full structure solution from the XRPD data.

470 This understanding of the phase behaviour and kinetics of transformations between various

471 menthol polymorphs provided a necessary foundation for the systematic study of thermodynamic 472 properties of menthols described in the following sections.

473 


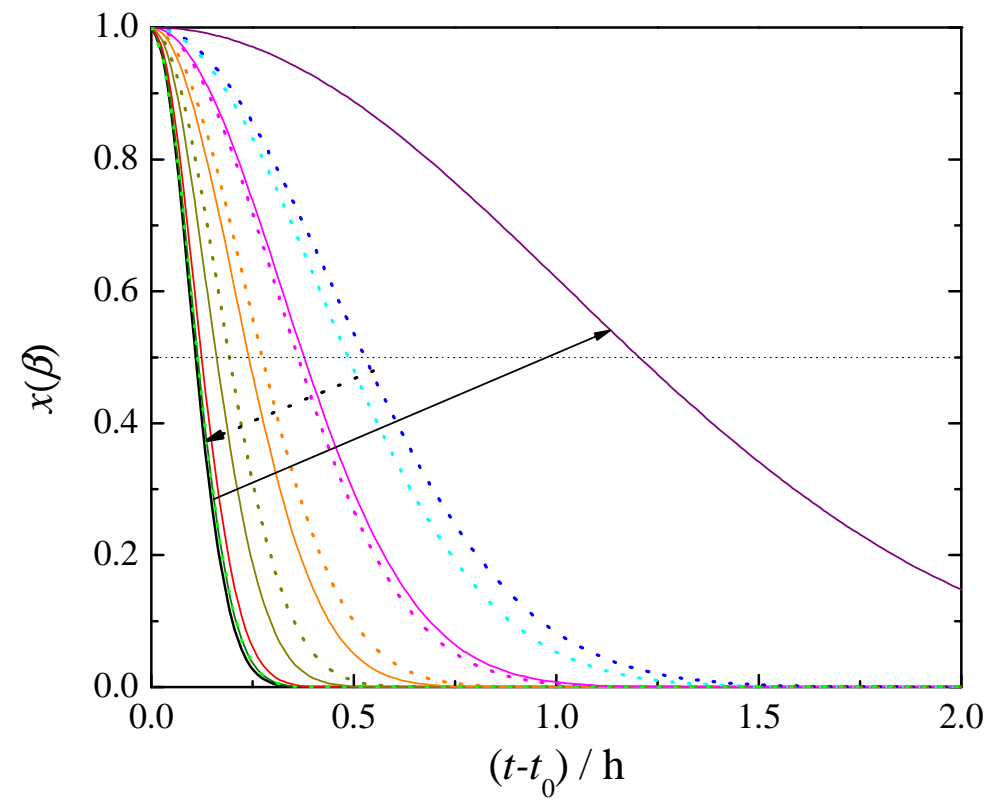

474

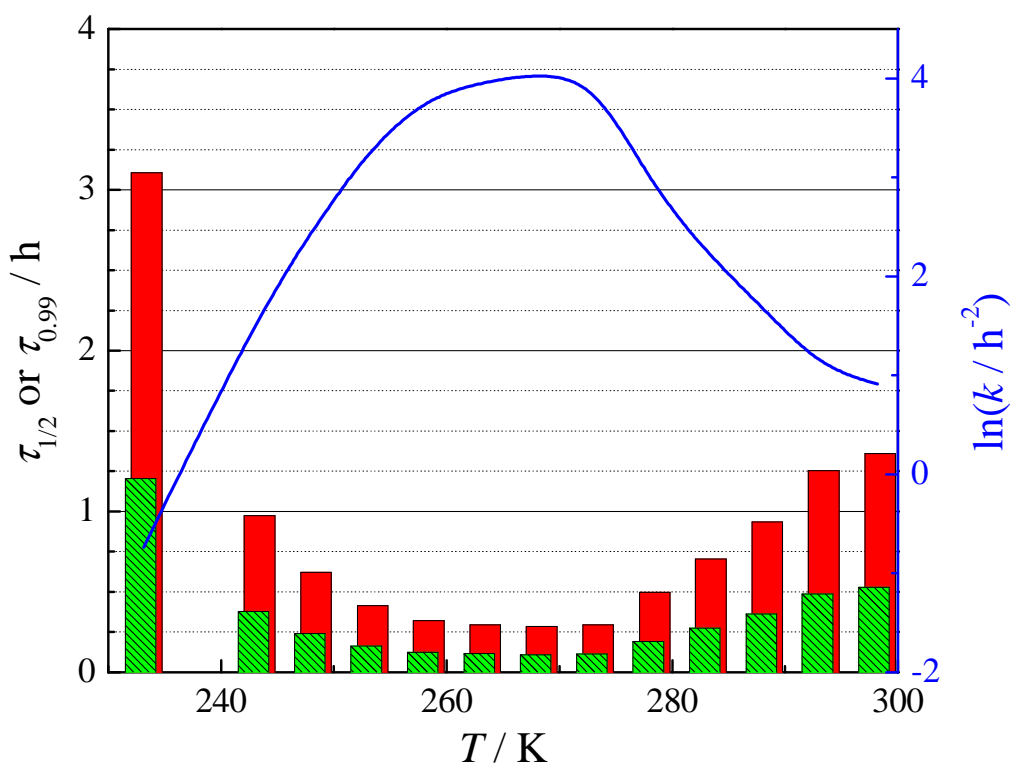

475

476 Figure 2. Conversion of the $\beta$ to $\alpha$ phase of DL-menthol at different temperatures.

477 Top: $x(\beta)$ is the fraction of the $\beta$ polymorph. JMA kinetics curves are shown instead of

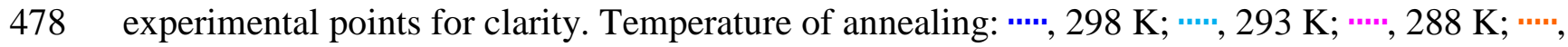

$479283 \mathrm{~K} ;$; '.", $278 \mathrm{~K} ; \cdots \cdot \cdots, 273 \mathrm{~K} ;-, 268 \mathrm{~K}$ (change of trend); 一, $263 \mathrm{~K} ;-, 258 \mathrm{~K}$; 一, $253 \mathrm{~K}$; 一,

$480248 \mathrm{~K} ;-, 243 \mathrm{~K}$; - $233 \mathrm{~K}$; Bottom: Kinetics parameters: 一, rate constant $k$ from Eq. (5) (right 481 axis), (hatched), phase change half-life, $\tau_{1 / 2}$; , phase change $99^{\text {th }}$ percentile, $\tau_{0.99}$ (left axis). 


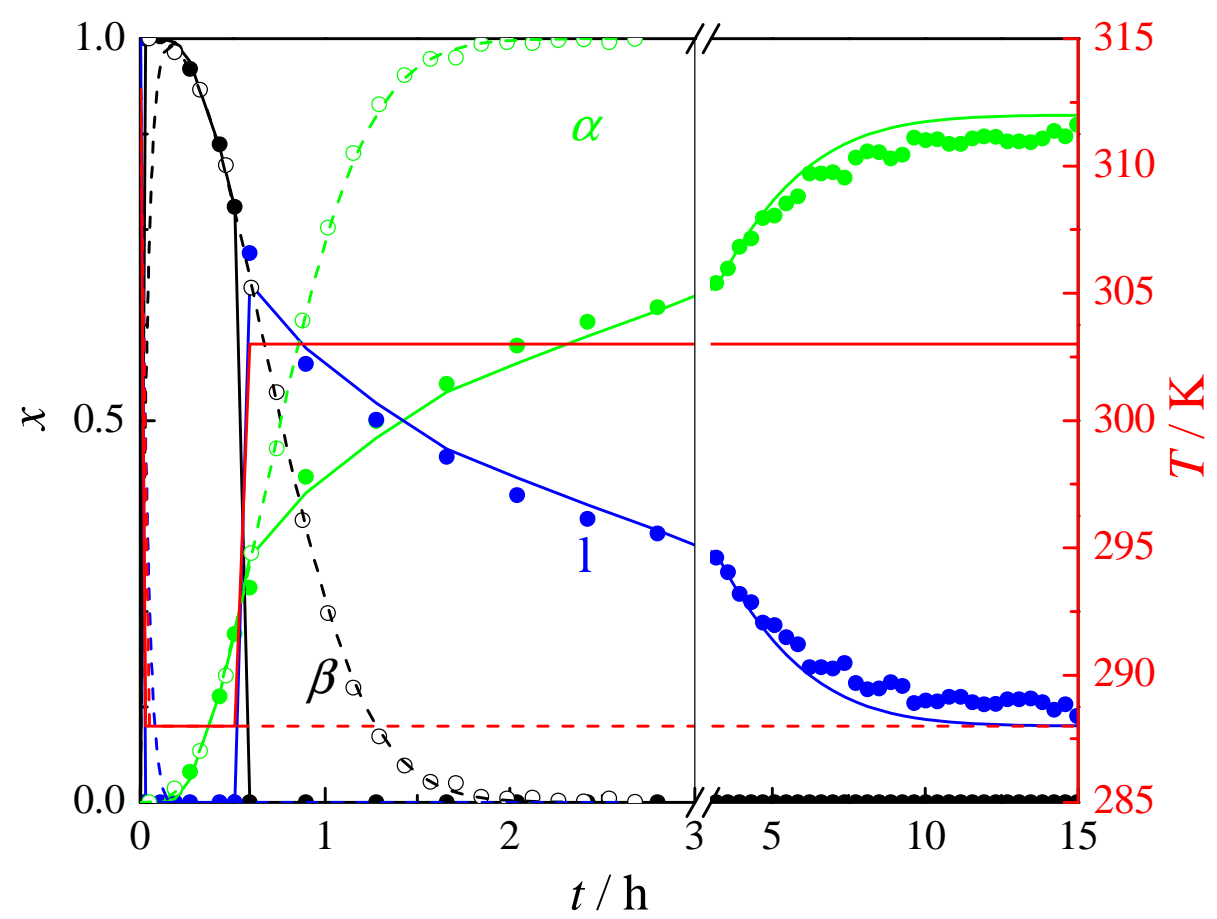

484 Figure 3. Comparison of kinetics of formation of the $\alpha$ phase by crystallization and by phase 485 transformation from the $\beta$ phase for DL-menthol.

$486-$, temperature (right axis); -,,$x=x(1) ;-, \bigcirc, x=x(\alpha) ;-, \boldsymbol{\Theta}, x=x(\beta)$. Lines are calculated 487 from the JMA equation, Eq. (5). Full symbols and solid lines belong to measurement at $303 \mathrm{~K}$ 488 (above $T_{\text {fus }, \beta}$ ), empty symbols and dashed lines to measurement at $288 \mathrm{~K}$ (below $T_{\text {fus }, \beta}$ ).

$490 \quad 3.3$ Condensed phase heat capacities

491 The experimental molar heat capacities of the $\alpha$ phase and liquid L-menthol measured in the 492 adiabatic calorimeter are presented in Table 3 and shown graphically in Figure 4. The 493 experimental heat capacities of the $\alpha$-crystalline and liquid phase of L- and DL-menthols 494 obtained by Tian-Calvet calorimetry are listed in Table 4 and displayed in Figure 5. The latter 495 measurements of the $\alpha$ phase were performed after maintaining the sample at $273 \mathrm{~K}$ for 3 hours 496 which was estimated as a sufficient time for a complete transformation as confirmed by the 497 absence of a $\beta$-phase melting peak. Since it was possible to obtain the pure $\beta$ form of DL-menthol 
498 in the DSC, measurements by Tian-Calvet calorimetry were repeated with a freshly crystallized

499 sample and resulted in noticeably lower heat capacities which were assigned to the $\beta$ polymorph

500 with a possible small amount of the $\alpha$ phase that may have been formed during the course of the

501 experiment.

502 As it is obvious from Table 4 and Figure 5, the heat capacities of both $\alpha$-crystalline and liquid L-

503 menthol obtained from two independent methods in this work are consistent within the

504 uncertainty of a heat capacity determination by Tian-Calvet calorimetry, with the exception of the

505 heat capacity data of the $\alpha$ form obtained by Tian-Calvet calorimetry above $280 \mathrm{~K}$. These data are

506 slightly higher due to that fact that they were not corrected for the premelting effects and a

507 possibly higher water content of the sample used. The effect of water contamination is within the

508 claimed uncertainty for the liquid phase, and the agreement of the results for L-menthol can serve

509 as a validation for the results obtained with the Tian-Calvet calorimeter for DL-menthol. The heat

510 capacities of the liquid L- and DL-samples are equal to within their experimental uncertainties,

511 but for the $\alpha$ phases, the heat capacity of DL-menthol is provably lower over the studied

512 temperature range by about $1 \%$ to $2 \%$.

513 The heat capacities of liquid and $\alpha$-crystalline L-menthol from Corvis and Espeau [6] are in a

514 remarkably good agreement with our results (within $3 \%$ ) when considering that a heat-flux DSC

515 was employed. It should be noted that the authors of [6] used a three-run procedure, repeated the

516 experiments several times with different samples and obtained deviations from reference data for

517 testing compounds (water and naphthalene) up to $10 \%$. By comparing with the reference data, a

518 steeper slope of temperature dependence of heat capacity data reported in [6] can be seen. The

519 authors claimed a somewhat optimistic expanded uncertainty (0.95 level of confidence) for L-

520 menthol (1.2\% to $3.2 \%$, which most likely reflects only a statistical component of uncertainty, 
521 i.e., type A uncertainty) when compared to the uncertainties of their measurements with the

522 reference materials. Corvis and Espeau [6] also reported heat capacities of the $\beta$ for of L-menthol

523 between $204 \mathrm{~K}$ and $226 \mathrm{~K}$, which are $11 \%$ to $16 \%$ lower than our adiabatic calorimetry results

524 for the $\alpha$ polymorph of L-menthol. A lower heat capacity for the metastable phase is in agreement

525 with our results on DL-menthol, but such a large difference between the two polymorphs is

526 unlikely.

527 To maintain internal consistency of the condensed-phase thermodynamic data, the heat-capacity

528 and melting-parameter data for L-menthol from the adiabatic calorimetry were used in further

529 calculations. The lower uncertainty of adiabatic calorimetry in comparison with Tian-Calvet

530 calorimetry and DSC also justified the choice. In deriving the thermodynamic functions of L-

531 menthol in the condensed state from (5 to 370) $\mathrm{K}$, smoothing of heat capacities above $5 \mathrm{~K}$ was

532 carried out with the use of overlapping polynomials. Heat capacities below $5 \mathrm{~K}$ were extrapolated

533 with a Debye function with three degrees of freedom: $C_{p, \mathrm{~m}}^{0}=3 R \cdot D\left(\left\langle\Theta_{\mathrm{D}}\right\rangle / T\right)$, where the average

534 Debye characteristic temperature was derived to be $\left\langle\Theta_{\mathrm{D}}\right\rangle=65.6 \mathrm{~K}$ from the experimental heat

535 capacities between $(5.0$ and 9.5$) \mathrm{K}$. Table 5 summarizes the thermodynamic functions of L536 menthol.

537 For user's convenience, the experimental data from Tian-Calvet calorimeter for DL-menthol 538 were represented by a polynomial equation:

$$
C_{p, \mathrm{~m}}^{0} /\left(\mathrm{J} \mathrm{K}^{-1} \mathrm{~mol}^{-1}\right)=a+b\left(\frac{T}{100 \mathrm{~K}}\right)+c\left(\frac{T}{100 \mathrm{~K}}\right)^{2}
$$

540 with parameters given in Table 6. All measured data points obtained (not just the averaged values 541 presented in Table 4) were used for deriving the polynomials. 
Table 3

Experimental molar saturation-pressure heat capacities for L-menthol obtained by adiabatic calorimetry ${ }^{\mathrm{a}}$

\begin{tabular}{|c|c|c|c|c|c|}
\hline$T / \mathrm{K}$ & $C_{\mathrm{s}, \mathrm{m}} / \mathrm{J} \cdot \mathrm{K}^{-1} \cdot \mathrm{mol}^{-1}$ & $T / \mathrm{K}$ & $C_{\mathrm{s}, \mathrm{m}} / \mathrm{J} \cdot \mathrm{K}^{-1} \cdot \mathrm{mol}^{-1}$ & $T / \mathrm{K}$ & $C_{\mathrm{s}, \mathrm{m}} / \mathrm{J} \cdot \mathrm{K}^{-1} \cdot \mathrm{mol}^{-1}$ \\
\hline \multirow{2}{*}{\multicolumn{2}{|c|}{$\begin{array}{l}\text { Series } 1 \text { (TAU-1) } \\
\text { crystal ( } \alpha \text { phase) }\end{array}$}} & 51.35 & 54.32 & 118.11 & 110.4 \\
\hline & & 53.83 & 56.47 & 119.87 & 111.7 \\
\hline 5.02 & 0.8545 & 56.32 & 58.63 & 121.64 & 113.1 \\
\hline 5.31 & 1.027 & 58.78 & 60.81 & 123.41 & 114.4 \\
\hline 5.63 & 1.231 & 61.29 & 62.85 & 125.18 & 115.8 \\
\hline 5.95 & 1.445 & 64.03 & 65.18 & 126.95 & 117.2 \\
\hline 6.26 & 1.675 & 66.85 & 67.74 & 128.73 & 118.4 \\
\hline 6.62 & 1.937 & 69.53 & 70.14 & 130.50 & 119.8 \\
\hline 7.00 & 2.276 & 72.08 & 72.41 & 132.28 & 121.1 \\
\hline 7.37 & 2.577 & 74.60 & 74.48 & 134.07 & 122.4 \\
\hline 7.74 & 2.937 & 77.11 & 76.77 & 135.85 & 123.7 \\
\hline 8.14 & 3.382 & 79.66 & 78.77 & 137.63 & 125.1 \\
\hline 8.58 & 3.847 & 82.26 & 80.88 & 139.41 & 126.4 \\
\hline 9.03 & 4.373 & 84.79 & 83.06 & 141.20 & 127.7 \\
\hline 9.49 & 4.870 & 87.34 & 85.27 & 142.99 & 128.9 \\
\hline 9.99 & 5.512 & 89.90 & 87.37 & 144.77 & 130.2 \\
\hline 10.51 & 6.205 & 92.42 & 89.76 & 146.56 & 131.5 \\
\hline 11.04 & 6.889 & 94.94 & 91.69 & 148.36 & 132.8 \\
\hline 11.61 & 7.681 & 97.47 & 93.81 & 150.15 & 134.1 \\
\hline 12.20 & 8.523 & 100.02 & 95.95 & 151.94 & 135.3 \\
\hline 12.83 & 9.473 & 102.58 & 98.22 & 153.73 & 136.6 \\
\hline 13.48 & 10.42 & 105.18 & 100.4 & 155.53 & 137.9 \\
\hline 14.15 & 11.42 & 107.78 & 102.4 & 157.32 & 139.1 \\
\hline 14.89 & 12.53 & & & 159.12 & 140.4 \\
\hline 15.66 & 13.66 & Series 2 & U-10) & 160.91 & 141.7 \\
\hline 16.43 & 14.93 & crystal $(o$ & se) & 162.72 & 143.0 \\
\hline 17.26 & 16.13 & 79.78 & 79.07 & 164.52 & 144.3 \\
\hline 18.12 & 17.43 & 81.50 & 80.47 & 166.32 & 145.5 \\
\hline 19.04 & 18.89 & 83.22 & 81.89 & 168.12 & 146.8 \\
\hline 20.00 & 20.23 & 84.94 & 83.28 & 169.92 & 148.0 \\
\hline 21.02 & 21.71 & 86.67 & 84.77 & 171.73 & 149.2 \\
\hline 22.08 & 23.27 & 88.39 & 86.22 & 173.53 & 150.5 \\
\hline 23.20 & 24.92 & 90.12 & 87.73 & 175.33 & 151.8 \\
\hline 24.41 & 26.58 & 91.85 & 89.21 & 177.14 & 153.1 \\
\hline 25.66 & 28.24 & 93.59 & 90.65 & 178.95 & 154.4 \\
\hline 26.93 & 29.92 & 95.32 & 92.09 & 180.76 & 155.6 \\
\hline 28.27 & 31.55 & 97.06 & 93.51 & 182.56 & 156.9 \\
\hline 29.67 & 33.28 & 98.80 & 95.01 & 184.37 & 158.2 \\
\hline 31.12 & 34.98 & 100.55 & 96.44 & 186.18 & 159.4 \\
\hline 32.66 & 36.66 & 102.30 & 97.81 & 188.00 & 160.7 \\
\hline 34.28 & 38.41 & 104.04 & 99.24 & 189.81 & 162.1 \\
\hline 36.00 & 40.06 & 105.80 & 100.7 & 191.62 & 163.3 \\
\hline 37.89 & 42.03 & 107.55 & 102.0 & 193.43 & 164.6 \\
\hline 39.90 & 43.93 & 109.31 & 103.5 & 195.25 & 165.9 \\
\hline 42.02 & 45.96 & 111.06 & 104.9 & 197.06 & 167.2 \\
\hline 44.24 & 48.03 & 112.82 & 106.2 & 198.87 & 168.5 \\
\hline 46.54 & 50.11 & 114.58 & 107.7 & 200.69 & 169.8 \\
\hline 48.92 & 52.21 & 116.34 & 109.0 & 202.50 & 171.1 \\
\hline
\end{tabular}




\begin{tabular}{|c|c|c|c|c|c|}
\hline$T / \mathrm{K}$ & $C_{\mathrm{s}, \mathrm{m}} / \mathrm{J} \cdot \mathrm{K}^{-1} \cdot \mathrm{mol}^{-1}$ & $T / \mathrm{K}$ & $C_{\mathrm{s}, \mathrm{m}} / \mathrm{J} \cdot \mathrm{K}^{-1} \cdot \mathrm{mol}^{-1}$ & $T / \mathrm{K}$ & $C_{\mathrm{s}, \mathrm{m}} / \mathrm{J} \cdot \mathrm{K}^{-1} \cdot \mathrm{mol}^{-1}$ \\
\hline 204.32 & 172.4 & 289.39 & 240.8 & 287.88 & 239.5 \\
\hline 206.14 & 173.7 & 291.22 & 242.6 & 289.68 & 241.3 \\
\hline 207.95 & 175.0 & 293.04 & 244.4 & 291.47 & 242.9 \\
\hline 209.77 & 176.4 & 294.86 & 246.6 & 293.25 & 244.8 \\
\hline 211.60 & 177.6 & 296.68 & 248.4 & 295.02 & 246.7 \\
\hline 213.42 & 178.9 & 298.50 & 250.6 & 296.79 & 248.6 \\
\hline 215.24 & 180.2 & 300.32 & 252.8 & 298.55 & 250.5 \\
\hline 217.07 & 181.5 & 302.14 & 255.3 & 300.30 & 252.7 \\
\hline 218.89 & 182.9 & 303.96 & 258.2 & 302.05 & 255.2 \\
\hline 220.72 & 184.2 & 305.78 & 261.9 & 303.78 & 257.9 \\
\hline \multirow[t]{2}{*}{222.55} & 185.4 & 307.59 & 267.2 & 305.50 & 261.4 \\
\hline & & 309.39 & 276.9 & 307.21 & 266.1 \\
\hline \multirow{2}{*}{\multicolumn{2}{|c|}{$\begin{array}{l}\text { Series } 3 \text { (TAU-10) } \\
\text { crystal ( } \alpha \text { phase) }\end{array}$}} & 311.16 & 301.9 & 308.90 & 274.2 \\
\hline & & 312.80 & 399.7 & 310.55 & 291.8 \\
\hline 216.36 & 180.9 & 314.05 & 917.0 & 312.60 & 435.0 \\
\hline 218.32 & 182.5 & 314.83 & 3386 & 314.23 & 1451 \\
\hline 220.14 & 183.7 & 315.18 & 15063 & 314.88 & 4980 \\
\hline 221.96 & 185.1 & 315.34 & 39619 & 315.12 & 10054 \\
\hline 223.78 & 186.5 & liquid & & 315.24 & 16051 \\
\hline 225.60 & 187.8 & 317.43 & 826.2 & 315.32 & 24245 \\
\hline 227.43 & 189.1 & 321.01 & 384.9 & 315.37 & 38440 \\
\hline 229.25 & 190.5 & 323.45 & 388.5 & 315.41 & 68331 \\
\hline 231.07 & 191.9 & 325.28 & 391.1 & liquid & \\
\hline 232.89 & 193.3 & 327.12 & 393.8 & 316.10 & 1070 \\
\hline 234.71 & 194.7 & 328.95 & 396.4 & 318.10 & 380.3 \\
\hline 236.53 & 196.1 & 330.79 & 399.1 & 320.34 & 383.5 \\
\hline 238.35 & 197.4 & 332.62 & 401.7 & 322.18 & 386.6 \\
\hline 240.18 & 198.8 & 334.46 & 404.2 & 324.01 & 389.3 \\
\hline 242.00 & 200.2 & 336.30 & 406.5 & 325.85 & 392.2 \\
\hline 243.83 & 201.7 & 338.14 & 408.8 & 327.67 & 394.8 \\
\hline 245.65 & 203.1 & 339.98 & 411.3 & 329.49 & 397.5 \\
\hline 247.48 & 204.5 & 341.82 & 413.4 & 331.30 & 400.1 \\
\hline 249.30 & 206.0 & 343.66 & 415.8 & 333.11 & 402.5 \\
\hline 251.12 & 207.5 & 345.50 & 417.9 & & \\
\hline 252.95 & 208.9 & 347.35 & 419.8 & \multicolumn{2}{|c|}{ Series 5 (TAU-10) } \\
\hline 254.77 & 210.4 & 349.19 & 421.7 & \multicolumn{2}{|c|}{ liquid, including super cooled } \\
\hline 256.59 & 212.0 & 351.04 & 423.4 & \multicolumn{2}{|c|}{ liquid } \\
\hline 258.41 & 213.7 & 352.88 & 425.1 & 312.20 & 370.6 \\
\hline 260.23 & 215.2 & 354.73 & 426.7 & 314.15 & 373.6 \\
\hline 262.05 & 216.8 & 356.58 & 428.4 & 316.02 & 376.5 \\
\hline 263.88 & 218.5 & 358.43 & 429.7 & 317.87 & 379.7 \\
\hline 265.70 & 220.1 & 360.27 & 431.1 & 319.72 & 382.6 \\
\hline 267.52 & 221.7 & 362.12 & 432.6 & 321.56 & 385.4 \\
\hline 269.34 & 223.4 & 363.97 & 433.8 & 323.40 & 388.2 \\
\hline 271.17 & 225.1 & 365.82 & 435.5 & & \\
\hline 272.99 & 226.5 & 367.67 & 436.2 & \multicolumn{2}{|c|}{ Series 6 (TAU-10) } \\
\hline 274.82 & 227.9 & & & \multicolumn{2}{|c|}{ crystal ( $\alpha$ phase) } \\
\hline 276.64 & 229.6 & \multicolumn{2}{|c|}{ Series 4 (TAU-10) } & 290.89 & 242.4 \\
\hline 278.46 & 231.1 & \multicolumn{2}{|c|}{ crystal ( $\alpha$ phase $)$} & 292.76 & 244.5 \\
\hline 280.29 & 232.6 & 278.81 & 231.4 & 294.53 & 246.2 \\
\hline 282.11 & 234.2 & 280.63 & 233.0 & \multicolumn{2}{|c|}{ continuous energy input } \\
\hline 283.93 & 235.8 & 282.45 & 234.5 & 306.62 & 874.7 \\
\hline 285.75 & 237.3 & 284.26 & 236.1 & liquid & \\
\hline 287.57 & 239.0 & 286.08 & 237.7 & 318.47 & 380.7 \\
\hline
\end{tabular}




$T / \mathrm{K} \quad C_{\mathrm{s}, \mathrm{m}} / \mathrm{J} \cdot \mathrm{K}^{-1} \cdot \mathrm{mol}^{-1}$

Series 7 (TAU-10)

crystal ( $\alpha$ phase)

291.80

293.66

295.44

continuous energy input

307.48

liquid

319.28

243.3

245.4

247.2

880.9

381.8

Series 8 (TAU-10)

crystal ( $\alpha$ phase)

291.08

293.06

294.94

296.82

298.69

300.55

302.40

304.24

306.07

\begin{tabular}{cc}
\hline$T / \mathrm{K}$ & $C_{\mathrm{s}, \mathrm{m}} / \mathrm{J} \cdot \mathrm{K}^{-1} \cdot \mathrm{mol}^{-1}$ \\
\hline 307.88 & 268.6 \\
309.65 & 279.9 \\
311.85 & 350.8 \\
313.82 & 896.7 \\
314.72 & 3282 \\
315.03 & 7459 \\
315.19 & 12074 \\
315.28 & 18701 \\
315.34 & 27475 \\
315.39 & 42162 \\
315.42 & 63161 \\
liquid & \\
316.21 & 819.2 \\
317.57 & 379.5 \\
318.82 & 381.4 \\
320.06 & 383.3 \\
321.31 & 385.3 \\
322.55 & 386.9 \\
323.79 & 388.8 \\
Series 9 (TAU-10) \\
liquid
\end{tabular}

\begin{tabular}{cc}
\hline$T / \mathrm{K}$ & $C_{\mathrm{s}, \mathrm{m}} / \mathrm{J} \cdot \mathrm{K}^{-1} \cdot \mathrm{mol}^{-1}$ \\
\hline 320.78 & 384.6 \\
323.31 & 388.4 \\
325.83 & 392.0 \\
328.34 & 395.8 \\
330.84 & 399.3 \\
333.33 & 402.6 \\
335.81 & 406.0 \\
338.29 & 409.0 \\
340.77 & 412.1 \\
343.25 & 415.1 \\
345.72 & 418.1 \\
348.20 & 420.7 \\
350.66 & 423.0 \\
353.12 & 425.1 \\
355.58 & 427.2 \\
358.04 & 429.4 \\
360.49 & 431.0 \\
362.94 & 432.8 \\
365.39 & 434.2 \\
367.84 & 435.7 \\
\hline
\end{tabular}

${ }^{\text {a }}$ Average heat capacities at the mean temperatures of experiments. The measurements were performed at $p(\mathrm{He})=$ $(5 \pm 1) \mathrm{kPa}$ (the pressure value corresponds to $T=293 \mathrm{~K})$; no adjustment of $C_{\mathrm{s}, \mathrm{m}}$ to $C_{p, \mathrm{~m}}^{0}$ at $p^{0}=10^{5} \mathrm{~Pa}\left(\right.$ i.e., $C_{\mathrm{s}, \mathrm{m}} \approx$ $C_{p, \mathrm{~m}}^{0}$ ) is needed due to small vapour pressure of the sample. The expanded uncertainty is $U(T)=0.02 \mathrm{~K}$, the relative expanded uncertainties are $U_{\mathrm{r}}\left(C_{\mathrm{s}, \mathrm{m}}\right)=0.02-4.57 \cdot 10^{-4}((T / \mathrm{K})-5)$ at $5 \mathrm{~K}<T<40 \mathrm{~K}$ and $U_{\mathrm{r}}\left(C_{\mathrm{s}, \mathrm{m}}\right)=0.004$ at $T>$ $40 \mathrm{~K}$ for 0.95 level of confidence $(k=2)$. 


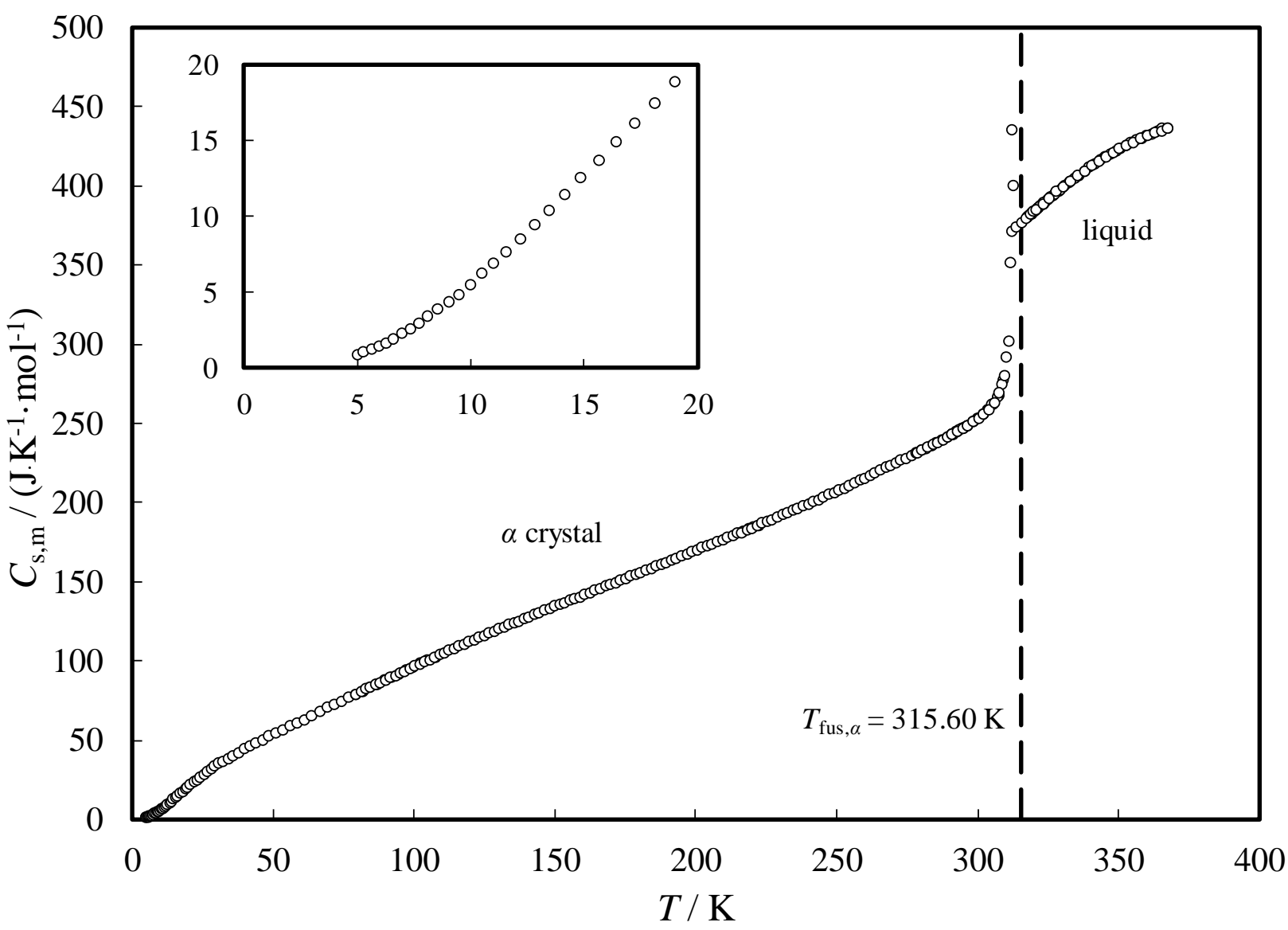

2 Figure 4. Condensed-phase heat capacities of L-menthol from adiabatic calorimetry

3 measurements

4

5 Table 4

6 Experimental standard molar heat capacities of the condensed phases $C_{p, \mathrm{~m}}^{0}$ measured by the Tian-

7 Calvet calorimeter at $100 \mathrm{kPa} .^{\text {a }}$

\begin{tabular}{cccccc}
\hline$T / \mathrm{K}$ & $\begin{array}{c}C_{p, \mathrm{~m}}^{0} / \\
\mathrm{J} \mathrm{K}^{-1} \mathrm{~mol}^{-1}\end{array}$ & $\Delta C_{p, \mathrm{~m}}^{0} \mathrm{~b}$ & $T / \mathrm{K}$ & $\begin{array}{c}C_{p, \mathrm{~m}}^{0} / \\
\mathrm{J} \mathrm{K}^{-1} \mathrm{~mol}^{-1}\end{array}$ & $\Delta C_{p, \mathrm{~m}}^{0} \mathrm{~b}$ \\
\hline \multicolumn{3}{c}{ L-Menthol } \\
$m=0.59114 \mathrm{~g}$ & \multicolumn{3}{c}{$\begin{array}{c}\text { DL-Menthol } \\
m=0.52334 \mathrm{~g}\end{array}$} \\
\hline \multicolumn{3}{c}{$\alpha$-crystalline } & \multicolumn{3}{c}{$\alpha$-crystalline } \\
\hline 265.2 & 221.5 & $0.79 \%$ & 265.0 & 217.6 & $-0.01 \%$ \\
270.0 & 225.6 & $0.78 \%$ & 270.0 & 221.3 & $0.03 \%$ \\
275.0 & 230.0 & $0.82 \%$ & 275.0 & 225.3 & $0.04 \%$ \\
280.0 & 235.1 & $1.19 \%$ & 280.0 & 229.5 & $-0.03 \%$ \\
285.0 & 240.5 & $1.58 \%$ & 285.0 & 234.2 & $0.00 \%$ \\
290.0 & 246.3 & $1.99 \%$ & & & \\
295.0 & 253.1 & $2.63 \%$ & & &
\end{tabular}




\begin{tabular}{cccccc}
\hline & liquid & & \multicolumn{3}{c}{ liquid } \\
\hline 325.9 & 395.1 & $0.74 \%$ & 315.4 & 377.3 & $0.06 \%$ \\
330.0 & 401.1 & $0.75 \%$ & 320.0 & 384.2 & $-0.10 \%$ \\
335.0 & 408.0 & $0.75 \%$ & 325.0 & 392.0 & $-0.07 \%$ \\
340.0 & 414.3 & $0.73 \%$ & 330.0 & 399.8 & $0.07 \%$ \\
345.0 & 420.5 & $0.82 \%$ & 335.0 & 406.9 & $0.13 \%$ \\
350.0 & 426.2 & $0.90 \%$ & 340.0 & 412.7 & $0.01 \%$ \\
355.0 & 430.8 & $0.89 \%$ & 345.0 & 418.1 & $-0.11 \%$ \\
& & & 350.0 & 423.7 & $-0.06 \%$ \\
& & & 355.0 & 429.0 & $0.03 \%$ \\
\cline { 3 - 5 } & & & 270.0 & $\beta$-crystalline \\
\cline { 3 - 5 } & & & 217.5 & $0.15 \%$ \\
& & & 280.0 & 219.5 & $0.07 \%$ \\
& & & & 223.1 & $-0.07 \%$ \\
& & & & & \\
\end{tabular}

8

$9{ }^{\text {a }}$ The standard uncertainty of the temperature is $u(T)=0.05 \mathrm{~K}$, and the combined expanded uncertainty of 10 the heat capacity is $U_{\mathrm{c}}\left(C_{p, \mathrm{~m}}^{0}\right)=0.01 C_{p, \mathrm{~m}}^{0}(0.95$ level of confidence). Mean values of four determinations.

$11{ }^{\mathrm{b}} \Delta C_{p, \mathrm{~m}}^{0}=100 \cdot\left(C_{p, \mathrm{~m}}^{0}-C_{p, \mathrm{~m}}^{0, \text { calc }}\right) / C_{p, \mathrm{~m}}^{0, \text { calc }}$ is the relative deviation from the fit; $C_{p, \mathrm{~m}}^{0, \text { calc }}$ was taken from Table 5 12 and calculated using Eq. (6) with parameters listed in Table 6 for L- and DL-menthol, respectively.

13 
Table 5

16 Standard molar thermodynamic functions of L-menthol in the crystalline and liquid states at a

17 standard pressure of $100 \mathrm{kPa}^{\mathrm{a}}$

\begin{tabular}{|c|c|c|c|c|}
\hline \multirow{2}{*}{$T / \mathrm{K}$} & $C_{p, \mathrm{~m}}^{0}$ & $\Delta_{0}^{T} H_{\mathrm{m}}^{0} / T$ & $\Delta_{0}^{T} S_{\mathrm{m}}^{0}$ & $-\Delta_{0}^{T} G_{\mathrm{m}}^{0} / T$ \\
\hline & \multicolumn{4}{|l|}{$\mathrm{J} \cdot \mathrm{K}^{-1} \cdot \mathrm{mol}^{-1}$} \\
\hline \multicolumn{5}{|c|}{ Crystal ( $\alpha$ phase $)$} \\
\hline 5 & $0.858 \pm 0.017$ & $0.2148 \pm 0.0043$ & $0.2864 \pm 0.0057$ & $0.0716 \pm 0.0014$ \\
\hline 10 & $5.528 \pm 0.098$ & $1.548 \pm 0.029$ & $2.099 \pm 0.040$ & $0.552 \pm 0.010$ \\
\hline 15 & $12.70 \pm 0.20$ & $4.037 \pm 0.069$ & $5.656 \pm 0.098$ & $1.619 \pm 0.028$ \\
\hline 20 & $20.26 \pm 0.27$ & $7.15 \pm 0.11$ & $10.35 \pm 0.17$ & $3.198 \pm 0.050$ \\
\hline 25 & $27.36 \pm 0.30$ & $10.49 \pm 0.15$ & $15.64 \pm 0.23$ & $5.151 \pm 0.073$ \\
\hline 30 & $33.65 \pm 0.29$ & $13.84 \pm 0.17$ & $21.20 \pm 0.28$ & $7.362 \pm 0.094$ \\
\hline 35 & $39.12 \pm 0.25$ & $17.07 \pm 0.18$ & $26.81 \pm 0.32$ & $9.74 \pm 0.11$ \\
\hline 40 & $44.06 \pm 0.18$ & $20.14 \pm 0.19$ & $32.36 \pm 0.35$ & $12.22 \pm 0.12$ \\
\hline 45 & $48.69 \pm 0.19$ & $23.06 \pm 0.19$ & $37.82 \pm 0.37$ & $14.76 \pm 0.13$ \\
\hline 50 & $53.14 \pm 0.21$ & $25.84 \pm 0.19$ & $43.18 \pm 0.40$ & $17.34 \pm 0.14$ \\
\hline 55 & $57.47 \pm 0.23$ & $28.52 \pm 0.19$ & $48.45 \pm 0.42$ & $19.93 \pm 0.15$ \\
\hline 60 & $61.81 \pm 0.25$ & $31.12 \pm 0.20$ & $53.64 \pm 0.44$ & $22.52 \pm 0.16$ \\
\hline 65 & $66.15 \pm 0.26$ & $33.64 \pm 0.20$ & $58.76 \pm 0.46$ & $25.11 \pm 0.17$ \\
\hline 70 & $70.48 \pm 0.28$ & $36.12 \pm 0.21$ & $63.82 \pm 0.48$ & $27.70 \pm 0.18$ \\
\hline 75 & $74.81 \pm 0.30$ & $38.56 \pm 0.21$ & $68.83 \pm 0.50$ & $30.27 \pm 0.19$ \\
\hline 80 & $79.11 \pm 0.32$ & $40.96 \pm 0.22$ & $73.79 \pm 0.52$ & $32.84 \pm 0.20$ \\
\hline 85 & $83.38 \pm 0.33$ & $43.33 \pm 0.22$ & $78.72 \pm 0.54$ & $35.39 \pm 0.21$ \\
\hline 90 & $87.62 \pm 0.35$ & $45.67 \pm 0.23$ & $83.60 \pm 0.56$ & $37.93 \pm 0.22$ \\
\hline 95 & $91.81 \pm 0.37$ & $47.99 \pm 0.24$ & $88.45 \pm 0.58$ & $40.47 \pm 0.23$ \\
\hline 100 & $95.95 \pm 0.38$ & $50.28 \pm 0.24$ & $93.27 \pm 0.60$ & $42.98 \pm 0.24$ \\
\hline 105 & $100.0 \pm 0.4$ & $52.55 \pm 0.25$ & $98.05 \pm 0.62$ & $45.49 \pm 0.25$ \\
\hline 110 & $104.0 \pm 0.4$ & $54.80 \pm 0.26$ & $102.8 \pm 0.6$ & $47.99 \pm 0.26$ \\
\hline 115 & $108.0 \pm 0.4$ & $57.03 \pm 0.27$ & $107.5 \pm 0.7$ & $50.48 \pm 0.27$ \\
\hline 120 & $111.8 \pm 0.4$ & $59.24 \pm 0.27$ & $112.2 \pm 0.7$ & $52.95 \pm 0.28$ \\
\hline 125 & $115.7 \pm 0.5$ & $61.42 \pm 0.28$ & $116.8 \pm 0.7$ & $55.41 \pm 0.29$ \\
\hline 130 & $119.4 \pm 0.5$ & $63.57 \pm 0.29$ & $121.4 \pm 0.7$ & $57.86 \pm 0.30$ \\
\hline 135 & $123.1 \pm 0.5$ & $65.71 \pm 0.29$ & $126.0 \pm 0.7$ & $60.30 \pm 0.31$ \\
\hline 140 & $126.8 \pm 0.5$ & $67.83 \pm 0.30$ & $130.6 \pm 0.7$ & $62.73 \pm 0.32$ \\
\hline 145 & $130.4 \pm 0.5$ & $69.92 \pm 0.31$ & $135.1 \pm 0.8$ & $65.15 \pm 0.33$ \\
\hline 150 & $134.0 \pm 0.5$ & $72.00 \pm 0.32$ & $139.5 \pm 0.8$ & $67.55 \pm 0.34$ \\
\hline 155 & $137.5 \pm 0.6$ & $74.05 \pm 0.32$ & $144.0 \pm 0.8$ & $69.95 \pm 0.35$ \\
\hline 160 & $141.1 \pm 0.6$ & $76.09 \pm 0.33$ & $148.4 \pm 0.8$ & $72.33 \pm 0.36$ \\
\hline 165 & $144.6 \pm 0.6$ & $78.11 \pm 0.34$ & $152.8 \pm 0.8$ & $74.70 \pm 0.37$ \\
\hline 170 & $148.1 \pm 0.6$ & $80.12 \pm 0.35$ & $157.2 \pm 0.9$ & $77.06 \pm 0.38$ \\
\hline 175 & $151.6 \pm 0.6$ & $82.11 \pm 0.35$ & $161.5 \pm 0.9$ & $79.42 \pm 0.38$ \\
\hline 180 & $155.1 \pm 0.6$ & $84.09 \pm 0.36$ & $165.8 \pm 0.9$ & $81.76 \pm 0.39$ \\
\hline 185 & $158.6 \pm 0.6$ & $86.06 \pm 0.37$ & $170.1 \pm 0.9$ & $84.09 \pm 0.40$ \\
\hline 190 & $162.2 \pm 0.6$ & $88.01 \pm 0.37$ & $174.4 \pm 0.9$ & $86.41 \pm 0.41$ \\
\hline 195 & $165.7 \pm 0.7$ & $89.96 \pm 0.38$ & $178.7 \pm 0.9$ & $88.72 \pm 0.42$ \\
\hline 200 & $169.3 \pm 0.7$ & $91.90 \pm 0.39$ & $182.9 \pm 1.0$ & $91.02 \pm 0.43$ \\
\hline 205 & $172.8 \pm 0.7$ & $93.83 \pm 0.40$ & $187.1 \pm 1.0$ & $93.31 \pm 0.44$ \\
\hline 210 & $176.4 \pm 0.7$ & $95.75 \pm 0.40$ & $191.4 \pm 1.0$ & $95.60 \pm 0.45$ \\
\hline 215 & $180.0 \pm 0.7$ & $97.67 \pm 0.41$ & $195.5 \pm 1.0$ & $97.87 \pm 0.46$ \\
\hline
\end{tabular}




\begin{tabular}{|c|c|c|c|c|}
\hline \multirow{2}{*}{$T / \mathrm{K}$} & $C_{p, \mathrm{~m}}^{0}$ & $\Delta_{0}^{T} H_{\mathrm{m}}^{0} / T$ & $\Delta_{0}^{T} S_{\mathrm{m}}^{0}$ & $-\Delta_{0}^{T} G_{\mathrm{m}}^{0} / T$ \\
\hline & \multicolumn{4}{|l|}{$\mathrm{J} \cdot \mathrm{K}^{-1} \cdot \mathrm{mol}^{-1}$} \\
\hline 220 & $183.7 \pm 0.7$ & $99.59 \pm 0.42$ & $199.7 \pm 1.0$ & $100.1 \pm 0.5$ \\
\hline 225 & $187.4 \pm 0.7$ & $101.5 \pm 0.4$ & $203.9 \pm 1.0$ & $102.4 \pm 0.5$ \\
\hline 230 & $191.1 \pm 0.8$ & $103.4 \pm 0.4$ & $208.1 \pm 1.1$ & $104.7 \pm 0.5$ \\
\hline 235 & $194.9 \pm 0.8$ & $105.3 \pm 0.4$ & $212.2 \pm 1.1$ & $106.9 \pm 0.5$ \\
\hline 240 & $198.7 \pm 0.8$ & $107.2 \pm 0.4$ & $216.3 \pm 1.1$ & $109.1 \pm 0.5$ \\
\hline 245 & $202.5 \pm 0.8$ & $109.1 \pm 0.5$ & $220.5 \pm 1.1$ & $111.4 \pm 0.5$ \\
\hline 250 & $206.5 \pm 0.8$ & $111.0 \pm 0.5$ & $224.6 \pm 1.1$ & $113.6 \pm 0.5$ \\
\hline 255 & $210.7 \pm 0.8$ & $112.9 \pm 0.5$ & $228.7 \pm 1.1$ & $115.8 \pm 0.5$ \\
\hline 260 & $215.1 \pm 0.9$ & $114.9 \pm 0.5$ & $232.9 \pm 1.2$ & $118.0 \pm 0.5$ \\
\hline 265 & $219.5 \pm 0.9$ & $116.8 \pm 0.5$ & $237.0 \pm 1.2$ & $120.2 \pm 0.5$ \\
\hline 270 & $223.9 \pm 0.9$ & $118.7 \pm 0.5$ & $241.2 \pm 1.2$ & $122.4 \pm 0.6$ \\
\hline 275 & $228.2 \pm 0.9$ & $120.7 \pm 0.5$ & $245.3 \pm 1.2$ & $124.6 \pm 0.6$ \\
\hline 280 & $232.4 \pm 0.9$ & $122.6 \pm 0.5$ & $249.5 \pm 1.2$ & $126.8 \pm 0.6$ \\
\hline 285 & $236.7 \pm 0.9$ & $124.6 \pm 0.5$ & $253.6 \pm 1.2$ & $129.0 \pm 0.6$ \\
\hline 290 & $241.5 \pm 1.0$ & $126.6 \pm 0.5$ & $257.8 \pm 1.3$ & $131.2 \pm 0.6$ \\
\hline 295 & $246.7 \pm 1.0$ & $128.6 \pm 0.5$ & $261.9 \pm 1.3$ & $133.4 \pm 0.6$ \\
\hline 298.15 & $250.1 \pm 1.0$ & $129.8 \pm 0.5$ & $264.6 \pm 1.3$ & $134.7 \pm 0.6$ \\
\hline 300 & $252.3 \pm 1.0$ & $130.6 \pm 0.5$ & $266.1 \pm 1.3$ & $135.5 \pm 0.6$ \\
\hline 305 & $258.3 \pm 1.0$ & $132.6 \pm 0.5$ & $270.4 \pm 1.3$ & $137.7 \pm 0.6$ \\
\hline 310 & $264.6 \pm 1.1$ & $134.7 \pm 0.6$ & $274.6 \pm 1.3$ & $139.9 \pm 0.6$ \\
\hline 315 & $271.4 \pm 1.1$ & $136.8 \pm 0.6$ & $278.9 \pm 1.3$ & $142.1 \pm 0.6$ \\
\hline 315.60 & $272.3 \pm 1.1$ & $137.1 \pm 0.6$ & $279.4 \pm 1.3$ & $142.3 \pm 0.6$ \\
\hline \multicolumn{5}{|l|}{ Liquid } \\
\hline 315.60 & $376.1 \pm 1.5$ & $179.8 \pm 0.7$ & $322.1 \pm 1.5$ & $142.3 \pm 0.6$ \\
\hline 320 & $383.1 \pm 1.5$ & $182.5 \pm 0.7$ & $327.3 \pm 1.5$ & $144.8 \pm 0.6$ \\
\hline 325 & $390.8 \pm 1.6$ & $185.7 \pm 0.8$ & $333.3 \pm 1.6$ & $147.7 \pm 0.6$ \\
\hline 330 & $398.1 \pm 1.6$ & $188.8 \pm 0.8$ & $339.4 \pm 1.6$ & $150.5 \pm 0.7$ \\
\hline 335 & $404.9 \pm 1.6$ & $192.0 \pm 0.8$ & $345.4 \pm 1.6$ & $153.4 \pm 0.7$ \\
\hline 340 & $411.3 \pm 1.6$ & $195.2 \pm 0.8$ & $351.5 \pm 1.6$ & $156.3 \pm 0.7$ \\
\hline 345 & $417.1 \pm 1.7$ & $198.4 \pm 0.8$ & $357.5 \pm 1.7$ & $159.2 \pm 0.7$ \\
\hline 350 & $422.3 \pm 1.7$ & $201.5 \pm 0.8$ & $363.5 \pm 1.7$ & $162.0 \pm 0.7$ \\
\hline 355 & $427.0 \pm 1.7$ & $204.7 \pm 0.8$ & $369.6 \pm 1.7$ & $164.9 \pm 0.7$ \\
\hline 360 & $431.0 \pm 1.7$ & $207.8 \pm 0.8$ & $375.6 \pm 1.7$ & $167.8 \pm 0.7$ \\
\hline 365 & $434.3 \pm 1.7$ & $210.9 \pm 0.9$ & $381.5 \pm 1.8$ & $170.7 \pm 0.7$ \\
\hline 370 & $437.0 \pm 1.7$ & $213.9 \pm 0.9$ & $387.5 \pm 1.8$ & $173.6 \pm 0.8$ \\
\hline
\end{tabular}

$18 \quad{ }^{a}$ Expanded uncertainties with 0.95 confidence level are reported. 
Table 6

26 Parameters of Eq. (6) for $C_{p, \mathrm{~m}}^{0}$ and standard deviation of the fit $\sigma$.

\begin{tabular}{cccccc}
\hline compound & $a$ & $b$ & $c$ & $\left(T_{\min }-T_{\max }\right)^{\mathrm{a}} / \mathrm{K}$ & $\sigma_{\mathrm{r}}{ }^{\mathrm{b}}$ \\
\hline DL-menthol $(\alpha$ crystal $)$ & 553.04 & -321.48 & 73.550 & $262-291$ & 0.04 \\
DL-menthol $(\beta$ crystal $)$ & 2646.2 & -1826.2 & 343.17 & $265-288$ & 0.18 \\
DL-menthol (liquid) & -1070.81 & 750.86 & -92.51 & $313-359$ & 0.10 \\
\hline
\end{tabular}

${ }^{a}$ Temperature range of experimental points used for development of the polynomial. We only present polynomials for measurements by Tian-Calvet calorimetry, while smoothed data are listed for adiabatic measurements in Table 4 .

$30{ }^{\mathrm{b}} \sigma_{\mathrm{r}}=100\left[\sum_{i=1}^{n}\left(C_{p, \mathrm{~m}}^{0} / C_{p, \mathrm{~m}}^{0, \text { calc }}-1\right)_{i}^{2} /(n-m)\right]^{1 / 2}$, where $n$ is the number of fitted data points and $m$ is the number

31 of adjustable parameters.

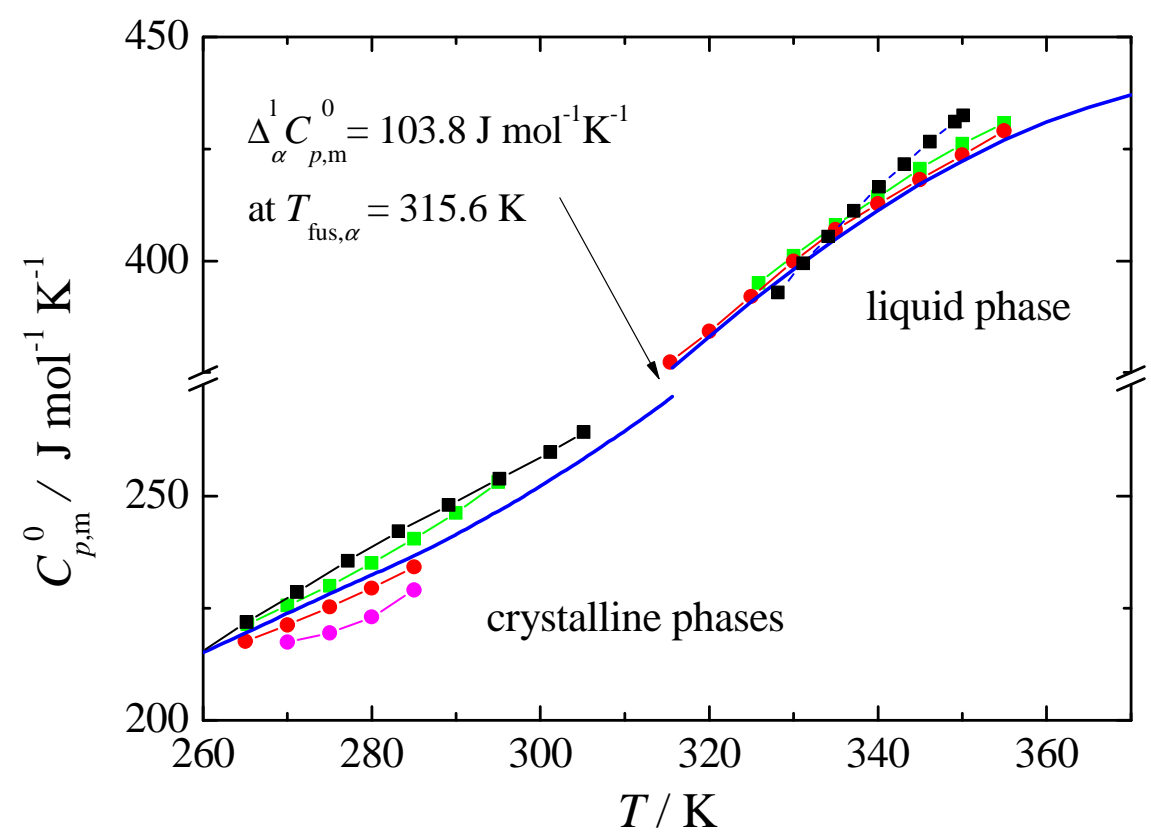

34 Figure 5. Condensed phase heat capacities $C_{p, \mathrm{~m}}^{0}$. L-menthol ( $\alpha$ crystal and liquid): - , adiabatic calorimetry (smoothed data visualized for clarity); $\square$, Tian-Calvet calorimetry; $\mathbf{\square}$, Corvis et al., DSC [6]; DL-menthol: $\bigcirc$, Tian-Calvet calorimetry ( $\alpha$ crystal and liquid); $\bigcirc$, Tian-Calvet calorimetry ( $\beta$ crystal). Note the break on the $y$-axis between the crystalline phases and liquid phases. 


\subsection{Vapour pressures}

41 The vapour pressures of liquid and $\alpha$-crystalline menthols were measured using two static 42 apparatus. The temporary stability of $\beta$-DL-menthol (on the order of tens of minutes) enabled 43 measurements of its vapour pressures using STAT6, however with a higher uncertainty. In this 44 case, the first measurement after crystallization had to be considered, which shows a slightly 45 effect from insufficient stabilization of temperature. Still, the measurements can definitely be 46 assigned to the $\beta$ phase, as demonstrated in Figure 6, and they are in good agreement with other

47 thermodynamically linked data. The lifetime of the other metastable polymorphs is much shorter 48 than the time scale of the vapour pressure measurements, which typically take days or weeks.

49 The vapour pressures determined in this work are listed in Table 7 and Table 8 . The vapour 50 pressure data determined using both apparatus for the same phases agree within the experimental

51 uncertainties as displayed in Figure 7. A multi-phase arc plot representation was used to visualize

52 the vapour pressure data as the common view $(\ln p$ as a function of $1 / T$ ) does not provide 53 reasonable resolution between the phases and between individual experimental points. The 54 construction of such a multi-phase arc plot (described in [52] and reprinted in the SD for reader's

55 convenience) is based on arc representation [53], but it allows visualization of vapour pressure 56 data of multiple condensed phases.

57 The vapour pressure measurements for the liquid and $\alpha$ phase of L-menthol are not consistent

58 with $\Delta_{\alpha}^{1} H_{\mathrm{m}}^{0}$ obtained by DSC and adiabatic calorimetry, but rather with a value obtained during

59 DSC experiments with a residual fraction of liquid. We assume that even during the vapour 60 pressure measurements, the L-menthol sample did not completely crystallize to the $\alpha$-form 61 despite one week of continuous measurement below $T_{\text {fus, } \alpha}$ (after a degassing procedure in the 
62 liquid phase). The crystallization in the static apparatus always took place during isotherms

63 between $301 \mathrm{~K}$ and $303 \mathrm{~K}$, where crystallization of the $\beta$ phase probably could not occur and the

64 slow direct crystallization of the $\alpha$ phase could result in a residual coexistence with the liquid.

65 Since kinetics of the transformation as well as the diffusion between the phases may affect the

66 measured pressure, no correction to obtain the sublimation pressure of the $\alpha$ phase was attempted.

67 The correlation for the $\alpha$ form of L-menthol was developed based on the liquid vapour pressures,

68 fusion properties, and heat capacities measured by adiabatic calorimetry.

69

$70 \quad$ Table 7

71 Experimental vapour pressures measured using STAT6 apparatus. ${ }^{\mathrm{a}}$

\begin{tabular}{|c|c|c|c|c|c|}
\hline$T / \mathrm{K}$ & $p / \mathrm{Pa}^{\mathrm{b}}$ & $\Delta p / \mathrm{Pa}^{\mathrm{c}}$ & $T / \mathrm{K}$ & $p / \mathrm{Pa}^{\mathrm{b}}$ & $\Delta p / \mathrm{Pa}^{\mathrm{c}}$ \\
\hline \multicolumn{3}{|c|}{ L-menthol } & \multicolumn{3}{|c|}{ DL-menthol } \\
\hline \multicolumn{3}{|c|}{$\alpha$-Crystalline + liquid phase ${ }^{d}$} & \multicolumn{3}{|c|}{$\alpha$-Crystalline phase } \\
\hline 273.64 & 0.244 & 0.014 & 273.65 & 0.259 & 0.001 \\
\hline 273.65 & 0.244 & 0.013 & 273.65 & 0.259 & 0.001 \\
\hline 273.65 & 0.242 & 0.011 & 273.66 & 0.261 & 0.003 \\
\hline 278.15 & 0.441 & 0.019 & 278.16 & 0.480 & 0.004 \\
\hline 278.15 & 0.440 & 0.018 & 278.16 & 0.479 & 0.003 \\
\hline 278.16 & 0.440 & 0.017 & 278.16 & 0.477 & 0.001 \\
\hline 283.15 & 0.839 & 0.032 & 283.15 & 0.922 & 0.006 \\
\hline 283.15 & 0.839 & 0.033 & 283.16 & 0.921 & 0.004 \\
\hline 283.15 & 0.840 & 0.034 & 283.16 & 0.926 & 0.009 \\
\hline 288.15 & 1.559 & 0.053 & 288.16 & 1.736 & 0.009 \\
\hline 288.15 & 1.557 & 0.051 & 288.16 & 1.734 & 0.007 \\
\hline 288.16 & 1.558 & 0.050 & 288.16 & 1.734 & 0.007 \\
\hline 293.14 & 2.829 & 0.082 & 293.14 & 3.173 & 0.001 \\
\hline 293.14 & 2.828 & 0.080 & 293.14 & 3.180 & 0.008 \\
\hline 293.14 & 2.831 & 0.083 & 293.15 & 3.183 & 0.007 \\
\hline 298.15 & 5.047 & 0.127 & 298.16 & 5.734 & 0.002 \\
\hline 298.15 & 5.039 & 0.119 & 298.16 & 5.733 & 0.001 \\
\hline 298.15 & 5.033 & 0.113 & 298.16 & 5.730 & -0.002 \\
\hline 303.14 & 8.771 & 0.157 & 303.14 & 10.09 & -0.01 \\
\hline 303.14 & 8.757 & 0.143 & 303.14 & 10.10 & 0.00 \\
\hline 303.14 & 8.761 & 0.147 & 303.15 & 10.10 & -0.02 \\
\hline 308.15 & 15.01 & 0.18 & \multicolumn{3}{|c|}{ Liquid phase } \\
\hline 308.15 & 15.00 & 0.17 & 293.14 & 3.971 & 0.005 \\
\hline 308.15 & 15.00 & 0.17 & 293.14 & 3.966 & 0.000 \\
\hline \multicolumn{3}{|c|}{ Liquid phase } & 293.14 & 3.969 & 0.003 \\
\hline 308.15 & 16.72 & -0.01 & 298.13 & 6.551 & 0.005 \\
\hline 308.15 & 16.70 & -0.02 & 298.14 & 6.556 & 0.003 \\
\hline 308.15 & 16.72 & -0.01 & 298.14 & 6.550 & -0.003 \\
\hline
\end{tabular}




\begin{tabular}{|c|c|c|}
\hline 303.13 & 10.59 & -0.01 \\
\hline 303.13 & 10.59 & -0.01 \\
\hline 303.14 & 10.60 & -0.01 \\
\hline 308.14 & 16.81 & -0.02 \\
\hline 308.14 & 16.83 & 0.00 \\
\hline 308.14 & 16.82 & -0.01 \\
\hline \multicolumn{3}{|c|}{$\beta$-Crystalline phase } \\
\hline 278.28 & 0.597 & 0.007 \\
\hline 278.28 & 0.607 & 0.011 \\
\hline 278.29 & 0.610 & 0.013 \\
\hline 283.12 & 1.090 & -0.005 \\
\hline 283.13 & 1.100 & 0.004 \\
\hline 283.13 & 1.093 & -0.003 \\
\hline 288.14 & 2.021 & 0.009 \\
\hline 288.14 & 2.010 & -0.002 \\
\hline 288.15 & 2.010 & -0.004 \\
\hline 293.14 & 3.627 & 0.016 \\
\hline 293.14 & 3.615 & 0.004 \\
\hline 293.14 & 3.596 & -0.015 \\
\hline 298.14 & 6.340 & -0.014 \\
\hline 298.14 & 6.361 & 0.008 \\
\hline 298.14 & 6.351 & -0.003 \\
\hline
\end{tabular}

$72{ }^{a}$ Standard uncertainty $u$ is $u(T)=0.02 \mathrm{~K}$ and the combined expanded uncertainty $U_{\mathrm{c}}(0.95$ level of 73 confidence, $k=2)$ is $U_{c}(p / P a)=0.005 p / P a+0.05$, except for $\beta$-crystalline phase, for which the

74 sublimation pressures are estimated to have a higher uncertainty described as $U_{\mathrm{c}}(p / \mathrm{Pa})=0.01 p / \mathrm{Pa}+0.1$.

$75{ }^{\mathrm{b}}$ Values are reported with one digit more than is justified by the experimental uncertainty to avoid round76 off errors in calculations based on these results.

$77{ }^{\mathrm{c}} \Delta p / \mathrm{Pa}=\left(p-p_{\text {calc }}\right) / \mathrm{Pa}$, where $p_{\text {calc }}$ is calculated from the SimCor results (Section 3.6).

$78{ }^{\mathrm{d}}$ Vapour pressures were measured for a mixture of the liquid and $\alpha$ phases. Values were not considered in 79 the SimCor procedure (Section 3.6), but only compared to the correlation derived from other experimental 80 data.

\section{$81 \quad$ Table 8}

82 Experimental vapour pressures measured using STAT8 apparatus. ${ }^{\text {a }}$

\begin{tabular}{cccccc}
\hline$T / \mathrm{K}$ & $p / \mathrm{Pa}^{\mathrm{b}}$ & $\Delta p / \mathrm{Pa}^{\mathrm{c}}$ & $T / \mathrm{K}$ & $p / \mathrm{Pa}^{\mathrm{b}}$ & $\Delta p / \mathrm{Pa}^{\mathrm{c}}$ \\
\hline \multicolumn{3}{c}{ L-menthol } & \multicolumn{3}{c}{ DL-menthol } \\
\hline \multicolumn{3}{c}{$\alpha$-Crystalline + liquid phase ${ }^{d}$} & \multicolumn{3}{c}{$\alpha$-Crystalline phase } \\
\hline 277.38 & 0.399 & 0.018 & 277.57 & 0.442 & 0.002 \\
277.41 & 0.401 & 0.018 & 277.59 & 0.442 & 0.001 \\
277.50 & 0.403 & 0.016 & 277.60 & 0.440 & -0.002 \\
282.34 & 0.758 & 0.031 & 282.56 & 0.853 & 0.004 \\
282.34 & 0.756 & 0.029 & 282.57 & 0.852 & 0.002 \\
282.34 & 0.759 & 0.032 & 282.59 & 0.854 & 0.002 \\
286.97 & 1.352 & 0.050 & 287.34 & 1.562 & 0.003 \\
286.97 & 1.354 & 0.052 & 287.43 & 1.579 & 0.002 \\
286.98 & 1.355 & 0.051 & 287.59 & 1.607 & -0.002 \\
291.56 & 2.353 & 0.076 & 292.79 & 3.041 & -0.001 \\
291.57 & 2.354 & 0.075 & 292.84 & 3.054 & -0.006 \\
291.60 & 2.364 & 0.076 & 292.90 & 3.078 & -0.004
\end{tabular}




\begin{tabular}{|c|c|c|c|c|c|}
\hline & & & & & \\
\hline 296.23 & 4.057 & 0.112 & 298.16 & 5.731 & -0.001 \\
\hline 296.23 & 4.052 & 0.107 & 298.17 & 5.739 & 0.001 \\
\hline 296.25 & 4.063 & 0.109 & 298.18 & 5.738 & -0.007 \\
\hline 300.84 & 6.809 & 0.139 & 303.17 & 10.13 & -0.01 \\
\hline 300.85 & 6.831 & 0.154 & 303.19 & 10.17 & 0.01 \\
\hline 300.86 & 6.832 & 0.147 & 303.20 & 10.19 & 0.02 \\
\hline 305.45 & 11.28 & 0.183 & \multicolumn{3}{|c|}{ Liquid phase } \\
\hline 305.45 & 11.28 & 0.191 & 293.54 & 4.140 & 0.009 \\
\hline 305.45 & 11.28 & 0.184 & 293.54 & 4.147 & 0.016 \\
\hline 310.04 & 18.33 & 0.22 & 293.55 & 4.144 & 0.008 \\
\hline 310.07 & 18.40 & 0.23 & 298.45 & 6.763 & 0.008 \\
\hline 310.07 & 18.42 & 0.24 & 298.46 & 6.780 & 0.018 \\
\hline 314.67 & 29.49 & 0.22 & 298.47 & 6.777 & 0.008 \\
\hline 314.67 & 29.46 & 0.20 & 303.42 & 10.89 & 0.00 \\
\hline 314.67 & 29.49 & 0.23 & 303.42 & 10.91 & 0.02 \\
\hline \multicolumn{3}{|c|}{ Liquid phase } & 303.43 & 10.91 & 0.01 \\
\hline 303.00 & 10.38 & -0.01 & 308.42 & 17.28 & 0.02 \\
\hline 303.00 & 10.37 & -0.02 & 308.43 & 17.28 & 0.01 \\
\hline 303.00 & 10.38 & -0.01 & 308.43 & 17.29 & 0.02 \\
\hline 308.18 & 16.76 & -0.01 & 313.42 & 26.80 & -0.04 \\
\hline 308.19 & 16.78 & -0.01 & 313.43 & 26.82 & -0.04 \\
\hline 308.20 & 16.78 & -0.02 & 313.44 & 26.86 & -0.03 \\
\hline 313.38 & 26.57 & -0.01 & 318.39 & 40.89 & 0.00 \\
\hline 313.38 & 26.58 & 0.00 & 318.40 & 40.92 & -0.01 \\
\hline 313.38 & 26.56 & -0.02 & 318.42 & 41.00 & 0.01 \\
\hline 318.43 & 40.80 & 0.00 & 323.41 & 61.49 & -0.01 \\
\hline 318.46 & 40.88 & -0.02 & 323.41 & 61.46 & -0.04 \\
\hline 318.47 & 40.94 & 0.00 & 323.41 & 61.46 & -0.04 \\
\hline 323.48 & 61.46 & -0.06 & 328.42 & 90.76 & -0.12 \\
\hline 323.50 & 61.58 & -0.04 & 328.42 & 90.86 & -0.02 \\
\hline 323.51 & 61.64 & -0.03 & 328.43 & 90.86 & -0.09 \\
\hline 328.56 & 91.37 & -0.06 & 333.43 & 132.19 & -0.01 \\
\hline 328.56 & 91.37 & -0.06 & 333.44 & 132.30 & 0.00 \\
\hline 328.56 & 91.38 & -0.05 & 333.44 & 132.26 & -0.04 \\
\hline 332.75 & 125.19 & -0.03 & 338.35 & 188.02 & -0.18 \\
\hline 332.75 & 125.17 & -0.05 & 338.35 & 187.96 & -0.24 \\
\hline 332.75 & 125.23 & 0.01 & 338.36 & 188.00 & -0.33 \\
\hline 337.81 & 180.38 & -0.12 & 343.20 & 262.65 & -0.28 \\
\hline 337.81 & 180.36 & -0.14 & 343.21 & 262.79 & -0.32 \\
\hline 337.82 & 180.51 & -0.12 & 343.21 & 262.85 & -0.26 \\
\hline 342.89 & 256.25 & -0.45 & 348.10 & 363.80 & 0.07 \\
\hline 342.89 & 256.28 & -0.42 & 348.11 & 363.84 & -0.12 \\
\hline 342.89 & 256.31 & -0.39 & 348.11 & 363.84 & -0.12 \\
\hline 347.88 & 357.33 & -0.43 & 353.02 & 497.60 & 0.26 \\
\hline 347.88 & 357.29 & -0.47 & 353.02 & 497.73 & 0.39 \\
\hline 347.88 & 357.26 & -0.50 & 353.03 & 497.91 & 0.26 \\
\hline 352.88 & 491.39 & -1.00 & 357.96 & 673.03 & 0.64 \\
\hline 352.88 & 491.41 & -0.98 & 357.96 & 673.21 & 0.82 \\
\hline 352.89 & 491.42 & -1.27 & 357.96 & 673.19 & 0.80 \\
\hline 357.86 & 666.19 & -2.10 & 362.97 & 903.12 & 1.39 \\
\hline 357.86 & 666.21 & -2.08 & 362.98 & 903.45 & 1.20 \\
\hline 357.87 & 666.45 & -2.24 & 362.98 & 903.60 & 1.35 \\
\hline 362.82 & 891.41 & -3.69 & & & \\
\hline 362.82 & 891.38 & -3.72 & & & \\
\hline 362.83 & 891.49 & -4.13 & & & \\
\hline
\end{tabular}


$83{ }^{\text {a }}$ Standard uncertainty $u$ is $u(T)=0.01 \mathrm{~K}$ and the combined expanded uncertainty $U_{\mathrm{c}}(0.95$ level of

84 confidence, $k=2)$ is $U_{c}(p / \mathrm{Pa})=0.01 p / \mathrm{Pa}+0.05$.

$85{ }^{\mathrm{b}}$ Values are reported with one digit more than is justified by the experimental uncertainty to avoid round-

86 off errors in calculations based on these results.

$87{ }^{\mathrm{c}} \Delta p / \mathrm{Pa}=\left(p-p_{\text {calc }}\right) / \mathrm{Pa}$, where $p_{\text {calc }}$ is calculated from the SimCor results (Section 3.6).

$88{ }^{\mathrm{d}}$ Vapour pressures were measured for a mixture of the liquid and $\alpha$ phases. Values were not considered in

89 the SimCor procedure (Section 3.6), but only compared to the correlation derived from other experimental 90 data.

91

92

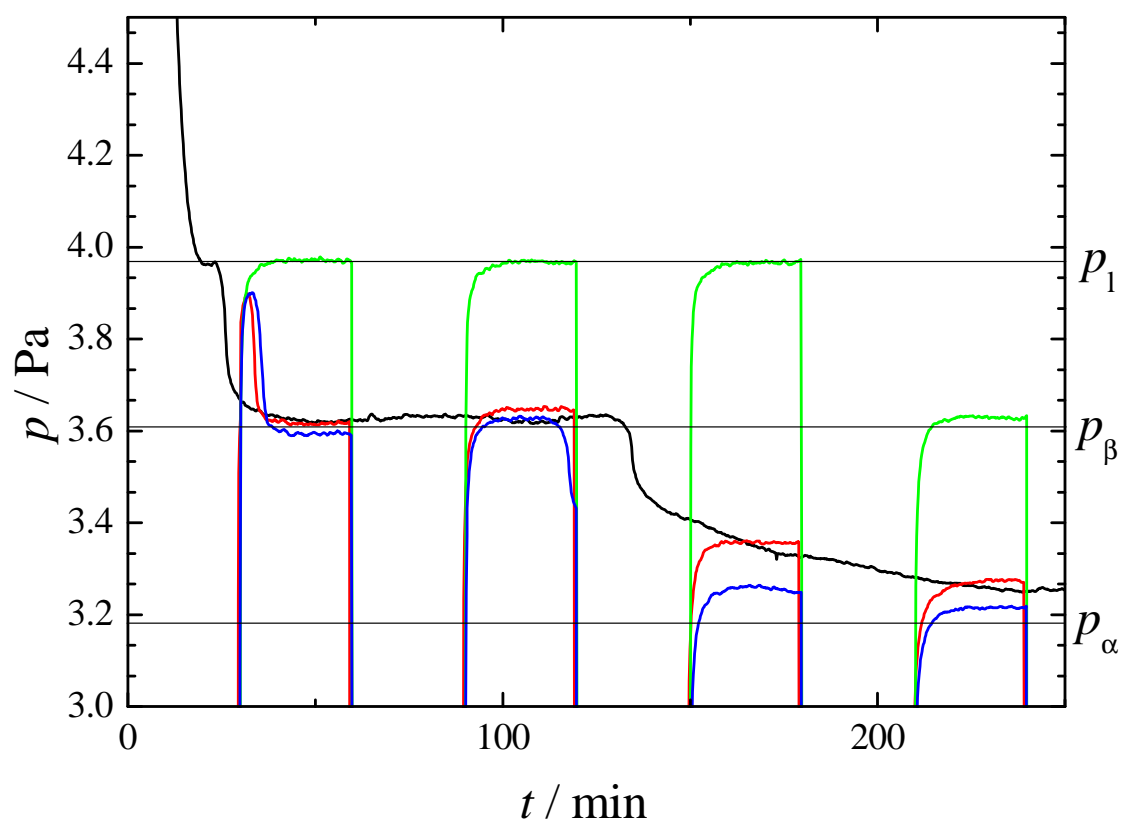

93

94 Figure 6. Records from vapour pressure measurement of DL-menthol at 293.15 K.

95 Liquid sample started to be cooled to $293.15 \mathrm{~K}$ at $t=0$. Records were corrected for the drift.

$96-$, liquid remains subcooled for an extended period;,-- , liquid crystalizes to the $\beta$ phase which 97 starts converting to the $\alpha$ phase after approximately 90 minutes; - , prolonged measuring cycle 98 (three drops in pressure correspond to decrease due to cooling, crystallization to the $\beta$ form, and 99 transformation to the $\alpha$ form).

100

101

102 

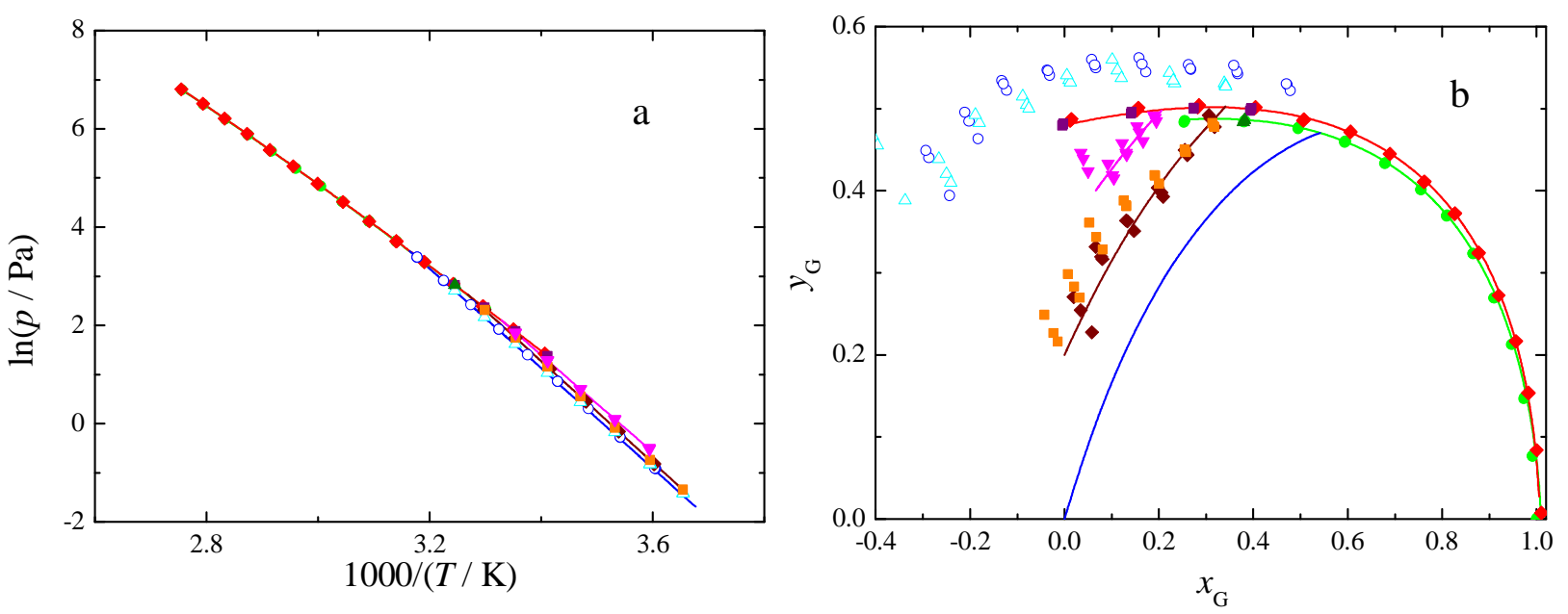

104 Figure 7. Comparison of vapour pressures of L- and DL-menthol measured in this work.

105 (a) common view; (b) multi-phase arc plot. $\bigcirc, \boldsymbol{\Delta}$, L-menthol (liquid, STAT8/STAT6); $\bullet$, 106 DL-menthol (liquid, STAT8/STAT6); O, $\triangle$, L-menthol $(\alpha$ crystal + liquid, STAT8/STAT6); $\diamond$, $107 \quad$, DL-menthol ( $\alpha$ crystal, STAT8/STAT6); $\nabla$, DL-menthol ( $\beta$ crystal, STAT6). Lines represent 108 results of SimCor (Section 3.6). Axes $x_{\mathrm{G}}$ and $y_{\mathrm{G}}$ are defined in Section 2 in SD.

\subsection{Thermodynamic properties in the ideal-gas state}

111 A menthol molecule consists of a cyclohexane frame with three functional groups (isopropyl,

112 methyl, and hydroxyl) attached to it. A cyclohexane molecule is known to occur in two stable

113 conformations: chair and twist-boat, where the latter is about $5.5 \mathrm{~kJ} \cdot \mathrm{mol}^{-1}$ less stable [54]. The

114 functional groups can be located either in equatorial or axial positions in both conformations. The

115 menthol molecule adopts a triaxial or triequatorial structure in the chair conformation, in contrast

116 to its diastereomers - iso-, neo-, and neoiso-menthols. The literature studying conformational

117 space of menthol usually assumes the existence of 9 conformers obtained by rotation of

118 asymmetrical tops in the equatorial chair conformation [55]. In some papers, 9 other conformers

119 based on the axial chair conformation are mentioned, but not studied with an argument that they

120 are clearly less stable [56]. 
121 The empirical labeling of menthol conformers used in $[55,56]$ is unclear, and we adopt a notation

122 according to the dihedral angles as used for aliphatic compounds [43]. The designation of each

123 conformer has form "XXX $\varphi \psi$ ", which starts with its frame conformation ("EQ" for equatorial,

124 "AX" for axial chair, and "TW?" for twist-boat) followed by labels for the dihedral angle of the 125 isopropyl and hydroxyl groups. The question mark in the case of twist-boat stands for the 126 orientation of the twisting axis in the cyclohexane ring; it is substituted by "I" if it passes through

127 the carbon atoms with the isopropyl and methyl group attached, "O" if it passes through the 128 carbon atom with the hydroxyl group attached and one methylene group, and "M" if it passes 129 through two methylene groups. The eight possible cyclohexane frames are schematically 130 displayed in Figure S6 in the SD and characterized in Table 9. Figure 8 highlights dihedral angles $131 \varphi=5-4-8-30$ and $\psi=4-5-20-31$ used in this work to systematically describe the position of the 132 isopropyl and hydroxyl tops, respectively. The minimal dihedral angles are designated as trans (t) $133 \approx 180^{\circ}$, gauche $\left(\mathrm{g}\right.$ or $\left.\mathrm{g}^{\prime}\right) \approx 60^{\circ}$ or $-60^{\circ}$, distorted gauche $\left(\mathrm{d}\right.$ or d') $\approx 90^{\circ}$ or $-90^{\circ}$, narrowed gauche 134 (n or $\left.\mathrm{n}^{\prime}\right) \approx 40^{\circ}$ or $-40^{\circ}$, and $\mathrm{x}$ for an unspecified position. The clockwise (R-) or counterclockwise 135 (S-) rotation of a top from eclipsed position or predominant rotation in the twist-boat frame is 136 marked by using or omitting a prime, respectively.

137 In total, 57 stable conformers were successfully optimized at the DFT B3LYP-D3/6-311+G(d,p) 138 level of theory. The stable conformers are summarized in Table 9 and listed in Table S4 in the 139 SD. Previous studies [55, 56] expected 9 EQ conformers, but the scan of isopropyl rotation 140 through EQxg conformers in [55] exhibited one additional minimum. It was however considered 141 to be an artifact caused by fixing the hydroxyl group position and was not studied further in [55]. 142 We performed a 2D scan and obtained 10 unambiguous minima, where each belongs to one 143 stable conformer. Our conformational search indeed determined the EQ conformers as the most 
144 stable ones, while all AX and TW conformers possess energies by more than $13 \mathrm{~kJ} \cdot \mathrm{mol}^{-1}$ greater 145 than the least stable EQ conformer (EQd'g), except for the three AXg'x conformers.

146 The literature does not reach full agreement about the most stable conformer. Egawa et al. [57] 147 detected a mixture of EQ1 conformers (in our notation EQgx) through a combination of gas 148 electron diffraction and calculations at the HF/6-31G(d) level of theory. Avilés Moreno et al. [56]

149 stated EQ1int2 (EQgg') was the most stable at the B3LYP/cc-pVDZ level of theory, but EQ1ext 150 (EQgt) at the B3LYP/6-31G(d) level of theory. Schmitz et al. [55] determined EQ1ext (EQgt) as 151 the most stable conformer at the three levels of theory: B3LYP/aug-cc-pVTZ, B3LYP/6$152311++\mathrm{G}(\mathrm{d}, \mathrm{p})$, and $\mathrm{MP} 2 / 6-311++\mathrm{G}(\mathrm{d}, \mathrm{p})$, in agreement with their microwave spectra 153 measurements. Our preliminary calculations without the D3 empirical correction resulted in a 154 relative energy of the EQgg' conformer of only $0.6 \mathrm{~kJ} \mathrm{~mol}^{-1}$ higher than that of EQgt, while 155 B3LYP-D3/6-311+G(d,p) level of theory, which should give more accurate relative energies, 156 predicts the EQgg' and EQgt to be essentially isoenergetic. The LCCSD(T)/aug-cc-pVQZ 157 calculations, however, clearly establish the EQgt conformer as the most stable one. The 158 calculated parameters of the Fourier expansion of three rotating $\mathrm{CH}_{3}$-tops for the EQgt conformer 159 are given in Table S5 in the SD.

160 The ideal-gas heat capacities, standard ideal-gas entropies, and ideal-gas thermal enthalpies of 161 enantiopure menthol at $p=0.1 \mathrm{MPa}$ at several temperatures are listed in Table 10 and the 162 calculated dipole moment at $298.15 \mathrm{~K}$ is $1.69 \mathrm{D}\left(1 \mathrm{D}=3.335641 \times 10^{-30} \mathrm{C} \cdot \mathrm{m}\right)$. It should be note 163 that including only ten EQ conformers (out of 57) in the calculation of the ideal-gas 164 thermodynamic properties has a negligible impact: $C_{p, \mathrm{~m}}^{0}$ differs by $0.1 \%$ at $300 \mathrm{~K}$ and by $1 \%$ at $165500 \mathrm{~K}$, and $S_{\mathrm{m}}^{0}$ by $0.1 \%$ at $500 \mathrm{~K}$ from the values presented in Table 10 when only ten EQ 166 conformers are considered. No literature data were found for comparison. 


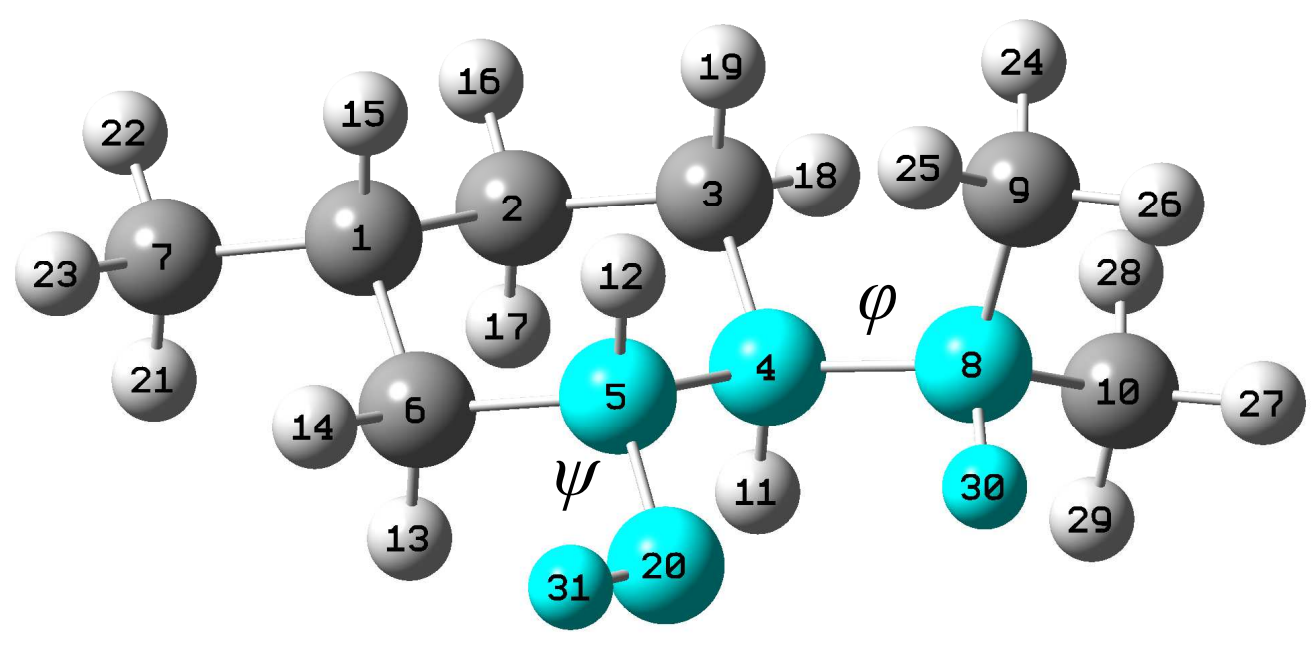

169 Figure 8. Most stable EQgt conformer of L-menthol with highlighted dihedral angles used to 170 designate the conformation. Numbering of atoms is according to [56] where the conformer is 171 designated as EQ1ext. The dihedral angles $\varphi=5-4-8-30(\mathrm{~g})$ and $\psi=4-5-20-31(\mathrm{t})$ define the 172 position of the rotating isopropyl and hydroxyl groups.

173

\section{Table 9}

176 Conformational analysis summary. Stable conformers grouped by the conformation of 177 cyclohexane frame and their range of relative energies.

\begin{tabular}{|c|c|c|c|c|c|c|c|c|}
\hline \multirow{2}{*}{ label } & \multirow[t]{2}{*}{$\begin{array}{c}\text { Ring } \\
\text { conformation }\end{array}$} & \multirow[t]{2}{*}{$\begin{array}{c}\text { Twisting } \\
\text { atoms }\end{array}$} & \multicolumn{3}{|c|}{ Position of } & \multirow{2}{*}{$\begin{array}{l}\text { Number of } \\
\text { conformers }\end{array}$} & \multicolumn{2}{|c|}{$\Delta E / \underset{\mathrm{a}}{\mathrm{kJ} \cdot \mathrm{mol}^{-1}}$} \\
\hline & & & isopropyl & hydroxyl & methyl & & $\min$ & $\max$ \\
\hline EQ & Chair & - & EQ & EQ & EQ & 10 & 0.0 & 11.7 \\
\hline $\mathrm{AX}$ & Chair & - & $\mathrm{AX}$ & $\mathrm{AX}$ & $\mathrm{AX}$ & 9 & 17.5 & 33.9 \\
\hline TWI & Twist-boat & 1,4 & $-b$ & EQ & $-b$ & 9 & 26.5 & 32.0 \\
\hline TWI' & Twist-boat & 1,4 & $-{ }^{b}$ & $\mathrm{AX}$ & $-{ }^{b}$ & 9 & 28.4 & 33.7 \\
\hline TWM & Twist-boat & 3,6 & $\mathrm{AX}$ & $\mathrm{AX}$ & EQ & 3 & 33.7 & 37.6 \\
\hline TWM' & Twist-boat & 3,6 & EQ & EQ & $\mathrm{AX}$ & 9 & 31.7 & 45.0 \\
\hline TWO & Twist-boat & 2,5 & EQ & $-{ }^{b}$ & $\mathrm{AX}$ & 5 & 31.2 & 35.6 \\
\hline TWO' & Twist-boat & 2,5 & $\mathrm{AX}$ & $-{ }^{b}$ & EQ & 3 & 30.2 & 32.1 \\
\hline
\end{tabular}

${ }^{a}$ Relative electronic energy calculated at the B3LYP-D3/6-311+G(d,p) level of theory with structure optimization at the same level of theory, except for EQ, for which the energies are calculated at LCCSD(T)/aug-cc-pVQZ with structure optimization at DF-MP2/aug-cc-pVQZ. 
184 Standard molar thermodynamic functions of enantiopure menthol in the ideal gaseous state (in

$185 \mathrm{~J} \cdot \mathrm{K}^{-1} \cdot \mathrm{mol}^{-1}$ ) at $p=0.1 \mathrm{MPa}$ calculated using the R1SM model. ${ }^{\mathrm{a}}$

\begin{tabular}{|c|c|c|c|}
\hline$T / \mathrm{K}$ & $\begin{array}{c}C_{p, \mathrm{~m}}^{0} / \\
\mathrm{J} \cdot \mathrm{K}^{-1} \cdot \mathrm{mol}^{-} \\
\end{array}$ & $\begin{array}{c}S_{\mathrm{m}}^{0} / \\
\mathrm{J} \cdot \mathrm{K}^{-1} \cdot \mathrm{mol}^{-1}\end{array}$ & $\begin{array}{c}\left(\Delta_{0}^{T} H_{\mathrm{m}}^{0} / T\right) / \\
\mathrm{J} \cdot \mathrm{K}^{-1} \cdot \mathrm{mol}^{-1}\end{array}$ \\
\hline 200 & 159.7 & 392.8 & 94.7 \\
\hline 210 & 166.0 & 400.8 & 97.9 \\
\hline 220 & 172.4 & 408.6 & 101.2 \\
\hline 230 & 178.8 & 416.4 & 104.4 \\
\hline 240 & 185.3 & 424.2 & 107.7 \\
\hline 250 & 192.0 & 431.9 & 110.9 \\
\hline 260 & 198.7 & 439.5 & 114.1 \\
\hline 270 & 205.5 & 447.2 & 117.4 \\
\hline 273.15 & 207.6 & 449.6 & 118.4 \\
\hline 280 & 212.3 & 454.8 & 120.7 \\
\hline 290 & 219.3 & 462.3 & 123.9 \\
\hline 298.15 & 224.9 & 468.5 & 126.6 \\
\hline 300 & 226.2 & 469.9 & 127.2 \\
\hline 310 & 233.2 & 477.4 & 130.5 \\
\hline 320 & 240.2 & 484.9 & 133.9 \\
\hline 330 & 247.1 & 492.4 & 137.2 \\
\hline 340 & 254.1 & 499.9 & 140.5 \\
\hline 350 & 261.0 & 507.4 & 143.9 \\
\hline 360 & 267.9 & 514.8 & 147.2 \\
\hline 370 & 274.8 & 522.3 & 150.6 \\
\hline 380 & 281.6 & 529.7 & 153.9 \\
\hline 390 & 288.3 & 537.1 & 157.3 \\
\hline 400 & 295.0 & 544.5 & 160.6 \\
\hline 500 & 357.0 & 617.1 & 193.9 \\
\hline 600 & 410.0 & 687.0 & 225.6 \\
\hline 700 & 454.8 & 753.7 & 255.2 \\
\hline
\end{tabular}

$186{ }^{a}$ Estimated standard uncertainty is $0.005 C_{p, \mathrm{~m}}^{0}, 0.009 S_{\mathrm{m}}^{0}$, and $0.010 H_{\mathrm{m}}^{0}$.

187

$188 \quad 3.6 \quad$ Simultaneous treatment of vapour pressures and related thermal data (SimCor method)

189 The selected experimental vapour data (given in bold in Table 11) were treated simultaneously

190 with $\Delta_{\mathrm{cd}}^{\mathrm{g}} C_{p, \mathrm{~m}}^{0}=C_{p, \mathrm{~m}}^{0}(\mathrm{ig})-C_{p, \mathrm{~m}}^{0}(\mathrm{~cd})$, where $C_{p, \mathrm{~m}}^{0}(\mathrm{ig})$ was from the ideal-gas calculations (Section

191 3.5) and $C_{p, \mathrm{~m}}^{0}(\mathrm{~cd})$ was obtained from the condensed-phase data given in Section 3.3 at

192 temperatures below $340 \mathrm{~K}$. Fusion temperatures and enthalpies recommended in this work were 
193 also included in the SimCor calculations. The SimCor method was described in detail in [23] (for

194 the reader's convenience, a detailed description of the SimCor method is also presented in the

$195 \mathrm{SD})$ and was used in our laboratory to develop recommended vapour pressure and

196 thermophysical data for several groups of crystalline and liquid compounds (see, for example,

197 [58] and references therein).

198 The Clarke and Glew equation [59] with four parameters was used for the SimCor analysis to 199 describe the vapour pressures and the derived thermal properties, which corresponds to a linear 200 temperature dependence of $\Delta_{\mathrm{cd}}^{\mathrm{g}} C_{p, \mathrm{~m}}^{0}$. The Clarke and Glew equation has the following form

201

$$
\begin{aligned}
R \ln \frac{p}{p^{0}}= & -\frac{\Delta_{\mathrm{cd}}^{\mathrm{g}} G_{\mathrm{m}}^{0}(\theta)}{\theta}+\Delta_{\mathrm{cd}}^{\mathrm{g}} H_{\mathrm{m}}^{0}(\theta)\left(\frac{1}{\theta}-\frac{1}{T}\right)+\Delta_{\mathrm{cd}}^{\mathrm{g}} C_{p, \mathrm{~m}}^{0}(\theta)\left[\frac{\theta}{T}-1+\ln \left(\frac{T}{\theta}\right)\right]+ \\
& +\left(\frac{\theta}{2}\right) \frac{\partial \Delta_{\mathrm{cd}}^{\mathrm{g}} C_{p, \mathrm{~m}}^{0}}{\partial T}(\theta)\left[\frac{T}{\theta}-\frac{\theta}{T}-2 \ln \left(\frac{T}{\theta}\right)\right]
\end{aligned}
$$

202 where $p^{0}=100 \mathrm{kPa}$ is a reference pressure, $\theta$ is a selected reference temperature, $R$ is the molar 203 gas constant, and $\Delta_{\mathrm{cd}}^{\mathrm{g}} G_{\mathrm{m}}^{0}$ and $\Delta_{\mathrm{cd}}^{\mathrm{g}} H_{\mathrm{m}}^{0}$ are the standard molar sublimation/vaporization Gibbs 204 energy and enthalpy, respectively.

205 The resulting parameters of the Clarke and Glew equation, Eq. (7), together with the standard 206 deviation of the fit, $\sigma$, are presented in Table 12. The comparison of the experimental values with 207 the Clarke and Glew equation, Eq. (7), developed using the SimCor method, is shown in Figure 2089.

209 The vapour pressure data for the liquid phase by Guetachew et al. [17] agree with our 210 measurements within their experimental uncertainties and were included in the correlation. The 211 sublimation pressures reported in [17] for unspecified polymorph are also in agreement with the 
212 SimCor results for the $\alpha$ form within combined uncertainties, but exhibit a different slope

213 resulting in the sublimation enthalpy deviating by $1.4 \mathrm{~kJ} \cdot \mathrm{mol}^{-1}$ from the sublimation enthalpy

$214 \Delta_{d}^{\mathrm{g}} H_{\mathrm{m}}^{0}$ obtained by the SimCor method. Kobe et al. [14] published a vapour pressure equation

215 without information on enantiomeric excess of menthol and temperature range of the

216 measurement. The experimental method and that they list the normal boiling point indicate that

217 their vapour pressure measurements were performed below atmospheric pressure. The agreement

218 with our correlation for L-menthol is within $3 \%$ above $380 \mathrm{~K}$. At lower temperatures, the

219 deviations increase due to a significantly lower $\Delta_{1}^{g} C_{p, \mathrm{~m}}^{0}$ resulting from their vapour pressure

220 measurements. The results by Keating et al.[15] are not plotted in Figure 9 since they are lower

221 by $15 \%$ to $32 \%$ than the SimCor results in the overlapping temperature range (see the discussion

222 in the next section).

\section{Table 11}

224 Overview of the available experimental vapour pressure data. ${ }^{a}$

\begin{tabular}{|c|c|c|c|c|}
\hline Reference & $N^{\mathrm{b}}$ & $\begin{array}{c}\left(T_{\min }-T_{\max }\right)^{\mathrm{c}} / \\
\mathrm{K}\end{array}$ & $\begin{array}{c}\left(p_{\min }-p_{\max }\right) / \\
\mathrm{Pa}\end{array}$ & Method \\
\hline \multicolumn{5}{|c|}{ L-Menthol $(\alpha-\mathrm{cr})$} \\
\hline Guetachew et al. [17] & 6 & $293-313$ & $2.9-26.5$ & Static \\
\hline This work, STAT6 & 24 & $274-308$ & $0.24-15.0$ & Static \\
\hline This work, STAT8 & 27 & $277-315$ & $0.40-24.5$ & Static \\
\hline \multicolumn{5}{|c|}{ L-Menthol (1) } \\
\hline Guetachew et al. $[17]^{\mathrm{d}}$ & 11 & $323-422$ & $61-13747$ & Static \\
\hline Keating et al. [15] & 14 & $298-430 / 374-404$ & $4.6-15000$ & Chromatography \\
\hline This work, STAT6 & 3 & 308 & 16.7 & Static \\
\hline This work, STAT8 & 39 & $303-363$ & $10.4-891$ & Static \\
\hline \multicolumn{5}{|c|}{ DL-Menthol $(\alpha$-cr $)$} \\
\hline This work, STAT6 & 21 & $274-303$ & $0.26-10.1$ & Static \\
\hline This work, STAT8 & 18 & $278-303$ & $0.44-10.2$ & Static \\
\hline & & DL-Menthol ( $\beta$-cr) & & \\
\hline
\end{tabular}


This work, STAT6

Keating et al. [15]

Keating et al. [15]

This work, STAT6

This work, STAT8

Kobe et al. [14]
15

21

21

12

45

S
$278-298$

DL-Menthol (1)

${ }^{a}$ References reporting single or two vapour pressure points obtained, for example, as part of the synthesis or VLE measurements on multi-component mixtures are not considered.

${ }^{\mathrm{b}} N$ stands for number of experimental points, $\mathrm{S}$ stands for smoothed data.

${ }^{\mathrm{c}}$ Temperature range of presented data. If two ranges are listed, they correspond to the range of presented (extrapolated) vapour pressure data and to the range, where the retention times were measured, respectively.

${ }^{\mathrm{d}}$ References in bold were included in the SimCor analysis.

\section{Table 12}

234 Parameters of the Clarke and Glew equation, Eq. (7), derived using the SimCor method at the 235 reference temperature $\theta=298.15 \mathrm{~K}$ and pressure $p^{0}=100 \mathrm{kPa}$.

\begin{tabular}{|c|c|c|c|c|c|c|c|}
\hline Compound & $\begin{array}{c}\left(T_{\min }-T_{\max }\right)^{\mathrm{a}} / \\
\mathrm{K}\end{array}$ & $\begin{array}{l}\Delta_{\mathrm{cd}}^{\mathrm{g}} G_{\mathrm{m}}^{0} / \\
\mathrm{J} \cdot \mathrm{mol}^{-1}\end{array}$ & $\begin{array}{l}\Delta_{\mathrm{cd}}^{\mathrm{g}} H_{\mathrm{m}}^{0} / \\
\mathrm{J} \cdot \mathrm{mol}^{-1}\end{array}$ & $\begin{array}{c}\Delta_{\mathrm{cd}}^{\mathrm{g}} C_{p, \mathrm{~m}}^{0} / \\
\mathrm{J} \cdot \mathrm{K}^{-1} \cdot \mathrm{mol}^{-1}\end{array}$ & $\begin{array}{c}\frac{\partial \Delta_{\mathrm{cd}}^{\mathrm{g}} C_{p, \mathrm{~m}}^{0}}{\partial T} / \\
\mathrm{J} \cdot \mathrm{K}^{-2} \cdot \mathrm{mol}^{-1}\end{array}$ & $\begin{array}{l}\sigma^{\mathrm{a} /} \\
\mathrm{Pa}\end{array}$ & $\sigma_{\mathrm{r}}^{\mathrm{a}}$ \\
\hline L-menthol ( $\alpha$ crystal) & $250-316$ & $\begin{array}{c}24590.5 \\
\pm 6.4^{\mathrm{b}}\end{array}$ & $\begin{array}{c}84421.4 \\
\pm 54.6\end{array}$ & $\begin{array}{l}-26.436 \\
\pm 0.444\end{array}$ & $\begin{array}{c}-0.2897 \\
\pm 0.0171\end{array}$ & N/A & N/A \\
\hline L-menthol (liquid) & $303-422$ & $\begin{array}{c}23898.4 \\
\pm 5.1\end{array}$ & $\begin{array}{c}72836.6 \\
\pm 47.3\end{array}$ & $\begin{array}{c}-134.27 \\
\pm 1.85\end{array}$ & $\begin{array}{c}-0.4595 \\
\pm 0.0526\end{array}$ & 27 & $0.66 \%$ \\
\hline DL-menthol ( $\alpha$ crystal) & $265-306$ & $\begin{array}{c}24214.7 \\
\pm 0.8\end{array}$ & $\begin{array}{c}85596.4 \\
\pm 24.1\end{array}$ & $\begin{array}{l}-19.524 \\
\pm 0.440\end{array}$ & $\begin{array}{c}-0.1385 \\
\pm 0.0179\end{array}$ & 0.007 & $0.40 \%$ \\
\hline DL-menthol ( $\beta$ crystal) & $270-298$ & $\begin{array}{c}23953.7 \\
\pm 4.0\end{array}$ & $\begin{array}{c}82083.7 \\
\pm 45.3\end{array}$ & $\begin{array}{l}-11.306 \\
\pm 0.235\end{array}$ & $0^{c}$ & 0.010 & $0.94 \%$ \\
\hline DL-menthol (liquid) & $293-363$ & $\begin{array}{c}23877.4 \\
\pm 0.6 \\
\end{array}$ & $\begin{array}{c}72673.5 \\
\pm 10.0 \\
\end{array}$ & $\begin{array}{c}-127.14 \\
\pm 0.89 \\
\end{array}$ & $\begin{array}{r}-0.7570 \\
\pm 0.0350 \\
\end{array}$ & 0.38 & $0.12 \%$ \\
\hline
\end{tabular}

${ }^{\mathrm{a}}$ The parameters of the Clarke and Glew equation, Eq. (7), developed by the SimCor method are valid over a 238 combined temperature interval of input thermodynamic data.

$239{ }^{a} \sigma$ is the standard deviation of the fit defined as $\sigma=\left[\sum_{i=1}^{n}(\Delta p)_{i}^{2} /(n-m)\right]^{1 / 2}$, where $\Delta p$ is the difference between

240 the experimental and the smoothed values, $n$ is the number of experimental points used in the fit and $m$ is the number 241 of adjustable parameters of the Clarke and Glew equation, Eq. (7). $\sigma_{\mathrm{r}}$ is the relative standard deviation of the fit

242 defined as $\sigma_{\mathrm{r}}=\left[\sum_{i=1}^{n}(\Delta \ln p)_{i}^{2} /(n-m)\right]^{1 / 2}$. Standard deviation for the $\alpha$ crystal of L-menthol (marked as N/A)

243 could not be calculated since no experimental vapour pressure data were included in the correlation. 
$244{ }^{b}$ The uncertainties quoted are standard uncertainty estimations of the optimized parameters. The parameters are reported with more digits than justified by the uncertainties to avoid round-off errors in calculations based on the correlation.

$247{ }^{\mathrm{c}}$ Set as zero due to a short temperature interval and higher uncertainty of the data.

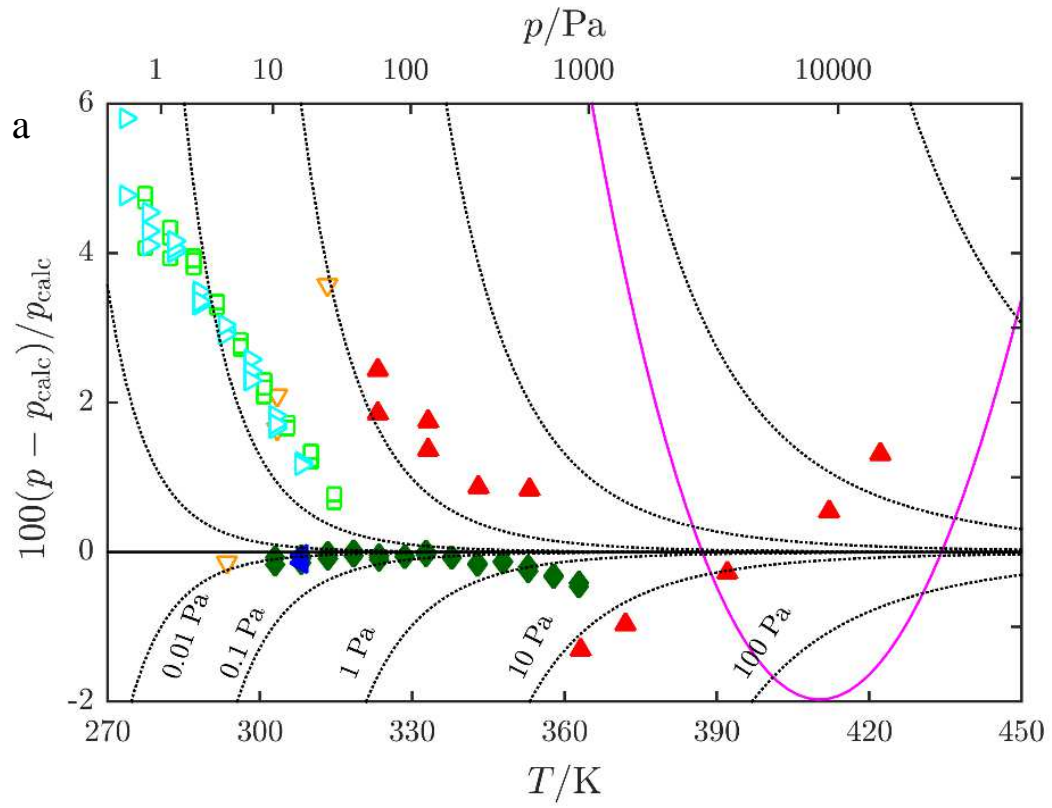

250

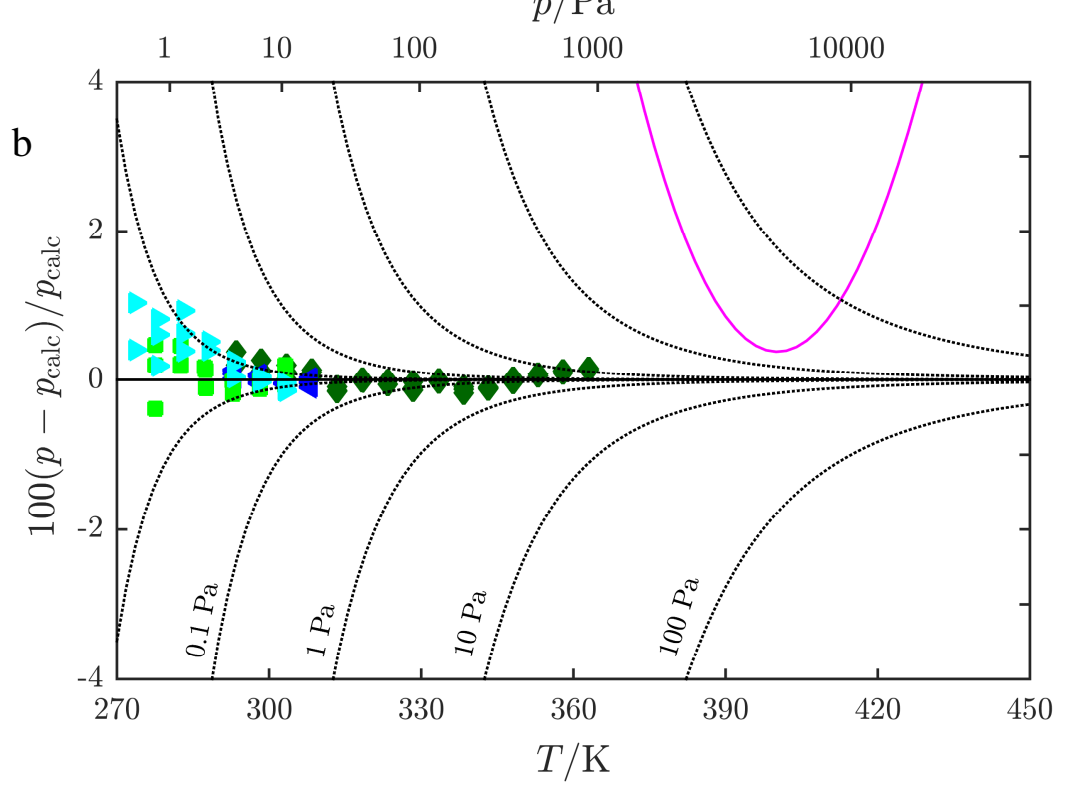

252 Figure 9. Comparison of experimental vapour pressures $p$ with values $p_{\text {calc }}$ developed by the 253 SimCor method for the studied menthols. (a) L-menthol; (b) DL-menthol; $\triangleright, \triangleright$, this work 
254 (STAT6, $\alpha$ crystal); $\square, \square$, this work (STAT8, $\alpha$ crystal); $\varangle$, this work (STAT6, liquid); $\bullet$, this 255 work (STAT8, liquid); $\nabla$, Guetachew et al. [17] ( $\alpha$ crystal); $\boldsymbol{\Delta}$, Guetachew et al. [17] (liquid); $256-$, Kobe et al. [14]; -..., lines representing constant absolute deviations. Results by Keating et al. 257 [15] are out of scale. Top pressure axis and absolute deviations are plotted for liquid. Empty 258 points were excluded from the SimCor analysis.

259 


\subsection{Mutual consistency of the studied thermodynamic properties}

261 Consistency in this work between the fusion parameters measured calorimetrically for DL262 menthol and those calculated at the triple point from the vapour pressure measurements,

263 compared in Table 2 is very good. The inconsistencies arising from the long-term coexistence of

264 the liquid and $\alpha$ phase in L-menthol for the vapour pressure, DSC, and adiabatic calorimetry 265 results was already discussed in Section 3.4.

266 Table 13 summarizes the vaporization/sublimation enthalpy data at $298.15 \mathrm{~K}$. The $\Delta_{1}^{\mathrm{g}} H_{\mathrm{m}}^{0}$ values 267 obtained by the SimCor method for L-menthol and DL-menthol at $298.15 \mathrm{~K}$ are equal to within 268 their estimated uncertainties, and the consistency with fusion enthalpies supports the SimCor

269 results for $\Delta_{\alpha}^{\mathrm{g}} H_{\mathrm{m}}^{0}$. The sublimation enthalpies of unspecified polymorphs of both menthols were 270 previously determined by Chickos et al. [47] (via the Clausius-Clapeyron equation from vapour 271 pressures obtained by a head-space method), but they are in disagreement with the SimCor 272 results despite their large stated uncertainty of $5 \%$. The vaporization enthalpy (and vapour 273 pressure of super cooled liquid in [15]) was determined using indirect gas-liquid chromatography 274 (GLC) method by Hoskovec et al. [16] and by Chickos and co-workers [13, 15]. It is outside the 275 scope of this work to analyse the reasons for differences between published values and 276 recommendation of this work (see Table 13); a general analysis of results obtained by the GLC 277 method was recently published by Koutek and co-workers $[60,61]$. It is however necessary to 278 mention that results of the GLC method are substantially influenced by i) the choice of reference 279 compounds and quality of their reference vapour pressure data and ii) the length of extrapolation 280 since chromatographic measurements are usually performed well above room temperature, while 281 the results are reported down to $298 \mathrm{~K}$. Hoskovec et al. [16] selected $n$-alkanes as reference 
282 compounds, a choice that was recently demonstrated to yield errors of hundreds percent when

283 determining vapour pressures of polar compounds, e.g. 1-alkanols [61]. The resulting 16.2

$284 \mathrm{~kJ} \cdot \mathrm{mol}^{-1}$ deviation from our value obtained by the SimCor method is therefore not surprising.

285 Chickos and co-workers [13,15] used 1-alkanols as reference compounds; however extrapolation

286 by at least $75 \mathrm{~K}$ was employed, and the reliability of their reference vapour pressures is

287 questionable (see, e.g., disagreement of [62] for 1-hexanol with our recent recommendation [43]).

288 In view of these facts, the agreement of several published values on both vaporization enthalpies

289 and super cooled vapour pressures with the SimCor results is rather good (but it may be

290 fortuitous).

291 The SimCor results combined with adiabatic calorimetry can be used to derive a recommended

292 value of standard ideal-gas molar entropy $S_{\mathrm{m}}^{0}(\mathrm{ig})$. The resulting value $S_{\mathrm{m}}^{0}(298.15 \mathrm{~K}, \mathrm{ig})=(465.3 \pm$

$2931.7) \mathrm{J} \cdot \mathrm{K}^{-1} \cdot \mathrm{mol}^{-1}$ is in agreement with the theoretical value from Table 10 obtained by statistical-

294 thermodynamics calculations, $(468.5 \pm 4.2) \mathrm{J} \cdot \mathrm{K}^{-1} \cdot \mathrm{mol}^{-1}$. Figure 10 shows excellent agreement

295 (within $3.5 \mathrm{~J} \cdot \mathrm{K}^{-1} \cdot \mathrm{mol}^{-1}$ ) between $\Delta_{\mathrm{cd}}^{\mathrm{g}} C_{p, \mathrm{~m}}^{0}$ obtained from calculated ideal-gas heat capacities and

296 calorimetrically determined heat capacities of crystalline and liquid phases with that derived

297 using the SimCor method, further demonstrating the internal consistency of our vapour pressure

298 and heat capacity data.

299 Vapour pressures of liquid phase of L-and DL-menthol together with recommended $T_{\text {cr-1 }}$ and

$300 \Delta_{\mathrm{cr}}^{1} H_{\mathrm{m}}^{0}$ from Table 2 were utilized to calculate the differences between the Gibbs energy of the

301 various observed polymorphs and the liquid phase $\left(\Delta_{\mathrm{cr}}^{\mathrm{g}} C_{p, \mathrm{~m}}^{0}\right.$ of all crystalline phases were 
302 considered equal to $\Delta_{\alpha}^{\mathrm{g}} C_{p, \mathrm{~m}}^{0}$ since heat capacities were not available for all polymorphs), and the 303 resulting Gibbs-energy diagrams of both menthols are presented in Figure 11.

305 Table 13

306 Comparison of vaporization/sublimation enthalpies at $298.15 \mathrm{~K}$

\begin{tabular}{lll}
\hline \multicolumn{1}{c}{ Source } & \multicolumn{1}{c}{ L- or D- menthol (enantiopure) } & \multicolumn{1}{c}{ DL-menthol (racemic) } \\
\hline \multicolumn{1}{c}{$\Delta_{1}^{\mathrm{g}} H_{\mathrm{m}}^{0} / \mathrm{kJ} \cdot \mathrm{mol}^{-1}$} \\
\hline SimCor, this work & $72.8 \pm 0.3^{\mathrm{a}}$ & $72.7 \pm 0.3^{\mathrm{a}}$ \\
\hline Hoskovec et al. $[16]$ & $56.6 \pm 2.8$ & $72.6 \pm 2.9$ \\
\hline Lipkind and Chickos [13] & $72.8 \pm 1.9,75.2 \pm 4.3,76.3 \pm 4.4$ & $74.2 \pm 2.8,73.9 \pm 0.4,73.7 \pm 0.4$ \\
\hline Keating et al. [15] & $73.7 \pm 0.4$ & \\
\hline & \multicolumn{1}{c}{$\Delta_{\alpha}^{\mathrm{g}} H_{\mathrm{m}}^{0} / \mathrm{kJ} \cdot \mathrm{mol}^{-1}$} \\
\hline SimCor, this work & $84.4 \pm 0.5^{\mathrm{a}}$ & $85.6 \pm 0.5^{\mathrm{a}}$ \\
\hline Chickos et al. [47] & 95.8 & 78.7 \\
\hline
\end{tabular}

307

$308{ }^{\text {a }}$ Expanded uncertainties with 0.95 level of confidence were estimated for the SimCor results based on standard error

309 estimations of the parameters and experimental uncertainty of the input data using the error propagation law 310 approximated by the Kragten algorithm [63]. 


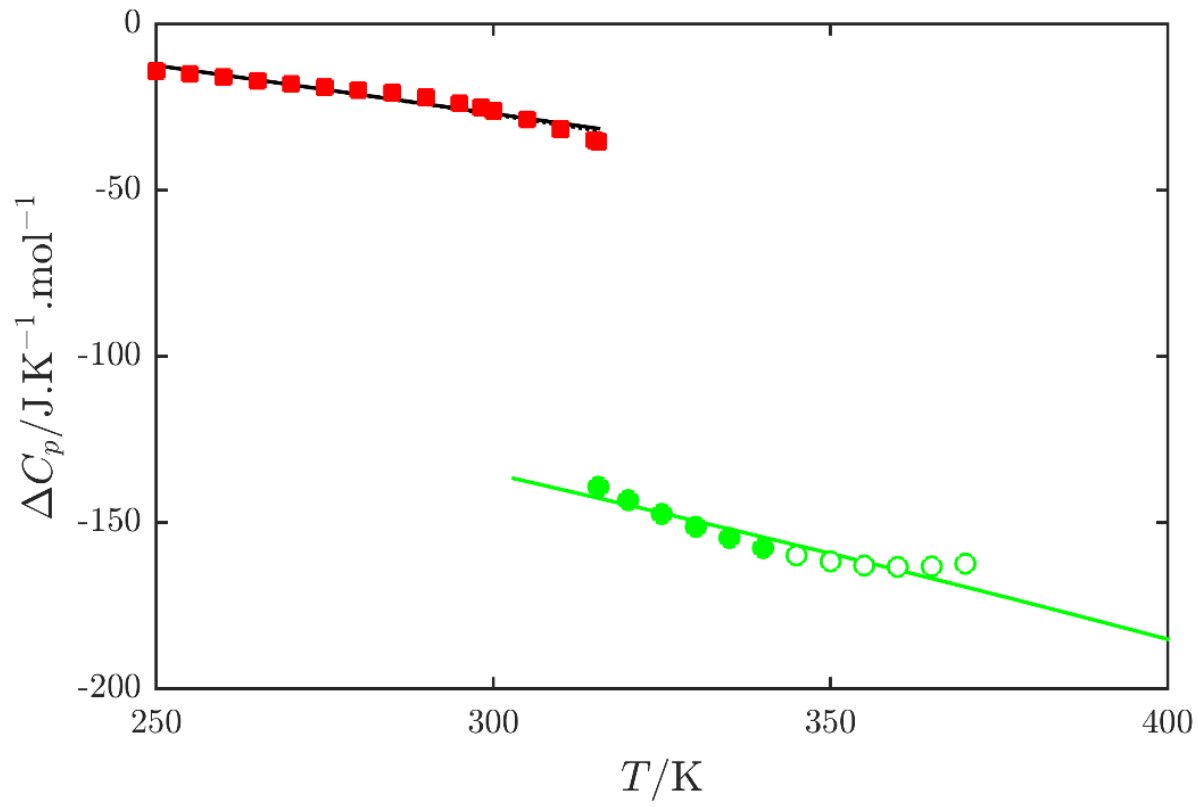

312

313 Figure 10. Description of differences in the heat capacity for L-menthol computed by the SimCor

314 method. Combination of adiabatic calorimetry and theoretical calculations: $\mathbf{\square}, \Delta_{\alpha}^{\mathrm{g}} C_{p, \mathrm{~m}}^{0} ; \bigcirc, \Delta_{1}^{\mathrm{g}} C_{p, \mathrm{~m}}^{0} ; \bigcirc$,

$315 \Delta_{1}^{\mathrm{g}} C_{p, \mathrm{~m}}^{0}$ (points excluded due to increasing $p V T$ correction). SimCor results:,$- \Delta_{\alpha}^{\mathrm{g}} C_{p, \mathrm{~m}}^{0} ;-, \Delta_{\mathrm{l}}^{\mathrm{g}} C_{p, \mathrm{~m}}^{0}$. 


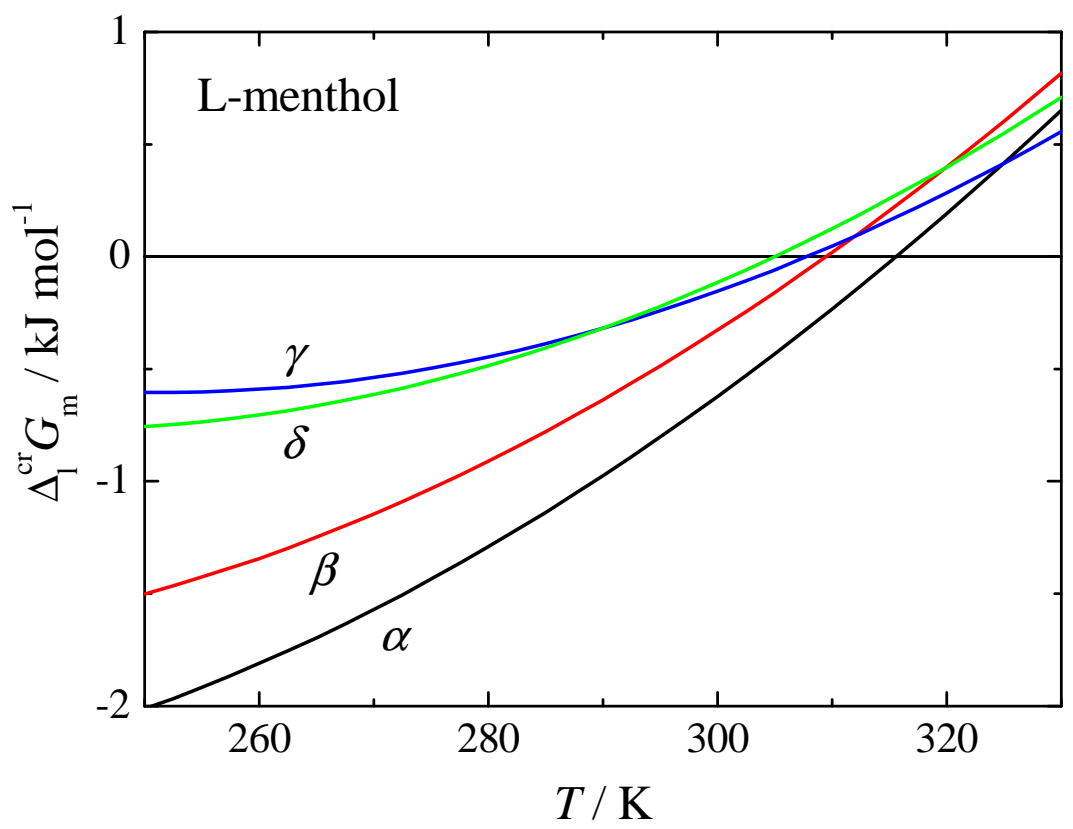

317

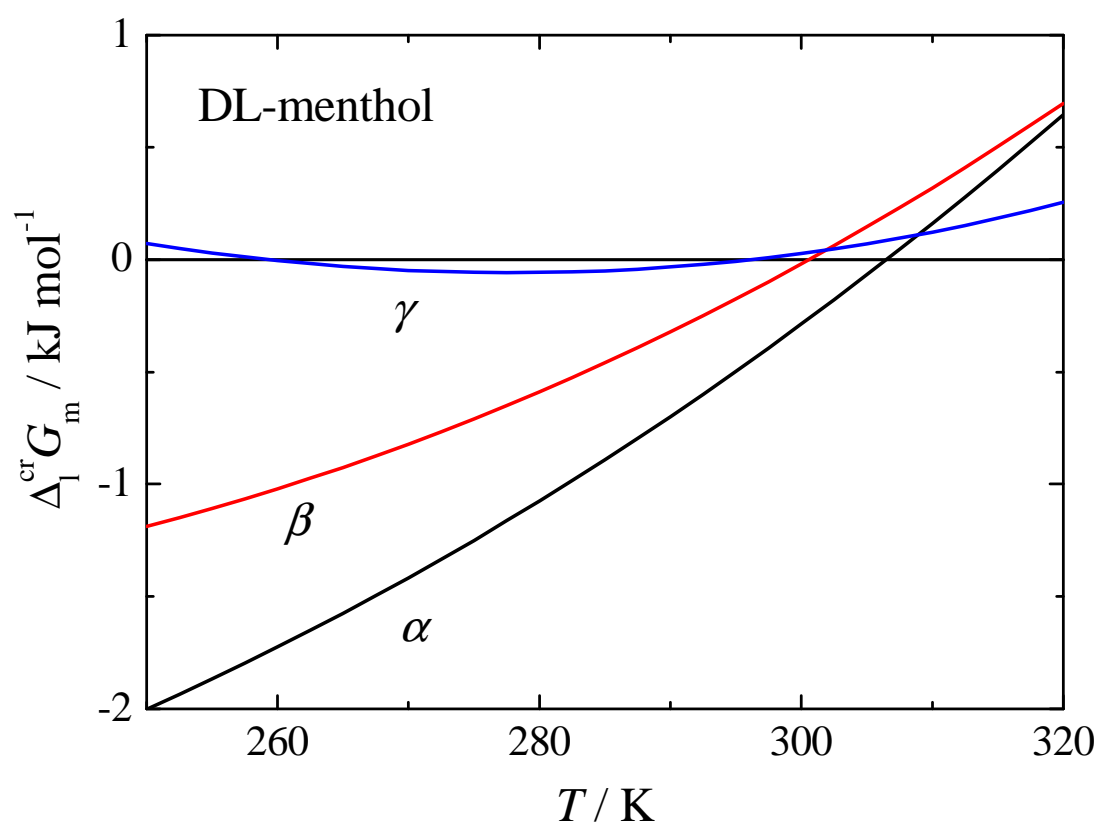

318

319 Figure 11. Difference between the Gibbs energy of observed polymorphs and liquid phase $\Delta_{1}^{\mathrm{c}} G_{\mathrm{m}}$ 320 for L- and DL-menthol.,$- \delta$ phase;,$- \gamma$ phase;,$- \beta$ phase;,$- \alpha$ phase. 


\section{Conclusions}

323 The thermodynamic properties of L- and DL-menthol, including vapour pressures, heat capacity

324 of condensed phases, and phase change temperatures and enthalpies are reported. Many of these

325 are reported for the first time. For both compounds, several concomitant polymorphs were

326 observed during the phase behaviour studies. The kinetics of phase transformation of the $\beta$ form

327 of DL-menthol to the stable $\alpha$ polymorph and the crystallization of the $\alpha$ polymorph was

328 thoroughly investigated by VT-XRPD. An optimal temperature interval for the formation of the $\alpha$

329 polymorph was determined based on these experiments. A significantly lower rate of formation

330 of the $\alpha$ polymorph by crystallization compared to that by the $\beta$ - to $\alpha$-polymorph transformation

331 was observed (a long-term coexistence of the $\alpha$ polymorph with the liquid phase was detected by

332 VT-XRPD). Experimental thermodynamic data were supplemented by ideal-gas thermodynamic

333 properties obtained by combining statistical thermodynamics and quantum chemical calculations.

334 A thorough conformational analysis performed using the DFT and LCCSD methods revealed the

335 existence of 57 stable conformers, many of which are reported for the first time. Calculated ideal-

336 gas heat capacities were combined with the experimental data on condensed-phase heat capacity,

337 vapour pressure, and phase-change properties and were treated simultaneously to obtain a

338 consistent thermodynamic description. The thermodynamic data and information on polymorphic

339 behaviour reported in this work form a necessary basis for phase equilibrium studies on mixtures

340 containing menthol and should be of interest to a wide range of applications including phase

341 separation processes and environmental modelling.

342 


\section{Acknowledgements}

345 Authors V.S., M.F., and K.R. acknowledge financial support from the Czech Science Foundation

346 (GACR No. 17-03875S). Author J.R. acknowledges financial support for the X-ray experimental

347 equipment from the project ASTRA of the Operation program Prague Competitiveness, (Project 348 No. CZ.2.16/3.1.00/24510). The authors would like to acknowledge T.L. Yurkshtovich

349 (Belarusian State University) for specific-rotation measurements on natural L-menthol, H. 350 Kolosovskaya (BelHard Group JSC) for GC-MS analysis of natural L-menthol, and A.F.

351 Kazakov (NIST) for performing calculations at the LCCSD(T)/aug-cc-pVQZ level of theory and 352 for the discussion concerning the statistical-thermodynamics calculations.

353 This article is a partial contribution of the National Institute of Standards and Technology (NIST) 354 and is not subject to copyright in the United States for the author A.B. Trade names are provided 355 only to specify procedures adequately and do not imply endorsement by the National Institute of 356 Standards and Technology. Similar products by other manufacturers may be found to work as 357 well or better.

\section{Appendix A. Supplementary Data}

360 Supplementary data associated with this article can be found, in the online version, at

361 Supplementary data contain detailed description of the SimCor method; description of multi-

362 phase Arc plot; tables and figures with details on adiabatic calorimetry experiments and XRPD

363 measurements; figure with labelling of possible cyclohexane frames; list of stable conformers of

364 menthol with their parameters; and parameters of methyl rotations of the most stable EQgt

365 conformer of L-menthol. 


\section{References}

368 [1] N. Galeotti, L. Di Cesare Mannelli, G. Mazzanti, A. Bartolini, C. Ghelardini, Menthol: a natural analgesic compound, Neurosci. Lett., 322 (2002) 145-148.

370 [2] Y. Corvis, P. Negrier, S. Massip, J.-M. Leger, P. Espeau, Insights into the crystal structure, 371 polymorphism and thermal behaviour of menthol optical isomers and racemates, 372 CrystEngComm, 14 (2012) 7055-7064.

373 [3] M. Okuniewski, K. Paduszyński, U. Domańska, (Solid + liquid) equilibrium phase diagrams in binary mixtures containing terpenes: New experimental data and analysis of several modelling strategies with modified UNIFAC (Dortmund) and PC-SAFT equation of state, Fluid Phase Equilib., 422 (2016) 66-77.

377 [4] T. Phaechamud, S. Tuntarawongsa, P. Charoensuksai, Evapouration Behaviour and 378 Characterization of Eutectic Solvent and Ibuprofen Eutectic Solution, AAPS PharmSciTech, 17 379 (2016) 1213-1220.

380 [5] I. Albuquerque, M. Mazzotti, Influence of Liquid-Liquid Phase Separation on the Crystallization of L-Menthol from Water, Chem. Eng. Technol., 40 (2017) 1339-1346.

[6] Y. Corvis, P. Espeau, Interpretation of the global heat of melting in eutectic binary systems, Thermochim. Acta, 664 (2018) 91-99.

384 [7] R. Verma, T. Banerjee, Liquid-Liquid Extraction of Lower Alcohols Using Menthol-Based 385 Hydrophobic Deep Eutectic Solvent: Experiments and COSMO-SAC Predictions, Ind. Eng. Chem. Res., 57 (2018) 3371-3381.

[8] F.E. Wright, The Crystallization Of Menthol, J. Am. Chem. Soc., 39 (1917) 1515-1524.

[9] J. Bernstein, R.J. Davey, J.O. Henck, Concomitant Polymorphs, Angew. Chem. Int. Ed. Engl., 38 (1999) 3440-3461.

[10] Y. Corvis, A. Wurm, C. Schick, P. Espeau, New menthol polymorphs identified by flash scanning calorimetry, CrystEngComm, 17 (2015) 5357-5359.

[11] M. Kuhnert-Brandstätter, R. Ulmer, L. Langhammer, Thermoanalytische Untersuchungen an Mentholen 1. Mitteilung, Arch. Pharm., 307 (1974) 497-503.

[12] P. Bombicz, J. Buschmann, P. Luger, N.X. Dung, C.B. Nam, Crystal structure of (1R,2S,5R)-2-isopropyl-5-methyl-cyclohexanol, (-)-menthol, Z. Kristallogr. Cryst. Mater., 214 (1999) 420.

[13] D. Lipkind, J.S. Chickos, An Examination of Factors Influencing the Thermodynamics of Correlation-Gas Chromatography as Applied to Large Molecules and Chiral Separations, J. Chem. Eng. Data, 55 (2010) 698-707.

[14] K.A. Kobe, T.S. Okabe, M.T. Ramstad, P.M. Huemmer, p-Cymene Studies. VI. Vapour Pressure of $p$-Cymene, Some of its Derivatives and Related Compounds, J. Am. Chem. Soc., 63 (1941) 3251-3252.

[15] L. Keating, H.H. Harris, J.S. Chickos, Vapour pressures and vaporization enthalpy of (-) $\alpha-$ bisabolol and (dl) menthol by correlation gas chromatography, J. Chem. Thermodyn., 107 (2017) $18-25$.

[16] M. Hoskovec, D. Grygarová, J. Cvačka, L. Streinz, J. Zima, S.P. Verevkin, B. Koutek, Determining the vapour pressures of plant volatiles from gas chromatographic retention data, J. Chromatogr. A, 1083 (2005) 161-172.

[17] T. Guetachew, I. Mokbel, I. Batiu, Z. Cisse, J. Jose, Vapour pressures and sublimation pressures of eight constituents of essential oils at pressures in the range from 0.3 $\mathrm{Pa}$ to $83.000 \mathrm{~Pa}$, ELDATA: Int. Electron. J. Phys.-Chem. Data, 5 (1999) 43-53. 
[18] V. Štejfa, M. Fulem, K. Růžička, C. Červinka, M.A.A. Rocha, L.M.N.B.F. Santos, B. Schröder, Thermodynamic study of selected monoterpenes, J. Chem. Thermodyn., 60 (2013) $117-125$.

415 [19] V. Štejfa, M. Fulem, K. Růžička, C. Červinka, Thermodynamic study of selected monoterpenes II, J. Chem. Thermodyn., 79 (2014) 272-279.

[20] V. Štejfa, M. Fulem, K. Růžička, C. Červinka, Thermodynamic study of selected monoterpenes III, J. Chem. Thermodyn., 79 (2014) 280-289.

[21] V. Štejfa, F. Dergal, I. Mokbel, M. Fulem, J. Jose, K. Růžička, Vapour pressures and thermophysical properties of selected monoterpenoids, Fluid Phase Equilib., 406 (2015) 124-133. [22] D. Zaitsau, E. Paulechka, D.S. Firaha, A.V. Blokhin, G.J. Kabo, A. Bazyleva, A.G. Kabo, M.A. Varfolomeev, V.M. Sevruk, Comprehensive study of the thermodynamic properties for 2methyl-3-buten-2-ol, J. Chem. Thermodyn., 91 (2015) 459-473.

[23] K. Růžička, V. Majer, Simultaneous Treatment of Vapour Pressures and Related Thermal Data Between the Triple and Normal Boiling Temperatures for $n$-Alkanes $\mathrm{C}_{5}-\mathrm{C}_{20}$, J. Phys. Chem. Ref. Data, 23 (1994) 1-39.

[24] J. Meija, B. Coplen Tyler, M. Berglund, A. Brand Willi, P. De Bièvre, M. Gröning, E. Holden Norman, J. Irrgeher, D. Loss Robert, T. Walczyk, T. Prohaska, Atomic weights of the elements 2013 (IUPAC Technical Report), in: Pure Appl. Chem., 2016, pp. 265.

[25] R. Sabbah, A. Xu-wu, J.S. Chickos, M.L.P. Leitão, M.V. Roux, L.A. Torres, Reference materials for calorimetry and differential thermal analysis, Thermochim. Acta, 331 (1999) 93204.

[26] H. Rietveld, A profile refinement method for nuclear and magnetic structures, J. Appl. Crystallogr., 2 (1969) 65-71.

[27] N.V.Y. Scarlett, I.C. Madsen, Quantification of phases with partial or no known crystal structures, Powder Diffr., 21 (2012) 278-284.

[28] G.J. Kabo, A.A. Kozyro, A.P. Marchand, V.V. Diky, V.V. Simirsky, L.S. Ivashkevich, A.P. Krasulin, V.M. Sevruk, M.L. Frenkel, Thermodynamic properties of heptacyclotetradecane C14H16, J. Chem. Thermodyn., 26 (1994) 129-142.

[29] F. Pavese, V.M. Malishev, Routine measurements of specific-heat capacity and thermalconductivity of high- $T_{\mathrm{c}}$ superconducting materials in the range 4-300 K using modular equipment, in: R.P. Reed, F.R. Fickett, L.T. Summers, M. Stieg (Eds.), Advances in Cryogenic Engineering, Vol 40, Pts A and B: Materials, Plenum Press Div Plenum Publishing Corp, New York, 1994, pp. 119-124.

[30] A.B. Bazyleva, A.V. Blokhin, G.J. Kabo, A.G. Kabo, Y.U. Paulechka, Thermodynamic properties of 1-bromoadamantane in the condensed state and molecular disorder in its crystals, J. Chem. Thermodyn., 37 (2005) 643-657.

[31] A.V. Blokhin, Y.U. Paulechka, G.J. Kabo, Thermodynamic Properties of [C6mim][NTf2] in the Condensed State, J. Chem. Eng. Data, 51 (2006) 1377-1388.

[32] G.W.H. Höhne, W.F. Hemminger, H.-J. Flammersheim, Differential Scanning Calorimetry, 2 ed., Springer Verlag, Berlin, 2003.

[33] M. Fulem, K. Růžička, P. Morávek, J. Pangrác, E. Hulicius, B. Kozyrkin, V. Shatunov, Vapour Pressure of Selected Organic Iodides, J. Chem. Eng. Data, 55 (2010) 4780-4784.

[34] V. Štejfa, M. Fulem, K. Růžička, P. Morávek, New Static Apparatus for Vapour Pressure Measurements: Reconciled Thermophysical Data for Benzophenone, J. Chem. Eng. Data, 61 (2016) 3627-3639. 
[35] K. Růžička, M. Fulem, V. Růžička, Recommended Vapour Pressure of Solid Naphthalene, J. Chem. Eng. Data, 50 (2005) 1956-1970.

459 [36] M. Fulem, K. Růžička, C. Červinka, M.A.A. Rocha, L.M.N.B.F. Santos, R.F. Berg, 460 Recommended vapour pressure and thermophysical data for ferrocene, J. Chem. Thermodyn., 57 461 (2013) 530-540.

462 [37] M.J. Frisch, G.W. Trucks, H.B. Schlegel, G.E. Scuseria, M.A. Robb, J.R. Cheeseman, G. Scalmani, V. Barone, B. Mennucci, G.A. Petersson, H. Nakatsuji, M. Caricato, X. Li, H.P. Hratchian, A.F. Izmaylov, J. Bloino, G. Zheng, J.L. Sonnenberg, M. Hada, M. Ehara, K. Toyota, R. Fukuda, J. Hasegawa, M. Ishida, T. Nakajima, Y. Honda, O. Kitao, H. Nakai, T. Vreven, J.A.M. Jr., J.E. Peralta, F. Ogliaro, M. Bearpark, J.J. Heyd, E. Brothers, K.N. Kudin, V.N. Staroverov, T. Keith, R. Kobayashi, J. Normand, K. Raghavachari, A. Rendell, J.C. Burant, S.S. Iyengar, J. Tomasi, M. Cossi, N. Rega, J.M. Millam, M. Klene, J.E. Knox, J.B. Cross, V. Bakken, C. Adamo, J. Jaramillo, R. Gomperts, R.E. Stratmann, O. Yazyev, A.J. Austin, R. Cammi, C. Pomelli, J.W. Ochterski, R.L. Martin, K. Morokuma, V.G. Zakrzewski, G.A. Voth, P. Salvador, J.J. Dannenberg, S. Dapprich, A.D. Daniels, O. Farkas, J.B. Foresman, J.V. Ortiz, J. Cioslowski, D.J. Fox, Gaussian 09, Revision D.01, Gaussian, Inc., Wallingford CT, 2013.

[38] M. Kállay, Z. Rolik, J. Csontos, P. Nagy, G. Samu, D. Mester, J. Csóka, B. Szabó, I. Ladjánszki, L. Szegedy, B. Ladóczki, K. Petrov, M. Farkas, P.D. Mezei, B. Hégely, Mrcc, a quantum chemical program suite, 2017.

[39] R.M. Parrish, L.A. Burns, D.G.A. Smith, A.C. Simmonett, A.E. DePrince, E.G. Hohenstein, U. Bozkaya, A.Y. Sokolov, R. Di Remigio, R.M. Richard, J.F. Gonthier, A.M. James, H.R. McAlexander, A. Kumar, M. Saitow, X. Wang, B.P. Pritchard, P. Verma, H.F. Schaefer, K. Patkowski, R.A. King, E.F. Valeev, F.A. Evangelista, J.M. Turney, T.D. Crawford, C.D. Sherrill, Psi4 1.1: An Open-Source Electronic Structure Program Emphasizing Automation, Advanced Libraries, and Interoperability, J. Chem. Theory Comput., 13 (2017) 3185-3197.

[40] P.R. Nagy, M. Kállay, Optimization of the linear-scaling local natural orbital CCSD(T) method: Redundancy-free triples correction using Laplace transform, J. Chem. Phys., 146 (2017) 214106.

[41] J. Pfaendtner, X. Yu, L.J. Broadbelt, The 1-D hindered rotor approximation, Theor. Chem. Acc., 118 (2007) 881-898.

[42] M.L. Frenkel, G.J. Kabo, K.N. Marsh, G.N. Roganov, R.C. Wilhoit, Thermodynamics of Organic Compounds in the Gas State, Thermodynamics Research Center, College Station, Texas, 1994.

[43] V. Štejfa, M. Fulem, K. Růžička, P. Matějka, Vapour pressures and thermophysical properties of selected hexenols and recommended vapour pressure for hexan-1-ol, Fluid Phase Equilib., 402 (2015) 18-29.

[44] V. Pokorný, V. Štejfa, M. Fulem, C. Červinka, K. Růžička, Vapour Pressures and Thermophysical Properties of Dimethyl Carbonate, Diethyl Carbonate, and Dipropyl Carbonate, J. Chem. Eng. Data, 62 (2017) 3206-3215.

[45] K.S. Pitzer, W.D. Gwinn, Energy Levels and Thermodynamic Functions for Molecules with Internal Rotation I. Rigid Frame with Attached Tops, J. Chem. Phys., 10 (1942) 428-440.

[46] C.C. Marston, G.G. Balint-Kurti, The Fourier grid Hamiltonian method for bound state eigenvalues and eigenfunctions, J. Chem. Phys., 91 (1989) 3571-3576.

[47] J.S. Chickos, D.L. Garin, M. Hitt, G. Schilling, Some solid state properties of enantiomers and their racemates, Tetrahedron, 37 (1981) 2255-2259. 
[48] L. Bruner, Ueber die Schmelzwärmen einiger organischen Verbindungen, Ber. Dtsch. Chem. Ges., 27 (1894) 2102-2107.

504 [49] A.H. White, W.S. Bishop, Dielectric Evidence of Molecular Rotation in the Crystals of Certain Non-aromatic Compounds, J. Am. Chem. Soc., 62 (1940) 8-16.

508 [51] M. Avrami, Kinetics of Phase Change. II Transformation-Time Relations for Random 509 Distribution of Nuclei, J. Chem. Phys., 8 (1940) 212-224. [52] V. Štejfa, Development of experimental and theoretical tools for thermodynamic studies in single component systems, Ph.D. Thesis, Department of Physical Chemistry, University of Chemistry and Technology, Prague, 2017, pp. 159.

[53] M. Čenský, V. Roháč, K. Rủžička, M. Fulem, K. Aim, Vapour pressure of selected aliphatic alcohols by ebulliometry. Part 1, Fluid Phase Equilib., 298 (2010) 192-198.

[54] D.J. Nelson, C.N. Brammer, Toward Consistent Terminology for Cyclohexane Conformers in Introductory Organic Chemistry, J. Chem. Educ., 88 (2011) 292-294.

[55] D. Schmitz, V.A. Shubert, T. Betz, M. Schnell, Exploring the conformational landscape of menthol, menthone, and isomenthone: a microwave study, Front. Chem., 3 (2015) 1-13.

[56] J.R. Avilés Moreno, F. Partal Ureña, J.J. López González, Hydrogen bonding network in a chiral alcohol: (1R,2S,5R)-(-)-menthol. Conformational preference studied by IR-Raman-VCD spectroscopies and quantum chemical calculations, Struct. Chem., 24 (2013) 671-680.

[57] T. Egawa, M. Sakamoto, H. Takeuchi, S. Konaka, Structural Determination of Menthol and Isomenthol, a Minty Compound and Its Nonminty Isomer, by Means of Gas Electron Diffraction Augmented by Theoretical Calculations, J. Phys. Chem. A, 107 (2003) 2757-2762.

[58] K. Růžička, M. Fulem, T. Mahnel, C. Červinka, Recommended vapour pressures for aniline, nitromethane, 2-aminoethanol, and 1-methyl-2-pyrrolidone, Fluid Phase Equilib., 406 (2015) 3446.

[59] E.C.W. Clarke, D.N. Glew, Evaluation of thermodynamic functions from equilibrium constants, Trans. Faraday Soc., 62 (1966) 539-547.

[60] K. Růžička, B. Koutek, M. Fulem, M. Hoskovec, Indirect Determination of Vapour Pressures by Capillary Gas-Liquid Chromatography: Analysis of the Reference Vapour-Pressure Data and Their Treatment, J. Chem. Eng. Data, 57 (2012) 1349-1368.

[61] B. Koutek, T. Mahnel, P. Šimáček, M. Fulem, K. Růžičcka, Extracting Vapour Pressure Data from GLC Retention Times. Part 1: Analysis of Single Reference Approach, J. Chem. Eng. Data, 62 (2017) 3542-3550.

[62] J. N'Guimbi, H. Kasehgari, I. Mokbel, J. Jose, Tensions de vapeur d'alcools primaires dans le domaine 0,3 Pa à 1,5 kPa, Thermochim. Acta, 196 (1992) 367-377.

[63] J. Kragten, Tutorial review. Calculating standard deviations and confidence intervals with a universally applicable spreadsheet technique, Analyst, 119 (1994) 2161-2165. 